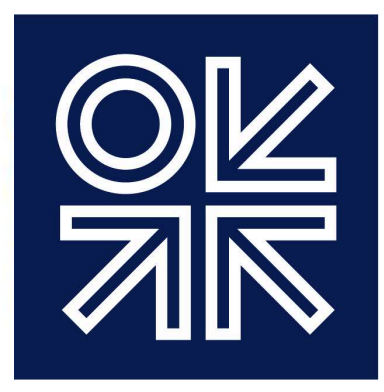

THE OXFORD

INSTITUTE

FOR ENERGY

STUDIES

February 2016

\title{
The Future of the Canadian Oil Sands
}

Growth potential of a unique resource amidst regulation, egress, cost, and price uncertainty

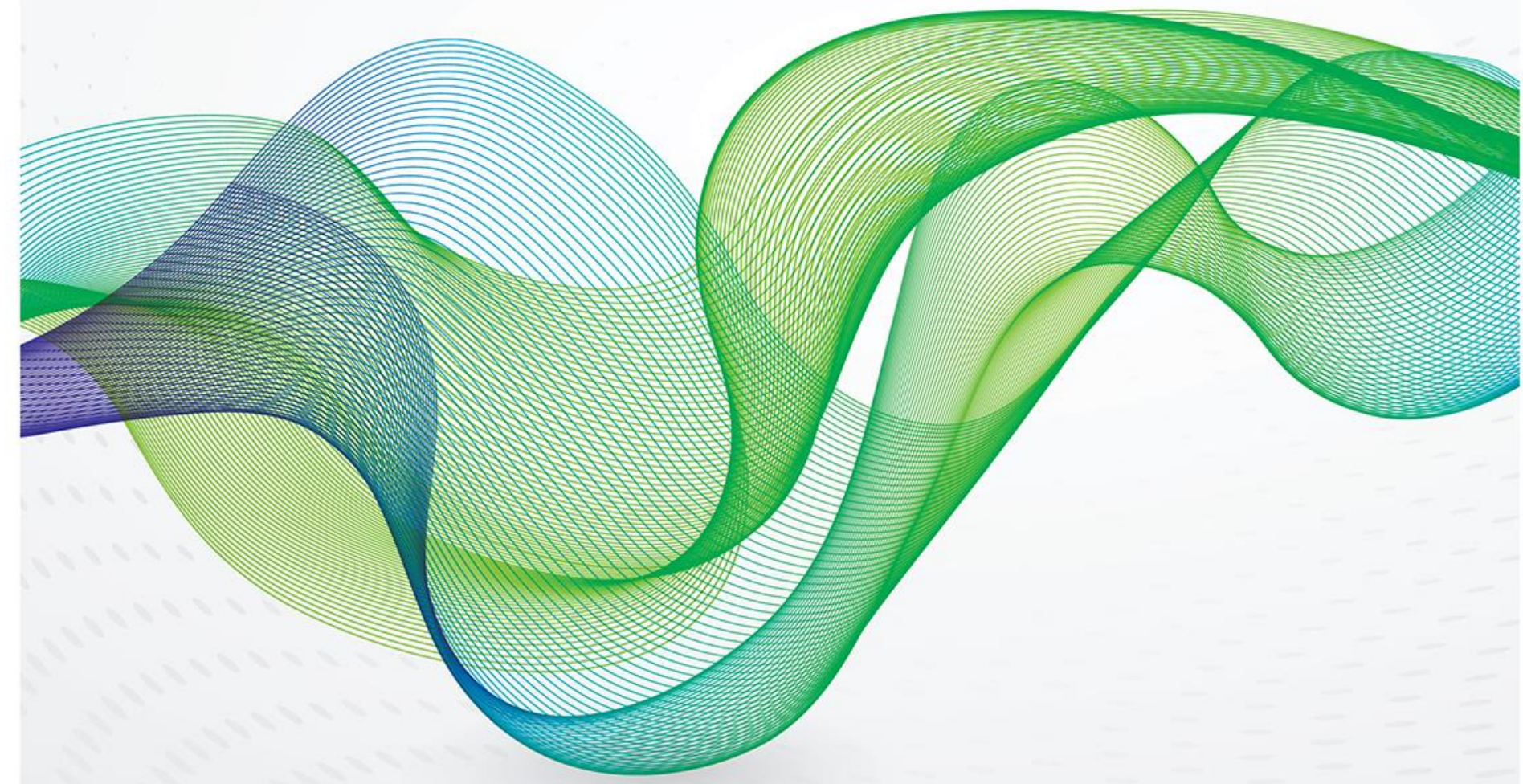


The contents of this paper are the authors' sole responsibility. They do not necessarily represent the views of the Oxford Institute for Energy Studies or any of its members.

Copyright $\odot 2016$

Oxford Institute for Energy Studies

(Registered Charity, No. 286084)

This publication may be reproduced in part for educational or non-profit purposes without special permission from the copyright holder, provided acknowledgment of the source is made. No use of this publication may be made for resale or for any other commercial purpose whatsoever without prior permission in writing from the Oxford Institute for Energy Studies.

ISBN 978-1-78467-051-1 


\section{Acknowledgements}

I would like to thank Bassam Fattouh for suggesting that I write on such a broad and interesting topic and for supporting the research when the page count went beyond what was originally planned. I am also grateful to Robert Skinner, Executive Fellow at the University of Calgary's School of Public Policy and a former director of this institute, for his help in providing initial context for the research. Jackie Forrest, Vice President of Research at ARC Financial, and Matthew Innes, of Evolution Management Solutions, both also based in Calgary, were of great help in reviewing the research through economic and technical lenses, respectively.

Most importantly, I owe much gratitude to my wife Stephanie for her patience and support while I worked through the research.

Peter Findlay

Calgary, January 2016 
Glossary / Acronyms

AECO

AOSP

AOSTRA

API

BC

Brownfield

CAGR

CAPP

CCEMC

CCS

CERI

CHOPS

COGD

CNRL

CSR

CSS

DILBIT

Dilbit

EOR

EORI

ESP

ET-DSP

ETF

FOB

Gcos

Gcos

GHG

Greenfield

IEA

In-situ
Alberta Electric Company; also used as the index for natural gas prices in Alberta

Alberta Oil Sands Project - a joint venture between Shell, Chevron, \& Marathon

Alberta Oil Sands Technology and Research Authority (now Alberta Innovates)

American Petroleum Institute - API gravity describes the heaviness of a crude

British Columbia (the Canadian province of)

A new project instalment that is an expansion or overhaul of a past installation Compound Annual Growth Rate

Canadian Association of Petroleum Producers

Climate Change and Emissions Management Corporation

Carbon Capture and Storage

Canadian Energy Research Institute

Cold Heavy Oil Production with Sand

Combustion Overhead Gravity Drainage

Canadian Natural Resources Limited

Corporate Social Responsibility

Cyclic Steam Stimulation

Diluted Bitumen

A mixture of two streams of crude oil: approximately $70-75 \%$ bitumen and $25-30 \%$ condensate

\section{Enhanced Oil Recovery}

Energy Return on Investment

Electronical submersible pumps

Electro-Thermal Dynamic Stripping Process

Exchange Traded Fund: Similar to a mutual fund, but with minimal management oversight; ETFs attempt to average the returns of a particular market or industry

Freight on Board

Great Canadian Oil Sands Company (now called Suncor Energy)

Great Canadian Oil Sands

Greenhouse Gases

A new project instalment that is built in a new area, rather than an expansion or rebuild of a past installation

International Energy Agency

Separating and producing bitumen from oil sands in-place rather than extracting the oil sands and removing the bitumen afterwards as is done in the mining technique 
LNG

LTO

LWD

Mining

NDP

NEB

NOC

$\mathrm{OB}_{\mathrm{v}}$

$\mathrm{OS}_{\mathrm{v}}$

PM

$R \& D$

SAGD

SCO

SGER

SOR

Synbit

TAGD

TAN

THAI

TSX

TV:BIP

Upgrader

USGC

VOC

WCSB
Liquefied Natural Gas

Light Tight Oil (oil produced from mature shale geology); also called 'shale oil' (not 'oil shale', which describes a different geology)

Logging while drilling enables drillers to see wireline-quality formation measurements during drilling from the help of well logging tools attached to the bottom-hole assembly

In this research, mining refers to the process of surface mining of oil sands ore, then separating out the bitumen through a number of process steps (see Appendix: Oil sands primer)

New Democratic Party: A political party that exists at both provincial and federal levels in Canada and is traditionally the more left-wing of the major parties. In 2015 it was elected to a majority government for the first time in Alberta. It has never been the governing party of Canada.

National Energy Board

National Oil Company

Volume of Overburden Removed

Volume of Oil Sands Mined

Particulate Matter

Research and Development

Steam Assisted Gravity Drainage

Synthetic Crude Oil

Specified Gas Emitters Regulation: Government of Alberta regulation to reduce emissions from oil sands producers and other large industrial emitters

Steam-to-Oil Ratio

A mixture of two streams of crude oil: approximately $50 \%$ bitumen and $50 \%$ Synthetic Crude Oil (SCO)

Thermal Assisted Gravity Drainage

Total Acid Number

Toe-to-Heel Air Injection

Toronto Stock Exchange

Ratio that describes the total volume of oil sands removed versus the amount of bitumen in-place for that volume

Processes oil sands produced bitumen into a lighter Synthetic Crude Oil (SCO) that can be more easily processed downstream by traditional refineries

United States Gulf of Mexico Coast

Volatile Organic Compounds

Western Canadian Sedimentary Basin - the large hydrocarbon-rich basin between the Rocky Mountains and Canadian Shield, touching parts of British Columbia, Alberta, Saskatchewan, and Manitoba 


\section{Preface}

This research was conceived with two central objectives: first, to help a global audience comprehend the uniqueness of the massive hydrocarbon resource that is Canada's oil sands. Second, and more importantly, the paper aims to provide insight into which economic factors will drive and constrain oil sands growth in the near term (until 2025) and long term (beyond 2025).

As with all major energy sources, there is undeniable uncertainty on both the supply and demand sides of the oil sands equation. This work attempts to provide perspective on these uncertain factors driving the production growth outlook, with quantitative insights where possible. Though the energy future is indeed difficult to predict, it behoves energy industry leaders, government planners, environmental activists, analysts, and investors alike to recognize the environmental and economic fundamentals underlying Canada's oil sands and how they impact the global energy supply.

With these goals in mind, the paper is separated into five sections:

- Section 1 highlights the environmental (including climate), political, reputational, and regulatory issues surrounding oil sands production.

- Section 2 addresses market access issues of Western Canadian crude oil that are constraining production growth from the oil sands.

- Section 3 tackles the cost of oil sands production, with a focus on inflation and production technology.

- Section 4 discusses the economic attractiveness for investors of the oil sands in the near and long term and summarizes what role the resource could play in future global supply.

- The Appendix provides a detailed oil sands primer as a recommended pre-read for those not closely familiar with Canadian oil sands history, production processes, or current production and marketing volumes. The geological and petrophysical nature of almost 2 trillion barrels of bitumen trapped amid sand makes the resource different to almost any other large producing basin in the world - this section highlights some of the more critical, unique elements. 


\section{Contents}

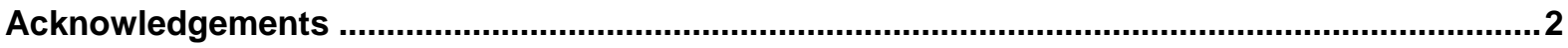

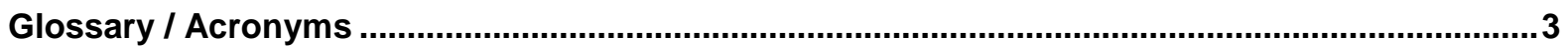

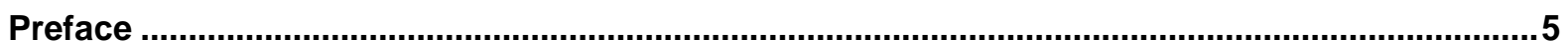

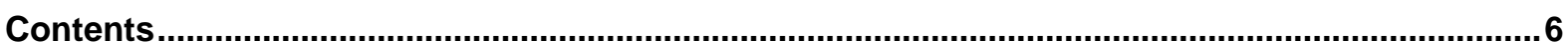

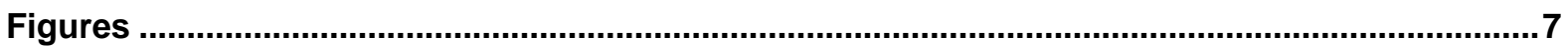

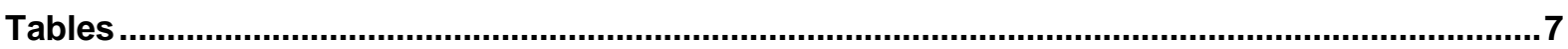

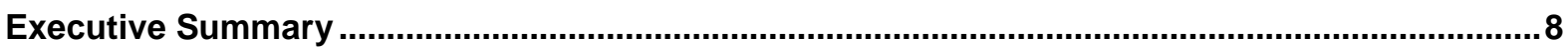

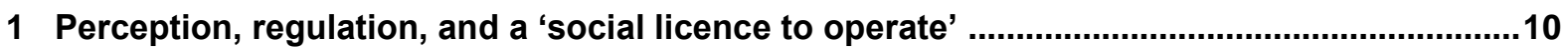

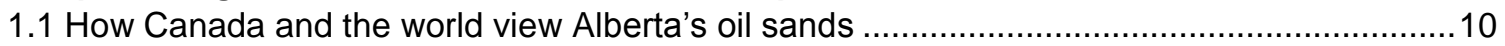

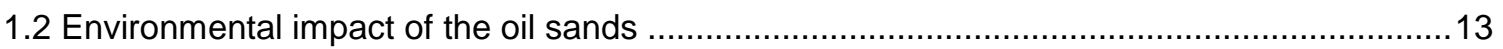

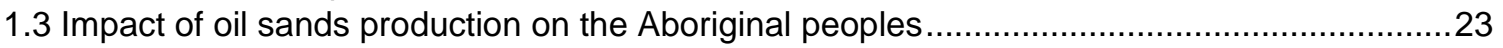

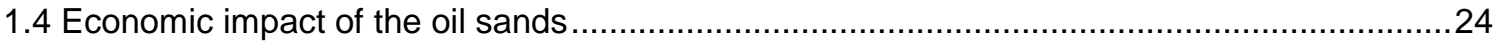

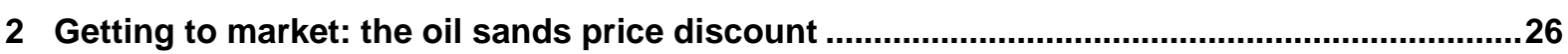

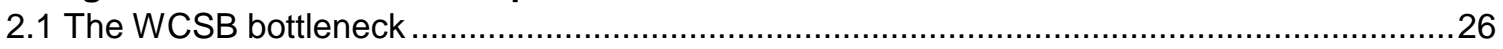

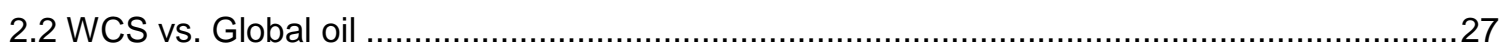

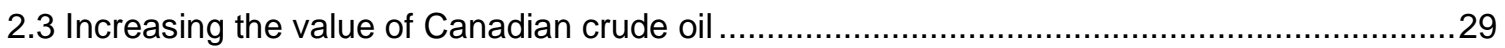

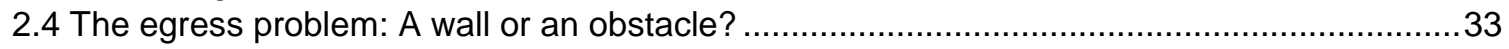

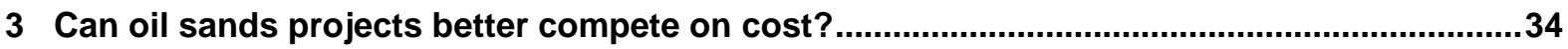

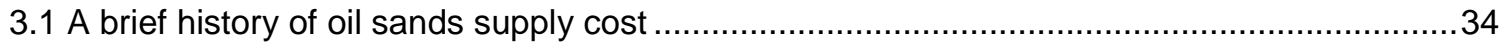

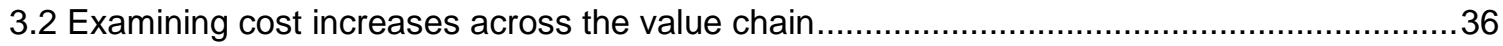

3.3 Technology as both a competitive necessity and investor promotion tool ..............................45

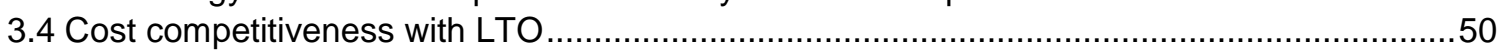

4 Economic attractiveness and growth outlook

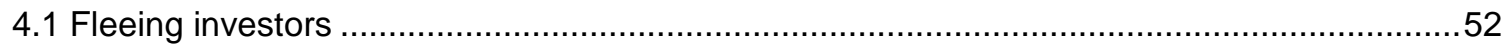

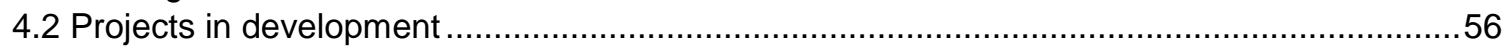

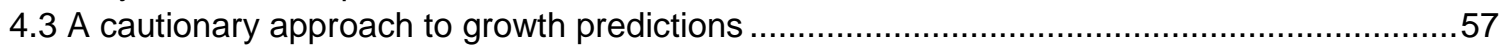

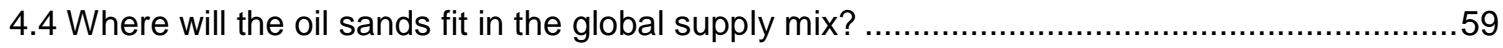

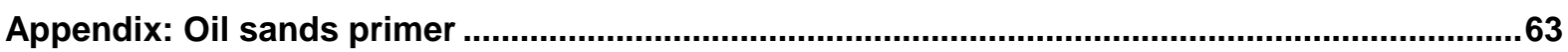

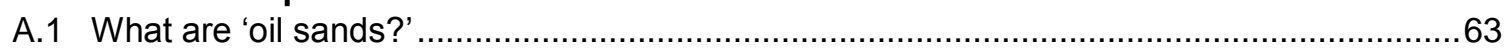

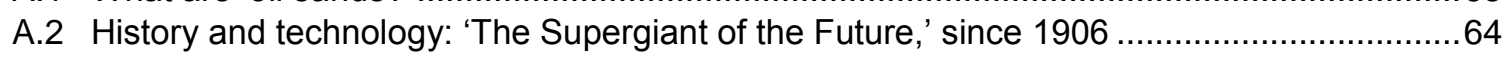

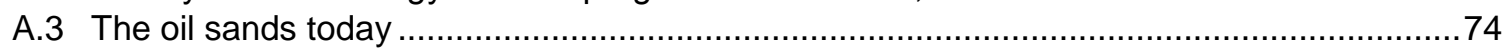

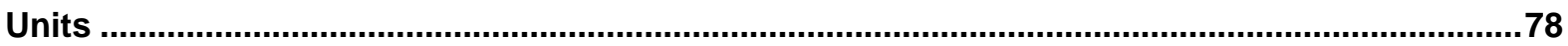

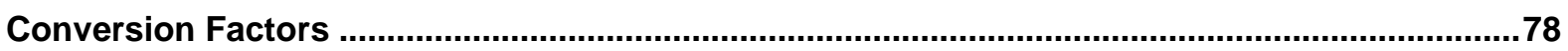

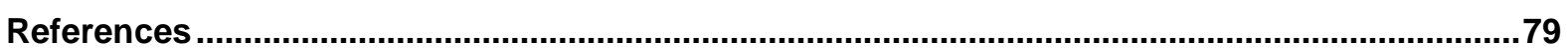

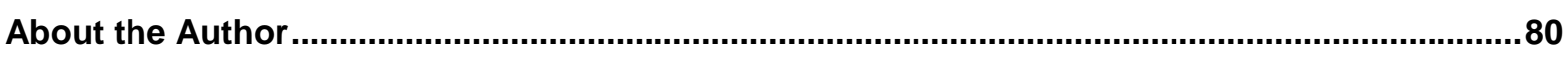

${ }^{*}$ All dollar values (\$) represent US dollars (USD), unless otherwise noted. 


\section{Figures}

Figure 1: Activist Billboard Comparing Oil Sands to the BP Horizon Oil Spill ...................................10

Figure 2: IHS Well-to-Wheels GHG Emissions of Oil Sands vs. Other US Crudes.............................18

Figure 3: Alberta's proposed Emissions Tax: Effect on Oil Sands Producers ......................................19

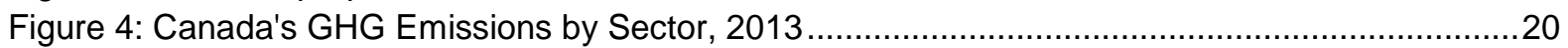

Figure 5: Western Canadian Sedimentary Basin (WCSB) Oil Pipeline Egress ...................................26

Figure 6: WCSB Supply and Bakken Movements vs. Egress Capacity ............................................27

Figure 7: Western Canadian Select (WCS) Crude Prices since 2005 ............................................28

Figure 8: FOB WCS vs. Mexico's FOB Maya Crude (\$ per Bbl, nominal) ........................................29

Figure 9: Real Oil Sands Supply Cost oF Bitumen vs. Crude Price ................................................34

Figure 10: Real (inflation adjusted) Greenfield Project Supply Cost Build-up ....................................36

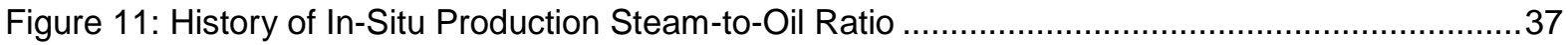

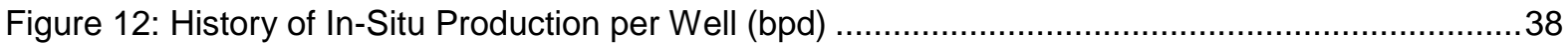

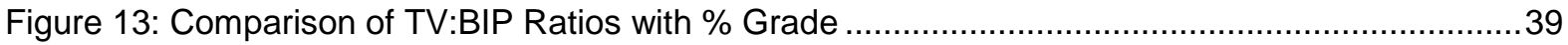

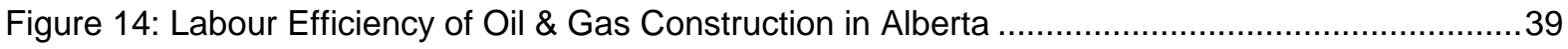

Figure 15: Alberta Natural Gas Price (AECO) versus Henry Hub and WTI.......................................41

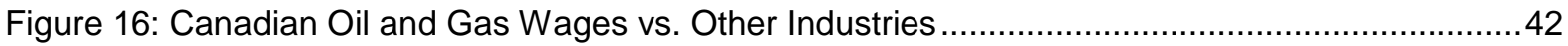

Figure 17: Alberta Safety Performance - Lost Time Injury Rate ..................................................... 42

Figure 18: The Strength of the Canadian Dollar as a Function of Crude Price ....................................44

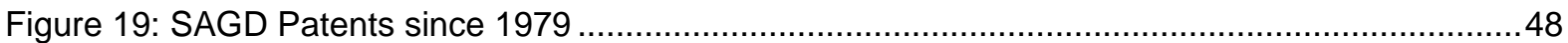

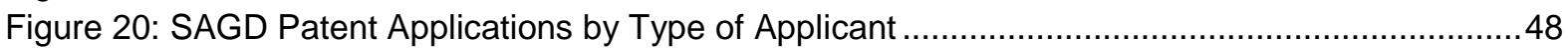

Figure 21: Illustration of Lean / JIT Drill Planning for Shale Gas / LTO ...........................................50

Figure 22: Supply Costs of Oil Sands vs. LTO (WTI in USD\$, nominal) .........................................51

Figure 23: Share Price Performance of Oil Sands Stocks vs. Market Indices....................................52

Figure 24: Global Corruption Index, Highlighting Major Oil Exporters ............................................5

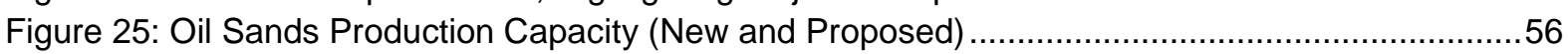

Figure 26: Suspended or Cancelled Production Projects (since 2011) ............................................57

Figure 27: In-Situ Oil Sands Production Forecast by the NEB in 2000, 000 bpd ............................58

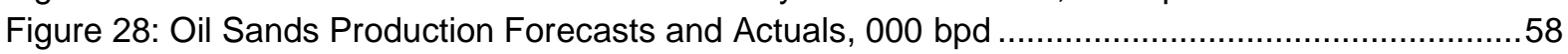

Figure 29: Current Supply (Break-even) Costs of New Sources of Oil..............................................59

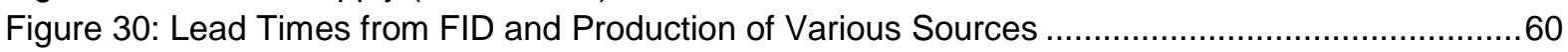

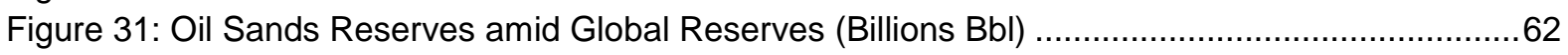

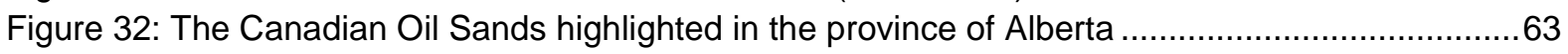

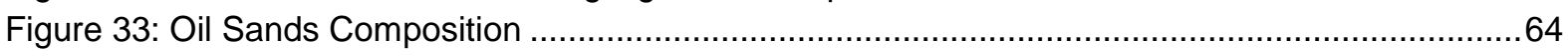

Figure 34: Futuristic Illustrative of the Oil Sands Value Chain during WWII.....................................66

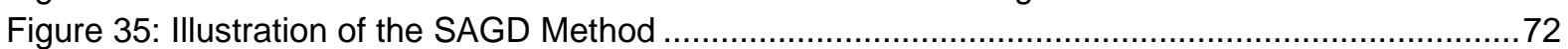

Figure 36: Well Productivity and \# in Production, by In-Situ Method (2013) ....................................73

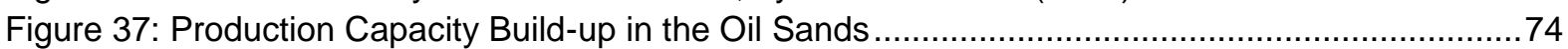

Figure 38: Oil Sands Production History, by Production Method...................................................... 75

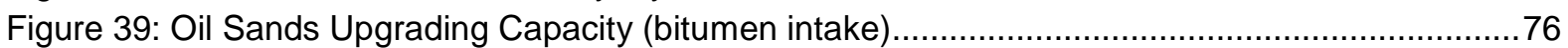

Figure 40: North American Refinery Demand (2014, Mbpd) …......................................................77

\section{Tables}

Table 1: Oil Sands CAC Emissions vs Canadian Total (2012) ....................................................14

Table 2: Change in Air Pollution Emissions Intensity (2005-2012) ...............................................14

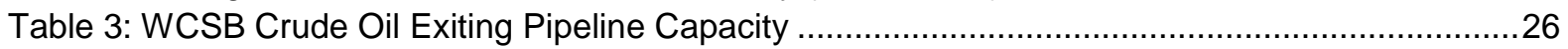

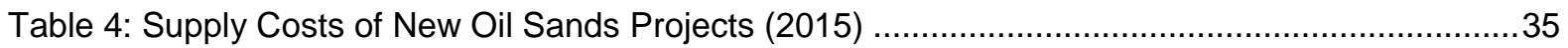

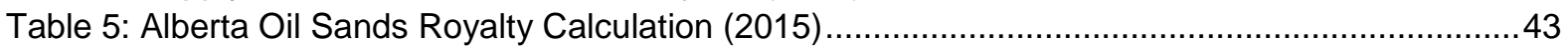

Table 6: Return on Capital across Industries in the Canadian Economy .........................................55 


\section{Executive Summary}

The oil sands are among the world's sources of 'difficult oil' (sometimes referred to as 'unconventional', depending on the definition standards) and are comparable in some respects to deep water, ultra-deep water, Arctic, and light tight oil (LTO), production of which is concentrated in North America for now). ${ }^{1}$ The fact that bitumen is cumbersome and costly to extract is why recoverable reserves of Canadian oil sands are estimated at 170 billion barrels, much less than the estimated 2 trillion barrels in place. What difficult oil plays have in common are high supply costs (often above $\$ 60$ per barrel) and an undeniable dependence on technological advances to remain economically attractive. Though Canada's oil sands, like other unconventional plays, will likely play an increasingly prominent role in meeting future global demand to 2035 and beyond, substantial improvements in production and processing technologies, or a return to sustained high crude prices (or likely both), are required to deliver similar capacity additions as the last decade. The world is estimated to need 10-15 million bpd of additional production in the next 20 years to meet the increasing demand of growing economies and global commercial transport, notwithstanding the need to offset declining production in conventional fields. More than one of these difficult oil sources will play a major role. With such a massive base of reserves to work off, oil sands investors, producers, and the Albertan and Canadian governments hope these bitumen deposits will become a more formidable pillar of global supply than its roughly 2.5 million bpd (2.6 per cent) contribution today.

For energy sources reaching society on a large-scale, an economic turning point occurs when the source crosses a threshold of attractiveness, regulatory and environmental acceptance, large-scale availability, and operational certainty. For North American shale gas, and subsequently LTO, this turning point occurred very rapidly around 2005 with the continuous amelioration of lateral (horizontal) well length, micro-seismic imaging, 3-D mapping, and more advanced, multi-stage hydraulic fracturing. In addition, North America's entrepreneurial culture, a pre-existing road and pipeline infrastructure, an adaptive oilfield services supply chain, and favourable mineral rights laws were also major enablers. These economic, rather than technical or geological, enablers act as central explanations for why this tipping-point threshold has not been reached for shale gas and LTO production in other areas of the world.

For the Canadian oil sands, however, the turning point metaphor seems less apt, at least at this point in its journey. Although overall oil sands production growth has been impressive and robust since 1999 , it seems that the more production barrels that come online from the massive heavy oil basin, the more headwinds arise that operators must overcome to deliver a return to increasingly impatient investors who have little to show from their investments in the past decade (even before the oil price rout).

Environmental regulations are becoming more onerous and costly to adhere to as scientists and environmental engineers learn more about the climate and ecological side-effects of the energy intensive extraction processes required to separate bitumen from sand. Environmental pressure groups are becoming better funded and more vocal, though the debate between industry proponents and activists is thankfully starting to become more rational and objective. Operators are working harder and spending more to address water usage sustainability, waste management (primarily 'tailing' ponds from mines), encumbered wildlife habitats, and regional air quality. Greenhouse gas (GHG) emissions from oil sands production are just under $70 \mathrm{Mt}$ (just 0.17 per cent of global emissions). Though the producers are currently taxed rather minimally for their emissions, a carbon pricing scheme has just been announced by the Alberta government to approximate the externalities associated with GHG emissions. The proposed regulation is dramatically less burdensome for oil sands producers than for coal power generators (who produce much less GDP per tonne of emissions). It will add roughly $\$ 0.5-4$ per barrel of production cost, and impose a cap of overall emissions of $100 \mathrm{Mt}$ per year, though this cap may be adjusted in the next decade as political parties and emission economics change.

\footnotetext{
${ }^{1}$ Robert Skinner, 'Difficult Oil', Oxford Institute for Energy Studies, 2005, http://www.oxfordenergy.org/wpcms/wpcontent/uploads/2011/02/Presentation30-DifficultOil-RSkinner-2005.pdf.
} 

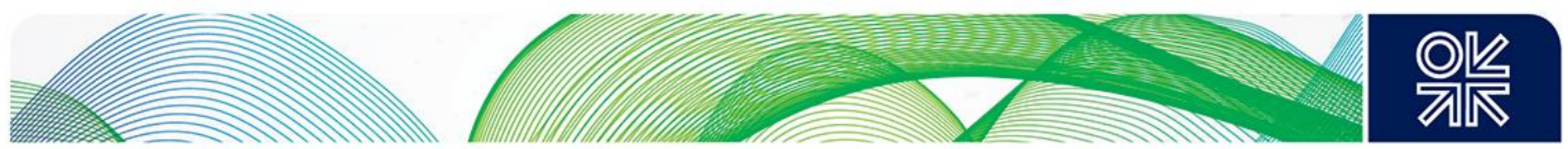

Following production growth of nearly 2 million bpd in the past 15 years, access to markets for the oil sands' diluted bitumen (DILBIT) and synthetic crude oil (SCO) will continue to be a major concern in the next decade. Much-needed large pipeline projects, President Obama's rejection of TransCanada's Keystone XL pipeline being the renowned example, have already been delayed by years and may never gain approval without substantial redesigns and political willpower. Rail transport is filling some of the gap, though at a higher cost and with somewhat limited room to scale up. The result is substantial pricing discounts to the North American WTI standard, itself trading below $\$ 50$ for much of 2015 and piercing below $\$ 30$ in January 2016.

Burdened with a history of neglect, Canada strives to improve the living conditions and representation of its Aboriginal peoples. Oil sands mines can hamper traditional Aboriginal lifestyles. Claims of overly polluted water and air, though at times unsubstantiated, have nonetheless tarnished public perception of oil sands production. Ongoing consultations with Aboriginal groups are needed to maintain trust and enable future growth.

Though less discussed in the media, the most challenging headwind for producers is likely cost escalation - the supply (break-even) cost for greenfield projects in 2014 was three to four times more expensive per barrel than it was in 2003, even after adjusting for inflation. Drastic improvements to operating efficiency, capital effectiveness, supply chain management, and overhead costs are needed to be economically attractive in a lower-price environment.

The challenges mentioned above, added to the strain of what could be a prolonged period of lower oil prices, has caused investors to flee in droves over the past five to ten years. Given the cumbersome and energy-intensive processes that are inherent to extracting bitumen (at least today), there are limits to the savings that operations excellence and cost-cutting initiatives can deliver. Technological advances do have the potential to make more substantial, step-change gains, though their approval and implementation cycles are often measured in decades rather than years. Furthermore, the widespread rollout of these technologies is stifled by the fact that many of these innovations are rather specific to locally unique geological formations within Canada's oil sands.

When compared with nimble LTO projects, oil sands investment decisions are slow, have historically been of much greater magnitude, and require large, well-funded balance sheets managed with longer-term foresight. Scale continues to be a formidable barrier to entry, essentially blocking out the type of enterprising smaller operators that made LTO so successful. That said, many feel that being so unique, oil sands development is still in its infancy and there are many aspects ripe for optimization. In this light, the current low-price environment may be the impetus needed to drive much-needed technological and process breakthroughs. For if operators only could find a way to make supply costs more globally competitive, the reserves are practically inexhaustible. It is this longterm thinking that will likely continue to drive oil sands growth forward in the long term, even though the near-term outlook appears subdued, if not dour, in the current low-price environment. 


\section{Perception, regulation, and a 'social licence to operate'}

\subsection{How Canada and the world view Alberta's oil sands}

Outside of government, academia, and well-financed integrated oil companies, the massive bitumen deposits in northern Alberta flew mostly under the public radar during the twentieth century. This institute did not address the basin in detail until discussions of 'difficult oil' became more prominent with the escalation of global oil prices in the early 2000s. ${ }^{2}$ Much of Alberta's citizenry outside the industry had heard little about the oil sands until rapid investment began to flow in.

In the past 10-15 years, the level of public interest has taken a volte-face to where oil sands issues have now come to the forefront of the public forum. Canada's national business newspapers are routinely rife with oil sands market insights and project updates, while federal and provincial elections (even those outside Alberta), often feature hard-line stances on oil sands environmental regulations, Aboriginal claims, and royalty schemes. Since the oil price spike before the 2008 financial crisis, the development of Canada's oil sands as a long-term surety against a dwindling supply of low-cost crude imports from outside North America has been a salient political topic. While US crude supply security has taken a backseat as a political issue due to the arrival of LTO, environmental advocacy has grown in political clout. The oil sands are now discussed in Washington less as an asset of energy security (like they were until 2008) and more of an environmental calamity, regardless whether such renunciation is warranted. Both in the US and Canada, it seems that funds generated for lobbying purposes by environmental activist groups and political donors are overwhelming those generated from the oil \& gas industry. ${ }^{3}$ These donors have taken as their central mandate a state-imposed moratorium on new oil sands projects and enabling infrastructure, claiming that all bitumen production is 'dirty' and at odds with any global progress on climate change.

FIGURE 1: ACTIVIST BILLBOARD COMPARING OIL SANDS TO THE BP HORIZON OIL SPILL

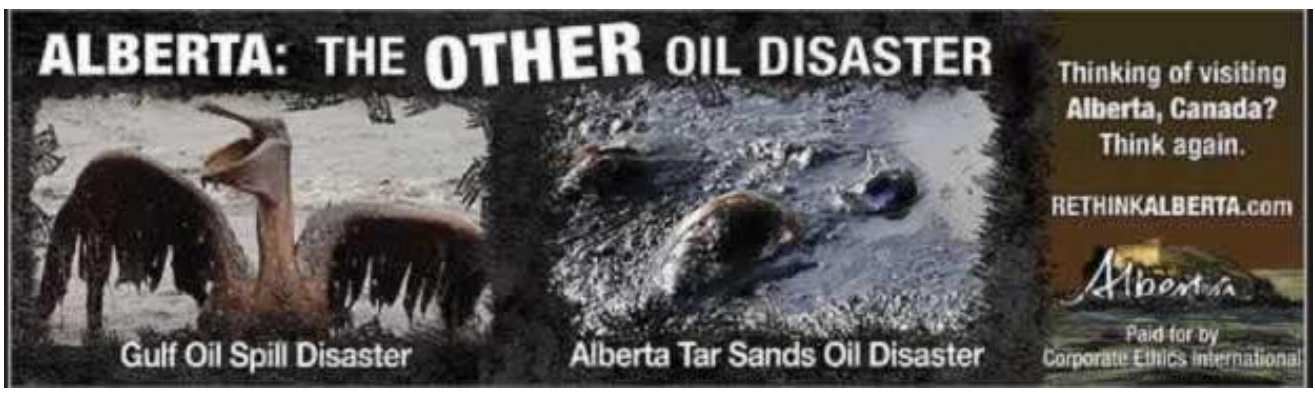

Note: Erected in four major US cities.

Source: Corporate Ethics International, public photograph.

\section{Importance of public perception}

Through burdensome regulation and approval delays, environmental and anti-industrial activism has considerably impeded oil sands production growth. Policies in democratic countries are ultimately derived from public opinion, whether in the production-focused region of Alberta, the current transport and refining geographies for the oil sands concentrated in the US, or new potential markets such as in Europe and democratic Asia. Public perception and consumer concern over burning 'dirty oil' products emanating from the oil sands in California and Europe has led to consideration of punitive regulations against Canadian heavy oil imports. ${ }^{4}$

\footnotetext{
${ }^{2}$ Robert Skinner, 'Difficult Oil', Oxford Institute For Energy Studies, 2005, http://www.oxfordenergy.org/wpcms/wpcontent/uploads/2011/02/Presentation30-DifficultOil-RSkinner-2005.pdf.

${ }^{3}$ An example of this is the largest US individual political contributor in 2014, Tom Steyer: Kenneth P. Vogel, 'Blue Billionaires On Top', Politico, 2015, http://www.politico.com/story/2015/01/blue-billionaires-on-top-114151.html

${ }^{4}$ Yadullah Hussain, 'Oilsands Dodge 'Dirty' Label In European Union After Directive Made Official', Financial Post, 2015,

http://business.financialpost.com/news/energy/oilsands-crude-will-no-longer-be-singled-out-by-eu-after-directive-made-official.
} 
The dual threat of misinformation and vilification of the oil sands has prompted the provincial government of Alberta to devote substantial resources to international awareness campaigns to ensure investment (and divestment) decisions are based on reliable environmental and economic information. The fundamental 'public square' debate in Alberta and around the world is essentially asking: to what extent should investment and government policy enable oil sands production given the economic growth, energy security, and tax revenue it generates, compared to any and all adverse environmental and community impacts?

\section{A call for rationality and open dialogue}

\section{Myopic environmental activism}

The debate often shows itself to be politically partisan, emotional, and polarizing. Oil sands foes who are concerned about increases in Canada's GHG emissions and ecological damage are much more inclined to denounce producers' treatment of Alberta's Aboriginal peoples and decry investor profits during periods of high oil prices. An example of this is the follow-up to a commentary calling for an oil sands pipeline moratorium in Nature, the prominent and highly respected journal of biological sciences. ${ }^{5}$ The eight originating scientists recruited 95 other scientists to their cause, self-proclaimed as 'a diverse group of scientists from across North America' citing a specific 'ten reasons for a moratorium' on oil sands projects and related infrastructure, with 'each grounded in science'. ${ }^{6,7}$ To be sure, several of their arguments highlight salient and genuinely irrefutable, harmful ecological impacts of oil sands production to Northern Alberta's ecosystem, especially associated with surface mining projects. Others are hardly scientific, but conjectural and rhetorical such as the statement that "continued expansion of oil sands and similar unconventional fuels in Canada and beyond is incompatible with limiting climate warming to a level that society can handle without widespread harm', and another stating that 'development and transport of oil sands is inconsistent with the title and rights of many Aboriginal Peoples of North America'. These comments obscure the reality that oil sands production today contributes around 0.17 per cent to global emissions, becoming less carbon intensive per barrel each year, deliver a rather high GDP to emissions ratio, and ignore the benefits that oil sands development brings to Aboriginal peoples. ${ }^{8,9}$

\section{The nomenclature battle}

Hostility can begin in the first sentence of a debate, with activist groups addressing the basin as the 'tar sands' rather than the now more accepted 'oil sands' nomenclature. In fact, both terms were used interchangeably for much of the basin's controversy-free early years (note that oil sands bitumen was initially used, ineffectively, for roofing and paving tar as far back as 1906). Starting in the 1990s, in the face of environmental opposition, the industry pushed for a consensus on the label 'oil', of which bitumen is a form and the ultimate end product of the production process. Technically speaking, 'oil' is more correct than 'tar' as the oil sands do not contain tar, but are 'tar-like' (actual tar is synthetically produced from coal, wood, petroleum, or peat). ${ }^{10}$

\section{Environmental indifference}

On the other side of the argument, history is chock-full of politicians and others ignoring the environmental impact of large-scale oil sands production, even when a scientific consensus exists. The past few decades are full of ironies of environmental extremists causing unnecessary environmental damage by blocking certain forms of development while more destructive forms replace them. ${ }^{11}$ In a similar irony, however, the numerous Canadian and Albertan political leaders

\footnotetext{
${ }^{5}$ Wendy J. Palen et al., 'Energy: Consider The Global Impacts Of Oil Pipelines', Nature 510, no. 7506 (2014): 465-467, doi:10.1038/510465a.

10 Reasons, 'Oil Sands Moratorium Press Release', 2013, http://www.oilsandsmoratorium.org/pr/.

7 Shawn McCarthy, 'Alberta'S Oil Sands Take A Hit As Scientists, Academics Call For Halt To Development', The Globe And Mail, 2015

8 The activist group was less 'diverse' than its claims - of the 103 signatories, 91 were scientists from the biological sciences, environmental and natural resources fields while 9 researched policy and political science - all faculties that have a reputation at North American universities to be less supportive of industry than the mainstream. Only one economist and one engineering professor signed the oil sands moratorium, as well as an archaeologist. ${ }^{8}$

9 Energy.alberta.ca, 'Alberta Energy: Facts And Statistics', 2015, http://www.energy.alberta.ca/oilsands/791.asp.

10 To be even more technically correct, and for better accuracy, one can turn to the French language, which refers to the formation as 'sables bitumineux' (translated to English as 'bituminous sands').

${ }^{11}$ The closing of nuclear energy plants in Germany and elsewhere, only to be replaced by coal power is an example of this
} 
who are strong oil sands advocates have arguably hampered growth projects due to their indifference to the impacts of global climate change and ecological preservation.

As Prime Minister of Canada between 2006 and 2015, Stephen Harper altered his public opinion and acknowledged the criticality of climate change as a world issue, claiming that Canada will do its part to contribute to the global effort. However, draconian cutbacks to funding for environmental and biological sciences as well as initiatives to limit how government scientists speak with the media rendered many mainstream Canadian voters cynical. ${ }^{12}$ Furthermore, the US review of the Keystone $\mathrm{XL}$ pipeline has now been rejected by US president Barack Obama based on concerns of global warming. Harper's reputation as a leader critical of taking action on climate change did little to assuage a sceptical American public. Furthermore, somewhat uninformed statements from politicians, like the below from Joe Oliver in 2013, then Canada's Minister of Natural Resources, further harmed Canada's environmental reputation around the world.

I think that people aren't as worried as they were before about global warming of two degrees...Scientists have recently told us that our fears (on climate change) are exaggerated. ${ }^{13}$

\section{Earning a 'social licence to operate'}

The challenges of developing the oil sands both profitably and responsibly are complex. Making sound investment decisions and writing effective, unbiased policy requires a broad local and global understanding of energy economics, geology, engineering, ecology, Aboriginal rights, market access, climate science, and politics. Individual experts or sources (not least this paper) are unable to comprehensively grasp all the widespread impacts and influences connected with oil sands decisions. Governmental agencies such as the National Energy Board (NEB), the expert group that regulates interprovincial and offshore energy projects including pipelines, and the past constituents of today's Alberta Energy Regulator (AER), had for decades acted as the impartial regulator that manages the regulation process. More recently, however, the emotional and political nature of environmental activism has pulled decision making into the political circle, laden with exaggeration and misinformation from both camps. Upon the NEB's approval in 2014 of Enbridge's proposed Northern Gateway pipeline (slated to carry oil sands crude to Canada's west coast before being tanked to Asia), major federal opposition party leaders Justin Trudeau and Thomas Muclair immediately vowed to reverse the decision if they were elected, even if the burdensome outstanding conditions were met. They insinuated that Stephen Harper's Conservative government was responsible for the NEB's review, notwithstanding the fact that the board includes acclaimed and objective experts in economics, engineering, Aboriginal law, and biology. ${ }^{14}$

Amidst this partisan environment, the Canadian oil \& gas industry is itself making a growing effort to address the public debate rationally and objectively. The producers and midstream operators who have taken major balance sheet stakes in the oil sands have been forced to counteract what they deem to be a populist and distorted campaigns that threaten their ability to operate. Historically, North American operators happily operated under the radar with regards to public perception, so long as they met governmental regulations and were able to get responsibly designed projects approved. This is no longer the case, as larger companies have worked diligently through their own brand and corporate social responsibility (CSR) departments, as well as industry funded collaborations such as the Canadian Association of Petroleum Producers (CAPP), to help educate public opinion and discourse. For example, Suncor and Enbridge have invested hundreds of millions of dollars in renewable energy both to gain a foothold in that growing market and to demonstrate that they think

\footnotetext{
12 Harper built his political standing from ideological roots in Alberta based on free markets and limited government intervention. Though regrettable in hindsight, during Harper's political ascent, suspicion of government overreach caused him to refer to environmental initiatives such as the Kyoto climate change accord as 'a socialist scheme to suck money out of wealthproducing nations' as well as the science that drove it as 'tentative and contradictory.' During the election year of 2006, he further displayed his ignorance around climate change by stating that 'we have difficulties in predicting the weather in one week or even tomorrow. Imagine in a few decades. - Joan Bryden, 'Siding With Skeptics, Tory MP Decries Climate-Change

'Alarmism", The Globe And Mail, 2010, http://www.theglobeandmail.com/news/politics/siding-with-skeptics-tory-mp-decriesclimate-change-alarmism/article4310491/.

${ }^{13}$ Charles Côté, 'Le Ministre Oliver: Des Sables Bitumineux Sans Limite, Une Menace Climatique «Exagérée»', La Presse (Translated From French), 2015.

${ }^{14}$ Laura Payton, 'Northern Gateway Pipeline Approved With 209 Conditions', Cbc.Ca, 2015,

http://www.cbc.ca/news/politics/northern-gateway-pipeline-approved-with-209-conditions-1.2678285.
} 
progressively about energy trends of the future. Beyond branding and public perception marketing, company-led public 'town hall' meetings are commonly used to promote open dialogue. Professional service firms supporting the industry in the accounting, information, consulting, research, and legal fields are also supporting their clients by contributing to conferences and events that boost public awareness of energy education. ${ }^{15}$ In fact, while the federal Conservative government made no effort to quell Canadian climate concerns (an action that might have catalyzed the approval of the Keystone XL pipeline), oil sands anchor producers CNRL, Suncor, Shell, and Cenovus proactively came out in favour of a meaningful carbon tax. ${ }^{16,17}$

As CSR efforts increase to educate the public, producers confront an interesting question: Why are we, as regulation-abiding companies operating in the oil sands, burdened with directing capital to building brand awareness of our otherwise unbranded, commodity product, while simultaneously educating the public to ensure an objective regulatory environment?

Theoretically, having the provincial and federal governments produce environmentally sound policy should generate a favourable reputation for Canada's energy industry while generating economic benefits for the public. Oil sands producers and midstream operators, however, have discovered they also need to be proactive in the public sphere to help earn their 'social licence to operate'. Their challenge is to not allow that oft-quoted term to become grounds for regulatory or activist overreach.

\subsection{Environmental impact of the oil sands}

Extracting and transforming viscous, bituminous sands into a usable crude product on a large scale is technically complex and energy-intensive - the associated environmental impact is correspondingly troublesome and costly to reduce. Though producers have spent billions to reduce both local pollution and global greenhouse gas impacts with admirable success, oil sands production still creates more land disturbance, uses more water, and emits more greenhouse gases per barrel produced than conventional production of light oil.

As the Canadian constitution grants management responsibility of natural resources to provinces, most oil sands production and upgrading remain within the jurisdiction of the province of Alberta and do not require federal approval. ${ }^{18}$ The federal government plays a larger role in pipeline and other interprovincial and international transportation, as well as when a project triggers federal authority such as Parks Canada or Health Canada. The federal government has not yet become involved in regulating GHG emissions and has left it to the provinces to take action, though this could change with the election of Justin Trudeau's Liberal party in October 2015.

\section{Local impact}

\section{Air pollution}

As with many industrial processes, bitumen extraction and upgrading produces regional air pollution that can damage terrestrial and aquatic ecosystems if accumulated in large enough concentrations. ${ }^{19}$ Furthermore, air pollution can endanger human health, as witnessed in the world's most polluted cities and industrial areas. Oil sands processes emit criteria air contaminants ${ }^{20}$ (CAC: $\mathrm{SO}$, NOx, Particulate Matter ${ }^{21}$, Volatile Organic Compounds, $\mathrm{CO}$, and $\mathrm{NH}_{3}$ ), heavy metals (lead, cadmium,

\footnotetext{
${ }^{15}$ Examples of this include IHS's "Oil Sands Dialogue", the JuneWarren Nickle's Energy Group and PwC's "Energy Visions"

${ }^{16}$ Geoffrey Morgan, 'Canadian Natural Resources Ltd Supports A Carbon Tax — But Only If It Funds New Technology',

Financial Post, 2015, http://business.financialpost.com/news/energy/cnrl.

${ }^{17}$ Geoffrey Morgan, 'Carbon Tax Should Apply To Companies And Consumers, Says Suncor Energy Inc's CEO', Financial

Post, 2015, http://business.financialpost.com/news/energy/carbon-tax-should-apply-to-companies-and-consumers-says-suncorenergy-incs-ceo.

${ }^{18}$ Upgraders are processing plants that reduce the viscosity of bitumen to enable processing in a typical refinery. The output of an upgrader is SCO - synthetic crude oil. See the Appendix: Oil Sands Primer for more information.

19 (Hrudey et al. 2010)

20 'Criteria air contaminants, or CACs, are the primary constituents of air pollution that lead to the most common, broad-scale air quality issues such as smog and acid rain.' (McWhinney 2014)

21 'Particulate Matter $\left(\mathrm{PM}_{\mathrm{x}}\right.$, where $\mathrm{x}$ refers to median particle size in micrometers) refers to a complex range of fine particles including soot, dust, dirt, and secondary acidic and organic aerosols which can remain suspended in air.' 'Total PM (TPM) refers to all suspended particles up to approximately 100 micrometres $(0.1 \mathrm{~mm})$ in diameter; PM less than 10 micrometres in diameter (PM10), sometimes referred to as coarse PM when excluding particles less than 2.5 micrometres; and PM less than 2.5 micrometres in diameter (PM2.5), sometimes referred to as fine PM.' (Hrudey et al. 2010)
} 
mercury, and vanadium), polycyclic aromatic hydrocarbons (PAHs) and Total Reduced Sulphur (including $\mathrm{H}_{2} \mathrm{~S}$ ). Though the CAC emission levels are substantial, in most cases they make up small percentages of Canada's total (see Table 1 ). ${ }^{22}$

TABLE 1: OIL SANDS CAC EMISSIONS VS CANADIAN TOTAL (2012)

\begin{tabular}{|c|c|c|c|c|c|c|c|c|}
\hline In Tons ( $T$ ) & TPM & $\mathrm{PM}_{10}$ & $\mathrm{PM}_{2.5}$ & SO $_{x}$ & $\mathrm{NO}_{\mathrm{x}}$ & VOC & $\mathrm{CO}$ & $\mathrm{NH}_{3}$ \\
\hline Mining & 751 & 372 & 199 & 2,885 & 3,826 & 18,947 & 3,461 & 162 \\
\hline In-Situ & 686 & 671 & 670 & 9,433 & 14,397 & 1,947 & 13,498 & - \\
\hline Upgrading & 4,379 & 2,638 & 1,256 & 99,545 & 26,445 & 24,819 & 14,201 & 1,197 \\
\hline O/S Total & 5,816 & 3,681 & 2,125 & 111,863 & 44,668 & 45,713 & 31,160 & 1,359 \\
\hline Can Total & $22,731,744$ & $7,081,067$ & $1,368,325$ & $1,287,662$ & $1,861,718$ & $2,026,674$ & $8,254,128$ & 495,522 \\
\hline $\begin{array}{l}\text { Oil Sands } \\
\text { (\% of Can) }\end{array}$ & $0.03 \%$ & $0.05 \%$ & $0.16 \%$ & $8.69 \%$ & $2.40 \%$ & $2.26 \%$ & $0.38 \%$ & $0.27 \%$ \\
\hline
\end{tabular}

Source: Environment Canada, Pollutant Inventories and Reporting Division, 2014.

Mining emissions, typically higher in VOC, arise from open-face mines, tailing ponds, and evaporation of froth extraction solvents. In-situ production drives air pollution through large-scale combustion of natural gas in the steam generation process. Analogous to a typical oil refinery, upgraders contribute the most air pollution, with their $\mathrm{SO}_{x}$ emissions being most concerning. Because of specific regulations incentivizing cleaner operations, producers' ability to reduce emissions of CACs has been impressive. Table 2 that demonstrates the improvements made over a seven-year period. ${ }^{22}$

TABLE 2: CHANGE IN AIR POLLUTION EMISSIONS INTENSITY (2005-2012)

\begin{tabular}{|l|c|c|c|c|c|c|c|c|}
\hline & TPM & $\mathbf{P M}_{10}$ & $\mathbf{P M}_{2.5}$ & $\mathbf{S O}_{\mathbf{x}}$ & \multicolumn{1}{c|}{$\mathbf{N O}_{\mathbf{x}}$} & \multicolumn{1}{c|}{ VOC } & CO & $\mathbf{N H}_{\mathbf{3}}$ \\
\hline Mining & $-19 \%$ & $-27 \%$ & $-33 \%$ & $-44 \%$ & $-21 \%$ & $-42 \%$ & $-74 \%$ & $-53 \%$ \\
\hline In-Situ & $-24 \%$ & $-32 \%$ & $-32 \%$ & $-78 \%$ & $-49 \%$ & $-70 \%$ & $-36 \%$ & $\mathrm{~N} / \mathrm{A}$ \\
\hline
\end{tabular}

Source: NPRI Facility Report Data; AER ST39/ST53.

Heavy metal and PAH pollution from the oil sands has been shown to be relatively small compared to other industrial activity in Canada, though PAH particles are often wind-blown and deposited in nearby lakes. This can potentially cause ecological damage, though none has been demonstrated todate. Also worrisome is the issue of soil and lake acidification from the acidification of $\mathrm{NO}_{x}$ and $\mathrm{SO}_{2}$. The soils of northern Alberta and the nearby lakes of the contiguous province of Saskatchewan are highly sensitive to acid deposits and have little buffering capability. Improved monitoring and further testing is being conducted to ensure that environmental impact is minimized. ${ }^{23}$

\section{Water usage and contamination}

Environmentalists and many others unfamiliar with resource conservation economics are appalled when learning that oil sands mines require approximately 13-14 barrels of water (in-situ production requires around three barrels of water) to produce just one barrel of bitumen crude. These facts are somewhat misleading, however, as much of this water is recycled in both production techniques. Furthermore, in-situ production is capable of reducing its freshwater needs by 50 per cent or more by substituting otherwise unusable brackish groundwater. The net effect is that mining projects have a non-recycled freshwater to bitumen produced ratio of 2-3 to 1, while in-situ production requires much less at a ratio of only 0.5 to 1 .

Nevertheless, with current mining production alone, notwithstanding new projects, more than 2 million bpd of freshwater is taken from the Athabasca River, the region's most important water source. At some estimated production growth rates, water requirements could triple by 2030 , as water usage per barrel for mines has not decreased since 2005. ${ }^{22}$ Removing excess water from the river can damage aquatic ecosystems and the Canadian and Albertan governments have accordingly limited water

\footnotetext{
22 (McWhinney 2014)

${ }^{23}$ (Hrudey et al. 2010); (McWhinney 2014)
} 
removals to 5.2 per cent of total river flow. Fortunately for producers, this restriction is at least four or five times greater than recent removal levels, even in low-flow months. ${ }^{24}$

As production growth shifts towards in-situ methods, water availability is less of a concern. SAGD operators have worked to increase recycle rates and brackish water usage to substantially reduce fresh groundwater requirements, though this effort can counterproductively increase the steam-to-oil ratio required, and the corresponding GHG emissions intensity, which is more of a concern than water usage. Longer-term seepage of polluted water into freshwater sources is concerning as the movement is so slow (approximately 1 metre per year). ${ }^{23}$ Improved monitoring has been called for by the scientific community and is being becoming embedded into provincial regulations.

\section{Land disturbance and tailings}

Certainly the most visually recognizable environmental impact of oil sands production is the substantial land disturbance associated with surface mining. Environmental activists, including prominent politicians, musicians, and Hollywood celebrities, who have toured the region by helicopter, have described the area as 'toxic', 'a wasteland', and 'like Hiroshima'. ${ }^{25}$ This negative publicity, even if unsubstantiated, hampers governments in developing production-friendly regulation and approving critical egress pipelines to the Pacific Coast and the US.

In fact, further research of land usage in the area paints a different picture. Of the oil sands' overall area of $141,000 \mathrm{~km}^{2}$ (roughly the size of Florida), only 3 per cent $\left(4,700 \mathrm{~km}^{2}\right)$ is mineable, and the rest can only be produced through in-situ methods. Of that mineable area, only 0.6 per cent $\left(835 \mathrm{~km}^{2}\right)$ had been disturbed at the end of 2012, amounting to 0.13 per cent of the area of Alberta. ${ }^{26}$ With fewer mining projects proposed and reclamation efforts underway, it is unlikely that this area would approach the 4,700 $\mathrm{km}^{2}$ mineable limit in the next two or three decades. As of 2012, when accounting for both mining and in-situ methods, one finds that the land disturbance due to bitumen production in the oil sands areas is less than one-third that of agriculture and much, much less than that of forestry. 27

Beyond the striking visual impact, surface mining land disturbance is difficult to reclaim. The process takes decades, and very little ( $<1$ per cent) of the disturbed land from mining to-date is considered 'certified reclaimed'. Wetlands, which cover two-thirds of the oil sands mineable area, and tailing ponds, which take decades to solidify, are especially difficult to reclaim. Suncor's first tailing pond, which started in 1967 , has just recently been reclaimed to a solid-state. ${ }^{28}$ Given that the public is increasingly sceptical of producers' ability to manage tailings over the long term, mine operators and government regulators could afford to take some lessons from the Canadian forestry industry in developing long-term environmental management techniques that progress towards sustainability.

The undeniable trend towards in-situ production, which disturbs approximately 7-15 per cent of the land of a mining project (just slightly higher than conventional oil production), alleviates concerns over future large-scale disturbances. That said, in-situ methods such as SAGD do require pipelines, roads, and seismic lines. Though these infrastructure elements are somewhat 'one-dimensional' in nature and occupy a small total area of land, there are substantial 'linear disturbances', such as fragmented forests, that impact the habitat of forest animals. Canada's threatened Caribou herds, which have been on a worrisome decline in the area and throughout the world, owe some of their collapse to oil sands production, among other human factors..$^{29,30}$

\section{Public health}

Health concerns around the impact of oil sands production have centred on the small community of Fort Chipewyan, located on the banks of Lake Athabasca and more than $220 \mathrm{~km}$ north of Fort

\footnotetext{
24 IHS CERA: Special Report, Critical Questions For The Canadian Oil Sands (Washington DC: IHS, 2013).

${ }^{25}$ Gary Mason, 'Hollywood Vs. Oil Sands? Not A Fair Fight', The Globe And Mail, 2013,

http://www.theglobeandmail.com/globe-debate/hollywood-vs-oil-sands-not-a-fair-fight/article14423129/.

26 (IHS CERA: Special Report 2013)

27 (McWhinney 2014)

28 Government of Alberta, Oil Sands Reclamation (Edmonton:

http://oilsands.alberta.ca/FactSheets/Reclamation_FSht_Sep_2013_Online.pdf, 2013).

${ }^{29}$ Caribou, also referred to as reindeer, are a species of deer located primarily in Canada. Caribou herds comprise one of the

world's great large-animal migrations. http://animals.nationalgeographic.com/animals/mammals/caribou/

30 (McWhinney 2014); IHS CERA: Special Report, Critical Questions For The Canadian Oil Sands (Washington DC: IHS, 2013).
} 
McMurray and downstream from the major mining projects. Considered Alberta's oldest settled community, Fort Chipewyan is today home to a population of approximately 1,000 predominantly Aboriginal residents. ${ }^{31}$ Widespread media claims of increased rates of cancer in the community due to oil sands pollution started in 2006 with a non-resident visiting doctor voicing dire warnings. ${ }^{32}$ Aboriginal and environmental activists cried foul and wilful neglect. However, several studies have since discredited the claims, including a Royal Society report in 2010 , quoted below, and recently a more conclusive report from the Alberta government in 2014:

\begin{abstract}
...there is no credible evidence to support the commonly repeated media accounts of excess cancer in
Fort Chipewyan being caused by contaminants released by oil sands operations, notably polycyclic aromatic hydrocarbons (PAH) and arsenic. In particular, common references to PAHs in relation to human cancer risk have been loose and inconsistent with the scientific understanding of human cancer risk from this class of compounds. ${ }^{33,34}$
\end{abstract}

Most consider the claims to be debunked, though Aboriginal leaders in the area have since funded their own studies which demonstrate some link to carcinogenic pollution. ${ }^{35}$ Notwithstanding these claims, there is a general consensus among the scientific community (as quoted below, again from the Royal Society) that a broader understanding of public health impact in these remote communities is needed:

The Environmental Impact Assessment (EIA) process that is relied upon by decision-makers... to make a determination whether proposed projects are in the public interest is seriously deficient in formal health impact assessment (HIA) and quantitative sociological impact assessment (SEIA) as would be required for World Bank projects, for example. ${ }^{33}$

\title{
Alberta Energy Regulator (AER): World class or industry-influenced?
}

Despite continued efforts to improve regulatory oversight of production, the Alberta Energy Regulator strives to make Alberta one of the safest, most environmentally responsible, and transparent jurisdictions among the world's oil-producing regions. ${ }^{36}$ Comparing levels of regulatory scrutiny in Alberta against those in the US Gulf Coast, Mexico, Russia, and Africa, as well as the National Oil Companies of Southeast Asia, South America, China, and the Middle East, it quickly becomes evident that Alberta is a global leader in driving environmental responsibility and compliance.

Nevertheless, the governments of Alberta and Canada have been consistently castigated by oil sands opponents as being too friendly, not truly at arm's length, to the oil and gas industry. A prime example of this is the proposal from the newly elected New Democratic Party (NDP) in Alberta to repeal the Responsible Energy Development Act of 2012. The initiative worked to combine the previously disparate Energy Resources Conservation Board (ERCB) and the Ministry of Environment into a single organization, the Alberta Energy Regulator (AER), in an effort to make the regulatory process more streamlined and efficient. The intent was to reduce uncertainty and improve competitiveness of oil and gas projects in the province, as well as ensure transparency and consistency of regulatory oversight. Though the effort was lengthy and cumbersome, the result has been lauded by industry and government alike as a giant leap forward in improving clarity, transparency, and approval times. The AER now considers itself one of the most effective regulatory bodies in the world for oil and gas

\footnotetext{
${ }^{31}$ Fort Chipewyan was founded by famous explorer Peter Pond of the North West Trading Company, as a trading post for the fur trade in 1788. It was during the period of 1778-1788 that Pond became familiar with the Athabasca region, and he was the first European settler to recognize the "tar" like substance in the oil sands; Government of Alberta, 'Peter Pond - Alberta

Energy Heritage', History.Alberta.Ca, 2015, http://history.alberta.ca/energyheritage/sands/origins/the-fur-trade-and-albertas-oilsands/peter-pond.aspx\#page-2

${ }^{32}$ The Pembina Institute, 'Briefing Note: Canadian Aboriginal Concerns With Oil Sands', 2010, https://www.pembina.org/reports/briefingnoteosfntoursep10.pdf.

${ }^{33}$ Steve H. Hrudey, Environmental And Health Impacts Of Canada's Oil Sands Industry: Executive Summary, The Royal Society Of Canada Expert Panel, 2010.

${ }^{34}$ Alberta Health Services, Appendix I: Fort Chipewyan Update, Surveillance \& Reporting Cancer Measurement Outcomes Research And Evaluation Cancer Control (Government of Alberta, 2014)

${ }_{35}$ CBC News, 'Fort Chipewyan Cancer Study Suggesting Oilsands Link To Be Released Today', Cbc. Ca, 2014, http://www.cbc.ca/news/canada/north/fort-chipewyan-cancer-study-suggesting-oilsands-link-to-be-released-today-1.2698430 ${ }^{36}$ The Alberta Energy Regulator (AER) is working with the University of Pennsylvania's Program on Regulation to determine where gaps exist between them and world-class regulators across industries.
} 
production, and it is looking to spread its self-proclaimed best practices around the world's oilproducing basins.

Oil and gas sceptics, including the left-leaning NDP party, decry the creation of the AER as part of what they claim was ongoing excessive influence of the industry on the historically business-friendly PC party, who had been in power in Alberta for 44 years until May 2015. As a result of the NDP win, its rhetoric during the election about re-evaluating regulatory practices creates doubt for the AER's future. Although it is concerning when oil sands producers work too closely with the regulator, there does need to be a certain level of minimum interaction for the appropriate regulations to be set, given the relative immaturity of oil sands processes and technologies (such as tailing reclamation or solvents used in SAGD). After all, over the long term it is in the best interest of producers to demonstrate environmental sustainability in order to maintain its social licence to operate. What is more concerning for the future of oil sands is if the AER becomes politicized, less effective, and more bureaucratic, hampering project economics and increasing risk for investors.

\section{Global impact: Greenhouse gas (GHG) emissions}

The 'carbon footprint' of bitumen production is likely the most emotive issue in oil sands politics and public debate. Vehement protests in the United States and Canada (and even as far away as Europe) denounce Alberta's oil sands as 'dirty' and representing a step in the wrong direction for global environmental progress. Still, it is clear that meeting global energy demand while maintaining environmental responsibility and economic growth for developed and developing populations alike is a highly complex and nuanced problem that necessitates a comprehensive understanding of environmental costs and economic benefits of multiple energy sources. Taking an informed political stance or writing effective policy on Alberta's oil sands, requires such an understanding. Multiple independent analyses have helped elucidate the public debate, though proselytizing is still widespread. ${ }^{37}$

\section{How much GHGs do oil sands projects emit?}

The challenge oil sands producers face in reducing GHG emissions (primarily carbon dioxide) comes back to the massive amount of energy needed to 'reverse geology' through the inherent low energy return on investment (EROI) of separating bitumen from sand. Currently, the vast majority of energy inputs to the oil sands are derived from fossil fuel combustion such as the burning of natural gas for heat, diesel fuel for mining trucks, and coal for producing much of the electricity on Alberta's grid. It is no surprise that surface mining emits less than most in-situ SAGD and CSS projects because of their higher EROI values.

Calculating the effective GHG emissions attributed to a certain industrial process is complicated as many estimates and assumptions are required along the process value chain. There is also debate as to how much of the value chain should be analyzed. Because per barrel emissions exceed other production sources on average, oil sands producers complain that the public is not getting the whole story when environmental groups make claims like 'oil sands production emits 3 to 4 times more greenhouse gases than producing conventional crude oil'. ${ }^{38}$ Oil sands production emissions are indeed substantially higher than those of conventional light oil from prolific reservoirs. That said, production is only a small proportion of the crude oil well to vehicle wheel value chain (approximately 20-30 per cent), Alberta's oil sands are located relatively close to its large-consuming American neighbour, and other heavy oil sources with higher production emissions are used by US refineries. Oil sands per barrel emissions are therefore closely in-line with the US average and in fact lower than several other sources of US crude, such as those from California's heavy oil fields as seen in Figure 2 (on the following page). That said, California's fields have been in decline for decades, while oil sands production will continue to grow, at least to some extent.

In aggregate, mining, in-situ, and upgrading emissions totalled approximately $62 \mathrm{Mt}$ of GHG emissions in 2013, about 8.5 per cent of Canada's output from all sectors. ${ }^{39}$ As a sparsely populated

\footnotetext{
37 Jacobs Consultancy, IHS, the Alberta Energy Research Institute, the United States Department of State and Environment Canada have undertaken efforts and debates in calculating and clarifying what are the true emissions from Alberta's oil sands 38 Tar Sands Solutions Network, 'Climate - Oil Sands Reality Check', Oil Sands Reality Check, 2015, 
country (albeit one with high individual energy consumption), Canada contributes only 1.6 per cent to global GHG emissions and the oil sands contribute roughly 0.17 per cent. ${ }^{40}$ Thus it is hardly surprising that the US Department of State concluded in 2014 that the Keystone XL pipeline and its enabling of oil sands growth is unlikely to have a discernible effect on global climate change. ${ }^{41}$ When questioned about the impact of carbon emissions from the oil sands in 2014, International Energy Agency chief economist Fatih Birol offered a global perspective for increases in GHG emissions until 2040:

...to be frank, the additional $\mathrm{CO}_{2}$ emissions coming from the oil sands is extremely low... the emissions of this additional production [increase in annual production from 2015-40] is equal to only 23 hours of emissions of China - not even one day. I hope all these [opponent] reactions are based on scientific facts and sound analysis. ${ }^{42}$

\section{FIGURE 2: IHS WELL-TO-WHEELS GHG EMISSIONS OF OIL SANDS VS. OTHER US CRUDES}

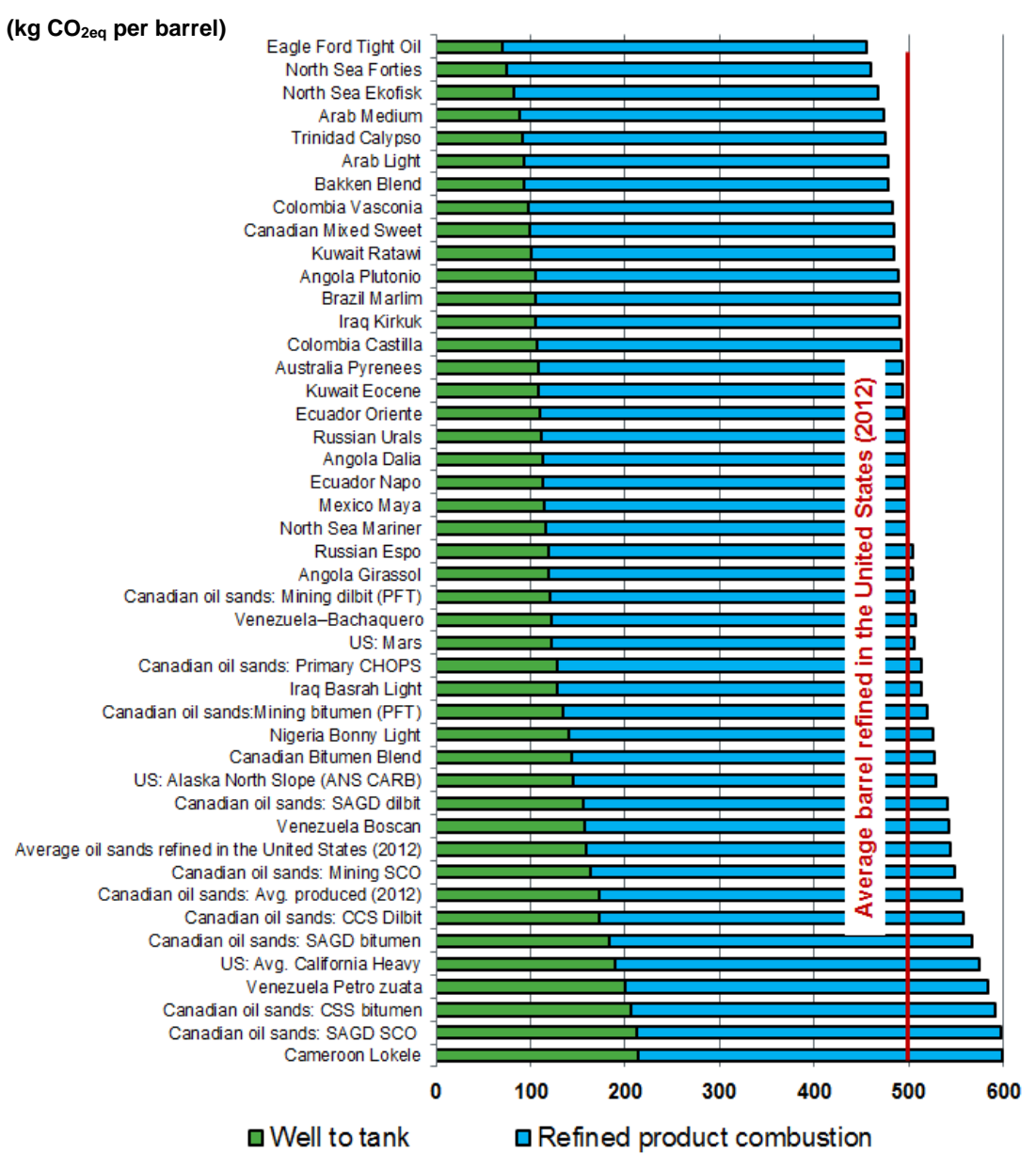

Source: IHS, @ $2015^{43}$

\footnotetext{
40 Natural Resources Canada, GHG Emissions, Oil Sands A Strategic Resource For Canada, North America And The Global Market (Government of Canada, 2015),

https://www.nrcan.gc.ca/sites/www.nrcan.gc.ca/files/energy/pdf/eneene/pubpub/pdf/os2015/14-0698-Oil-Sands-GHGEmissions_us_access_eng.pdf.

${ }^{41}$ United States Department of State, Final Supplemental Environmental Impact Statement For The Keystone XL Project: Applicant For Presidential Permit: Transcanada Keystone Pipeline, LP (Bureau of Oceans and International Environmental and Scientific Affairs, 2014).

${ }^{42}$ Yadullah Hussain, 'New Emissions From Canada's Oil Sands 'Extremely Low,' Says IEA's Chief Economist', Financial Post, 2015, http://business.financialpost.com/news/energy/new-emissions-from-canadas-oil-sands-extremely-low-says-ieas-chiefeconomist.

${ }^{43}$ See IHS Energy. Comparing GHG Intensity of Oil Sands and the Average US Crude Oil. Oil Sands Dialogue. Calgary, 2014, as well as Birn, Kevin, and Jeff Meyer. Why the Oil Sands? Oil Sand Dialogue. IHS Energy, 2015.
} 
What Canadians are concerned about is the growth of oil sands emissions when compared with other sectors of the economy where emissions are shrinking. These concerns tend to be somewhat aloof to the GDP generated per produced barrel, versus other emissions sources like coal or even gas power generation.

\section{Punitive vs. comprehensive GHG regulations}

Binding agreements between nations have been hard to come by with so many disparate economic, geopolitical, and environmental interests involved, and few of the world's major emitters have substantially reduced emissions. Without a meaningful price on carbon emissions, politicians and environmental activists resolved to reducing emissions have resorted to obstructing individual production and midstream projects. An example of this is the environmental movement against Albertan exit pipelines, which by themselves emit very little GHG but do enable oil sands production expansion. The strategy has been described as a 'Whac-a-Mole' approach to emissions reduction: striving to squash new fossil fuel projects wherever they may arise. ${ }^{44}$

Frustrated with inaction on carbon pricing, activist groups call for a complete ban on all oil sands production, irrespective of how individual projects are managing their GHG emissions. Such rulings, if enacted, would be an example of a punitive regulation - one that discriminately penalizes one form of pollution over another, irrespective of the magnitude of GHGs emitted. The underlying logic is that the government or environmental groups are able to determine which individual industrial projects are in the best long-term interest of the public.

Despite its reputation as something of an environmental pariah within the confederation, in 2007 Alberta became the first Canadian province (and well ahead of any US state) to enact a carbon pricing mechanism: the 'Specified Gas Emitters Regulation'. The policy essentially charges industrial emitters CAD $\$ 15$ per tonne $\mathrm{CO}_{2}$ for emissions that are beyond a 12 per cent reduction from an established baseline. This penalty is to be increased in 2016 to CAD $\$ 30$ per tonne $\mathrm{CO}_{2}$ on declaration of the newly elected NDP government. ${ }^{45}$ The programme is essentially punitive in intent, in that its goal is only to reduce production of large emitters, rather than emissions from other sectors such as transportation and land usage, though the cost burden is quite low - even producers who did not lower their emissions intensity are paying emissions costs of less than CAD $\$ 1$ per barrel.

FIGURE 3: ALBERTA'S PROPOSED EMISSIONS TAX: EFFECT ON OIL SANDS PRODUCERS

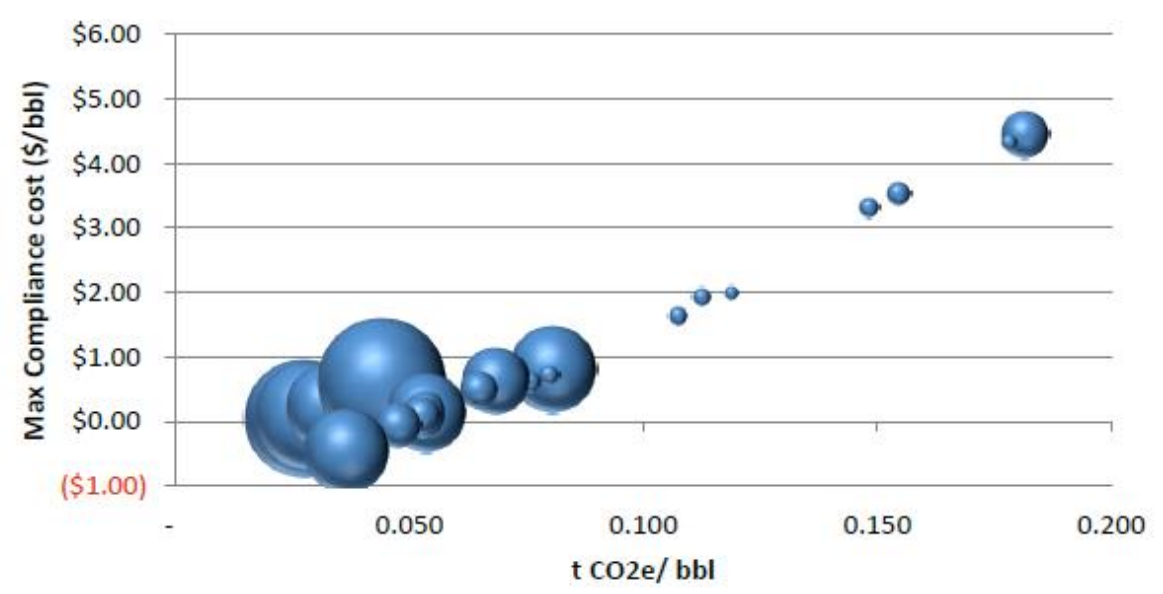

Source: Government of Alberta Climate Leadership report to Minister, November 2015.

\footnotetext{
44 'Whac-a-Mole' is a children's carnival / arcade game where players use a mallet to knock randomly appearing toy moles or gophers back into their holes. Regardless of how quickly a skilled player can supress emerging moles, new moles always arise, seemingly faster as the level of the game increases. This is analogous to attempting to obstruct all new arising oil production projects individually, rather than having widespread regulation that penalizes emissions, leading to an overall reduction. ${ }^{45}$ Industrial emitters are considered those with more than 100,000 tonnes of CO2 emissions per year. Given that oil sands emissions for 2013 were $62 \mathrm{Mt}$, the regulation encompasses all of Alberta's medium and large oil and gas producers, few of whom have been able to meet the 12 per cent reduction standard without substantial cuts to production.
} 
A recent government review of Alberta's carbon pricing mechanism was completed in late November 2015 , and the likely to be followed recommendation is to move to a broad-based tax on emissions such that consumer and industrial polluters alike will be charged $\$ 30$ per tonne of GHG emissions. Though this would seem to have a substantial price increase for producers, a free-emission credit for production intensity in the top quartile of energy intensity is recommended, meaning that many producers could pay less than what they are today. Figure 3 summarizes the government panel's recommendations - demonstrating that the majority of production will not have major increases in GHG costs (size of bubbles in the chart represent the magnitude of production of the facilities modelled).

\section{Oil sands emissions economics}

Alberta and the neighbouring province of Saskatchewan (also with substantial oil and gas resources) are the highest-emitting provinces in Canada per capita, each with annual emissions of around 67 tonnes GHG per resident. These values are more than triple the Canadian average of 21 tonnes per capita, and are in fact significantly higher than even the world's most carbon-intensive countries like Qatar and the UAE. ${ }^{46}$ Natural resource dominated economies that require large amounts of energy, power grids that run primarily on coal versus hydroelectric power, and sparse population density are the major drivers of this discrepancy. As Canada aims to reduce its overall emissions in accordance with international reduction objectives, serious considerations are needed as to how best to cutback, especially in Alberta.

\section{FIGURE 4: CANADA'S GHG EMISSIONS BY SECTOR, 2013}

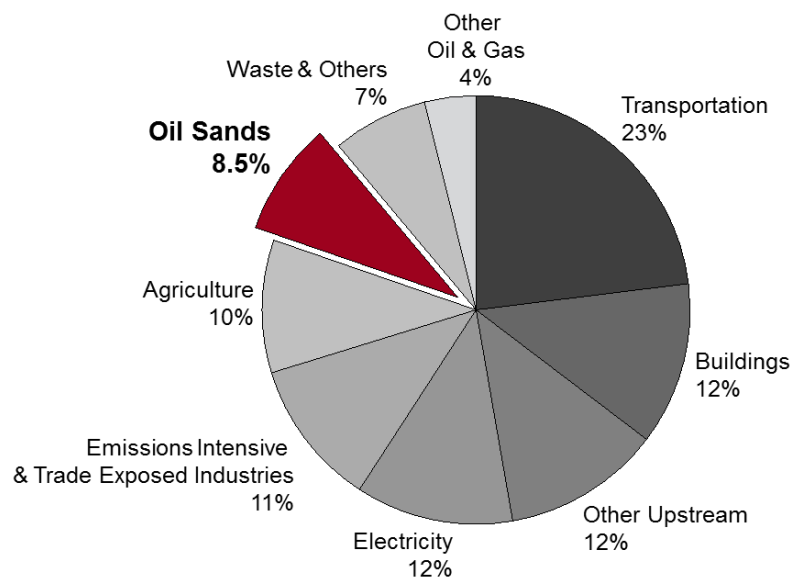

Source: Environment Canada / CAPP.

In the next two years, the provinces of British Columbia, Alberta, Quebec, and Ontario are introducing significant pricing on carbon, in one form or another. Further emissions pressure could come from the federal government following the election of the Liberal Party in October 2015. If Canada was to put a meaningful price on carbon emissions, one potent enough for the country to do its part in limiting global temperature rise to the prescribed maximum 2 degrees Celsius, which sources of emissions from Figure 4 above would be reduced? For example, Canada could enforce an aggressive CAD $\$ 75$ per tonne carbon tax - a 150 per cent increase from today's top rate, but less than some European countries like Sweden, where some emissions are taxed as high as CAD\$150 per tonne.

A major portion of Canada's emissions from electricity generation are derived from coal plants in Alberta and Saskatchewan, as the rest of the country's power needs are primarily provided by emission-free nuclear and hydroelectric generation. In the hypothetical CAD $\$ 75$ per tonne situation mentioned above, Canadian coal plants, which emit roughly 1 tonne per MWh and sell their generation for an average of roughly CAD\$40-70 per MWh, would have to charge an additional

\footnotetext{
46 Environment Canada, 'Greenhouse Gas Emissions By Province And Territory - Environmental Indicators - Environment Canada', Ec.Gc.Ca, 2015, http://www.ec.gc.ca/indicateurs-indicators/default.asp?lang=en\&n=18F3BB9C-1. Numbers taken from 2013 for emissions and population.
} 

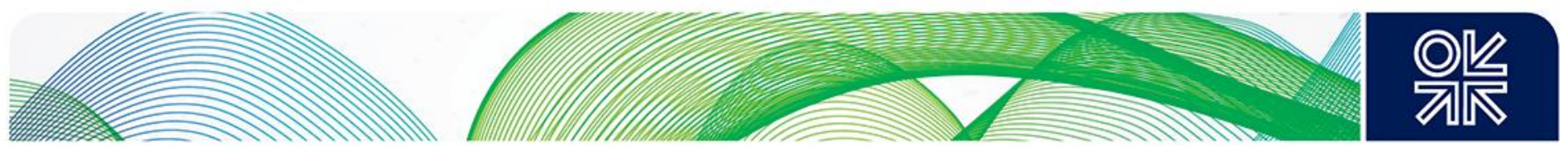

CAD\$70-80 per MWh, doubling or tripling the original price, to maintain the same level of profitability. ${ }^{47}$ Certainly, this would promote a shift toward lower-emitting sources like nuclear, renewables, and potentially even coal plants with carbon capture technology.

On the contrary, oil sands production is less sensitive to an elevated carbon tax. Production from a SAGD operation might produce $150 \mathrm{~kg}$ of GHG emissions per barrel, and in the above CAD\$75 per tonne scenario this amounts to a total cost per barrel for oil sands producers of around CAD\$8-10 per barrel, a significant operating cost addition for producers indeed, but an unlikely one that itself would stymie projects from starting if oil prices rebound to above, say, $\$ 70$ per barrel. Because of relatively manageable cost (even at lower emissions rates), University of Alberta economics professor Andrew Leach, who led the climate recommendation report on behalf of the NDP government, acknowledged, in separate research, that 'the cost of upstream emissions policy is unlikely to have a meaningful impact on oil sands growth in the near term'. 48

Though Leach's statement was made well before the collapse of the crude oil price, most of Alberta's oil sands producers realize that a carbon tax will not in and of itself hinder their growth unless it is punitively charged on their production alone, rather than across all forms of GHG emissions where consumers (voters) would be unlikely to support an exorbitant rate. Suncor CEO Steve Williams pleads their case in May 2015:

\begin{abstract}
We think climate change is happening. We think a broad-based carbon price is the right answer. If you look at carbon production in a modern economy, about 80 per cent of it is at the point of consumption or the point of use. So targeting fees just on industry does not get to it. ${ }^{49}$
\end{abstract}

In reality, oil sands producers are well aware of the importance of reducing carbon emissions and already have 'internal carbon prices' that they use when modelling future cash flows on production. Prices used have been seen to vary extensively between CAD $\$ 10$ (per tonne) and more than $\operatorname{CAD} \$ 100.50$

\title{
Can oil sands GHG emission intensity be reduced?
}

With oil sands operators reducing production-related GHG emissions intensity per barrel in the past 25 years by an estimated 25-40 per cent, many are optimistic about the future. ${ }^{51}$ However, many of these past gains were due to producers growing out of their infancy and correspond to basic operating improvements that may be difficult to continue. Extraction from mining, for example, has made few per barrel reductions in the past five to ten years, with notable exceptions being the introduction of cogeneration at Imperial's 'next generation' Kearl mine and Shell's Scotford Carbon Capture and Storage (CCS).

For in-situ production, emissions are primarily derived from making steam using natural gas. Producers who have demonstrated improvements in their steam-to-oil ratio for profitability reasons have also enjoyed the financial benefit of reducing their emissions. Up until the collapse of natural gas prices in 2008, there was talk in Alberta about building nuclear fission reactors to make the massive amounts of steam required for burgeoning SAGD production. This could reduce emissions intensity by 90 per cent or more, though it would create challenging project economics with the cost and lengthy construction timelines of building nuclear plants. Other in-situ production technologies have the potential to make significant, if incremental reductions. Among these, one standout technology is

\footnotetext{
7 Intergovernmental Panel on Climate Change, Annex III: Technology-Specific Cost And Performance Parameters., Climate Change 2014: Mitigation Of Climate Change. Contribution Of Working Group III To The Fifth Assessment Report Of The Intergovernmental Panel On Climate Change (IPCC, 2014).

${ }^{48}$ Boskovic, Branko, and Andrew Leach. Leave It In The Ground? Oil Sands Extraction in the Carbon Bubble. Edmonton: University of Alberta, 2014. http://www.uwinnipeg.ca/economics/docs/leach-oil-sands.pdf.

${ }^{49}$ Geoffrey Morgan, 'Carbon Tax Should Apply To Companies And Consumers, Says Suncor Energy Inc's CEO', Financial Post, 2015, http://business.financialpost.com/news/energy/carbon-tax-should-apply-to-companies-and-consumers-says-suncorenergy-incs-ceo.

50 The Canadian Press, 'Companies Accelerate Carbon Pricing Plans To Mitigate Risk', The Globe And Mail, 2015.

${ }^{51}$ IHS study references an emissions reduction of 26 per cent from Environment Canada from 1990-2013, while the RSC report references a 39 per cent reduction over the period 1990-2010. ${ }^{33}$
} 

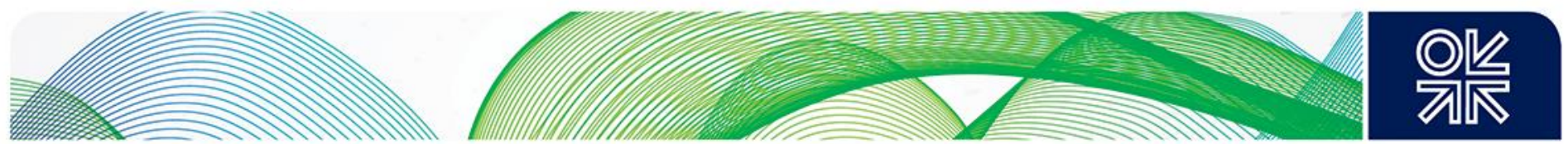

the use of solvents, which replace much of the steam required in SAGD, and could reduce in-situ emissions by 25 per cent or more (to be discussed in more detail in subsection 3.3). ${ }^{52}$

Alberta's collected carbon tax goes to the independent, though government overseen, Climate Change and Emissions Management Corporation (CCEMC), which is in charge of distributing more than CAD $\$ 200$ million annually of grants and investments to emission reducing technologies. Access to these funds for developing technology is competitive and requires 'skin in the game' - that is, funding commitments from the private sector (above and beyond the carbon taxes collected from the private sector), of which more than CAD $\$ 2$ billion has been invested to date. ${ }^{53}$

Further to this, in a collaborative effort to solve some of the oil sands environmental challenges around both local impact and global emissions, producers joined together in 2012 to create Canada's Oil Sands Innovation Alliance (COSIA). ${ }^{54}$ The member-funded group aims to lower the cost and development time for innovations in five Environmental Priority Areas: Tailings, Water, Land, Greenhouse Gases, and Monitoring. Although each of these focus areas is needed to reduce comprehensive environmental impact, it is primarily the GHG emissions of extraction and upgrading that have the potential to significantly constrain future production growth. COSIA's stated GHG goals include:

- improving energy efficiency in all aspects of oil sands operations, including the production of steam for in-situ (in place) recovery of bitumen

- recovering waste heat for reuse

- design and operating best practices

- measurement, monitoring, and verification

- $\quad$ reducing flaring, venting, and fugitive emissions

- $\quad$ CCS of CO2 from steam generators and other large oil sands facilities

- $\quad$ producing alternative energy

- $\quad$ exploring regional opportunities to reduce GHG emissions with non-industry parties 55

Several projects are currently underway that address these goals and have the potential to make significant reductions in GHG emissions. ${ }^{56}$ Though these technologies and future innovations could provide the combined incremental reductions needed to make the oil sands at par with, or even less emission intensive than, conventional oil production, they do come at a cost. Without a more substantive price on GHG emissions (the current CAD $\$ 30$ per tonne tax will not likely dictate project economics) or a substantial recovery of natural gas prices to pre-2008 levels (doubtful due to the advent of shale gas), it is difficult for producers to justify to their shareholders the increased costs of implementing complex GHG reduction initiatives on a large scale. Indeed, capital and operating costs and complexities in the oil sands are already formidable before adding the burden of reducing emissions. This headwind against reducing GHG intensity is exacerbated by the 2014 crash in global crude prices and resultant smaller operating margins. As discussed later in this paper, it is more likely that the pressures on production cost and the resulting innovative extraction technologies, especially in SAGD, will drive down GHG emissions as a 'nice-to-have' outcome, rather than what COSIA is developing; the production SOR ratio 'dog' wags the GHG intensity 'tail'. The challenge is that

\footnotetext{
52 'Imperial Oil developed Liquid Addition to Steam for Enhanced Recovery. Pilot tests of this new technology have demonstrated significant process efficiencies, reducing GHG emissions by $25 \%$ ' - CAPP

${ }^{53}$ Shawn McCarthy and Jeff Lewis, 'The Race To Find Transformative Carbon Strategies Is On', The Globe And Mail, 2015,

http://www.theglobeandmail.com/report-on-business/the-race-for-transformative-carbon-strategies-is-on/article26231817/. ${ }^{54}$ COSIA members comprise more than 90 per cent of production in Canada: BP Canada, Canadian Natural Resources

Limited, Cenovus Energy Inc., ConocoPhillips Canada Resources Corp., Devon Canada Corporation, Imperial Oil, Nexen, Shell Canada Energy, Statoil Canada Ltd., Suncor Energy Inc., Syncrude Canada Ltd., Total E\&P Canada Ltd., and Teck Resources Limited

${ }^{55}$ Cosia.ca, 'Greenhouse Gases - COSIA', 2015, http://www.cosia.ca/initiatives/greenhouse gases.

${ }^{56}$ CNRL has spearheaded development of an Algal Bio-refinery with support from the government of Canada's National Research Council that will be shared with other industry players through COSIA. The project takes $\mathrm{CO}^{2}$, wastewater, and waste heat from oil sands production to promote growth of algae that is pressed to produce bio-oil (used as refinery feedstock or as a diluent for bitumen or SCO) and fertilizer. CNRL aims to reduce CO2 emissions by 15 per cent at its Horizon mine and by 30 per cent at its Primrose in-situ site. Other projects such as incorporating gas turbine cogeneration into the steam boiler process, molten carbonate fuel cells, and vacuum insulated SAGD tubing show some promise.
} 

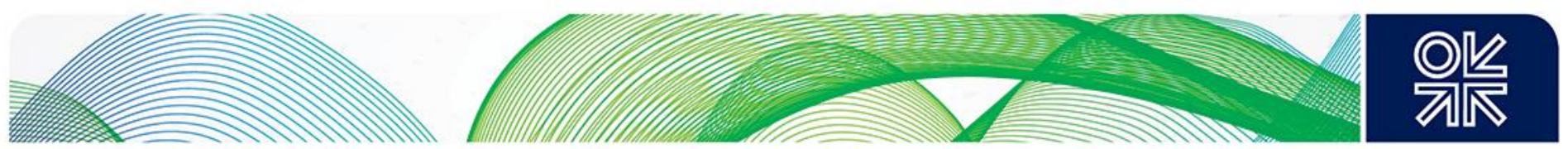

production technologies are understandably proprietary, unshared between producers, and will take longer to develop to a commercial scale (discussed further in section 3).

\title{
1.3 Impact of oil sands production on the Aboriginal peoples
}

\section{A history of distrust}

Once the Canadian provinces joined into a Confederation back in 1867, the new federal government moved forcefully to assimilate Aboriginal peoples. ${ }^{57,58}$ Canada's founding and otherwise venerated Prime Minister Sir John A. MacDonald actively promoted the idea of a status Indian (making a clear demarcation from white settlers) and developed the inhumane residential school system. ${ }^{59}$ MacDonald described his intent to the Canadian House of Commons in 1883:

\begin{abstract}
Indian children should be withdrawn as much as possible from the parental influence, and the only way to do that would be to put them in central training industrial schools where they will acquire the habits and modes of thought of white men. ${ }^{60}$
\end{abstract}

In causing widespread family separation, societal destruction, and many deaths from disease and mental illness, these residential schools lasted over 100 years and are considered one of the greatest moral stains on Canada's history. It is amid the legacy of these schools, as well as multiple other forms of bigotry and cultural ignorance, that today many of Canada's Aboriginal peoples are distrustful of provincial and federal governments, as well as private sector investors, even when they are proposing projects with tremendous economic benefits to their often impoverished communities.

\section{Opposition to development}

Canada's Aboriginal population is growing rapidly - an estimated 23,000 Aboriginal people live in the oil sands region in Northern Alberta. ${ }^{61,62}$ Many of these residents rely on the boreal forest, the principal land type in the region, for livelihood activities such as fishing, trapping, and hunting. Substantial opposition, including calls for a moratorium on production, to oil sands development exists among some of the Aboriginal groups. Primarily cited concerns are around water removal from the Athabasca River, local water and air pollution from production sites, and adverse impacts on Caribou populations. These groups have felt ignored by government agencies and industry, and have taken their grievances to the courts, claiming a lack of adherence to their treaty rights. However, many of their protests have not been substantiated with verified scientific evidence, as in the case of cancer concerns due to pollution. As a result, the protests have been relatively unsuccessful in stopping oil sands projects to-date, though they do act to delay projects coming online, add unforeseen costs, and subsequently hurt the economic return on investment. The recently elected federal Liberal government (which oversees Aboriginal policies) has promised further engagement and powers for Aboriginal communities with respect to resource development, which could prove challenging for producers.

\section{A proactive approach}

Seemingly just in the past decade, oil sands companies and government agencies have become more aware of the challenges that Aboriginal peoples face, the past atrocities committed against them

\footnotetext{
57 Having arrived in over 12,000 years ago in North America, Aboriginal peoples developed numerous cultures and societies in Western Canada that have advanced considerably by the time Europeans first made contact in the 1700s. A multitude of treaties aimed at expropriating land across the vast western territories for European settler commercial interests were imposed, including a concerted British effort to "civilise the Indian" in Canada and throughout its empire.

58 Aboriginal Affairs \& Northern Development Canada, A History Of Treaty-Making In Canada (Government of Canada, 2010).

59 Timothy J. Stanley, 'John A. Macdonald'S Aryan Canada: Aboriginal Genocide And Chinese Exclusion', Activehistory.Ca,

2015, http://activehistory.ca/2015/01/john-a-macdonalds-aryan-canada-aboriginal-genocide-and-chinese-exclusion/.

${ }^{60}$ Daniel Schwartz, 'Cultural Genocide Label For Residential Schools Has No Legal Implications, Expert Says', Cbc.Ca, 2015,

http://www.cbc.ca/news/aboriginal/cultural-genocide-label-for-residential-schools-has-no-legal-implications-expert-says1.3110826

61 Natural Resources Canada, Aboriginal Peoples, Oil Sands: A Strategic Resource For Canada, North America And The Global Market (Government of Canada, 2015)

http://www.nrcan.gc.ca/sites/www.nrcan.gc.ca/files/energy/pdf/eneene/pubpub/pdf/12-0655-OS-Aboriginal-eng.pdf.

${ }^{62}$ Canada's aboriginal population numbers more than 1.4 million as of 2011 (4.3 per cent of the country's population at that

time). First Nations, Métis, and Intuit peoples are all considered aboriginal Canadians. Of the 616 First Nations groups, 45 are

in Alberta, and 18 of those are located in the oil sands regions. 6 Métis settlements are also contained within the oil sands.
} 
and their culture, and the opportunities that oil sands development can bring to their communities. In 2012, Aboriginal contractors grossed CAD $\$ 1.8$ billion in revenues and Aboriginal employment in the oil sands was over 1,700. All major oil sands operators have developed increasingly comprehensive Aboriginal relations strategies aimed at increasing Aboriginal employment, empowering Aboriginal contractors, and ensuring formal and informal consultations are a critical gate in project planning. Syncrude and Cenovus focus on corporate social responsibility investments in Aboriginal communities, scholarship, and leadership programmes. Cenovus prides itself on its local relationships with local residents and trappers. In general, proactive operators feel that the financial investment in maintaining strong relationships with Aboriginal communities will pay off in the form of an improved local labour force and fewer project delays. As the Royal Society of Canada's oil sands report in 2010 summarized:

Consultations need to achieve meaningful agreements that will allow First Nations and Métis populations affected by developments to participate tangibly in benefits of development, rather than simply having to adapt to negative impacts. ${ }^{63}$

\subsection{Economic impact of the oil sands}

Oil sands extraction, transport, and processing has become a critical pillar of the Canadian economy, the engine of growth upon which Canada was able to quickly ride out the global financial crisis of 2008-09. Oil sands production requires much more manufactured inputs and labour from across the country than conventional production does. Just taking a glance at the national business news or one of the federal debates preceding the fall 2015 election, one can grasp the oil sands significance to the Albertan and Canadian economies.

In an effort to educate policy makers and the Canadian citizenry, research groups such as CERI, IHS, and the Conference Board of Canada, among others, have developed in-depth calculations to demonstrate the economic value added by oil sands development. ${ }^{64}$ Though the estimates vary, annual GDP impact hovers around CAD $\$ 100$ billion, though this will drop in 2015 with the depressed prices for crude and reduced capital investment. This amounts to approximately 5 per cent of Canada's GDP. More importantly, the oil sands (as part of the nation's extractive industries) act as a 'leading edge' of economic growth. That is, oil sands development drives a disproportionate amount of growth and balance of trade for the country. Of Canada's largest and most influential companies, it is the energy, mining, and petroleum firms that receive the largest amount of foreign direct investment. ${ }^{65}$

Employee compensation in the oil and gas industry tends to be substantially higher than in other industries. Despite the loss of hundreds of thousands of jobs in lower-paying manufacturing to lowercost developing countries over the past decade, Canada delivered one of the stronger economic records among its G7 peers following the financial crisis due in no small part to accelerated oil sands development amid robust crude prices.

\section{Royalties \& taxes: Collecting government revenue vs. incentivizing growth}

Unlike the United States, mineral rights are not included with surface rights as a part of land ownership in Canada; they are owned by the provincial governments as part of the Natural Resources Transfer Act of 1930. Today, the province has the subsurface rights to 81 per cent of Alberta's land (97 per cent in the oil sands areas) and distributes producing rights through competitive auctions. In addition to collecting sale revenue from these auctions, the provincial government collects royalties based on producing revenues and provincial corporate tax, applicable to all corporations. In 2012, oil sands production directly accounted for almost one-third of provincial government revenues and 6 per cent of federal revenues. ${ }^{66}$ It is clear that both levels of government are dependent on current and future production to maintain spending on social programs for their citizens. Increases to royalty rates and corporate taxation have in recent years formed the platforms of left-leaning political platforms, to

\footnotetext{
${ }^{63}$ Steve H. Hrudey, Environmental And Health Impacts Of Canada's Oil Sands Industry: Executive Summary, The Royal Society Of Canada Expert Panel, 2010.

64 (Millington and Murillo 2015), (Burt, Crawford and Arcand 2012), and (Bonakdarpour and Forrest 2014)

65 Foreign Affairs, Trade and Development Canada, 'Foreign Direct Investment Statistics', 2015,

http://www.international.gc.ca/economist-economiste/statistics-statistiques/investments-investissements.aspx?lang=eng.

66 (Bonakdarpour and Forrest 2014)
} 
some extent in an attempt to satisfy populist contempt for wealth within the energy industry. Regardless of whether these sentiments are justified, such increases will limit the amount of investment in new projects and could counterproductively reduce overall government revenues. 


\section{Getting to market: the oil sands price discount}

\subsection{The WCSB bottleneck}

Crude oil refining capacity tends to coalesce around population density, tidewater access, and petroleum-producing geology. Alberta lacks two of these three - the population density of the four Western Canadian provinces is only around 3.8 people per square $\mathrm{km}$, compared with 35 in the US and 270 in the UK. The result is that refining capacity in Western Canada is only about 0.6 million bpd, even slightly less than the region's demand at 0.7 million bpd, and only 17 per cent of the Western Canadian Sedimentary Basin (WCSB) production of 3.5 million bpd in $2014 .{ }^{67}$ Remotely located, like many of the world's prolific oil basins, the WCSB has had to build up world-scale pipeline capacity over the decades to get its oil to market. This has been accomplished by sending much of it to the US Midwest with the help of the Enbridge Mainline, in service since 1950. With rapid oil sands production growth since 2000 and a shortage of refinery space able to take heavy crude in the Midwest, producers have been looking to new markets in Eastern Canada, the US Gulf Coast, and Asia, exporting the crude from ports and terminals on Canada's West Coast.

FIGURE 5: WESTERN CANADIAN SEDIMENTARY BASIN (WCSB) OIL PIPELINE EGRESS

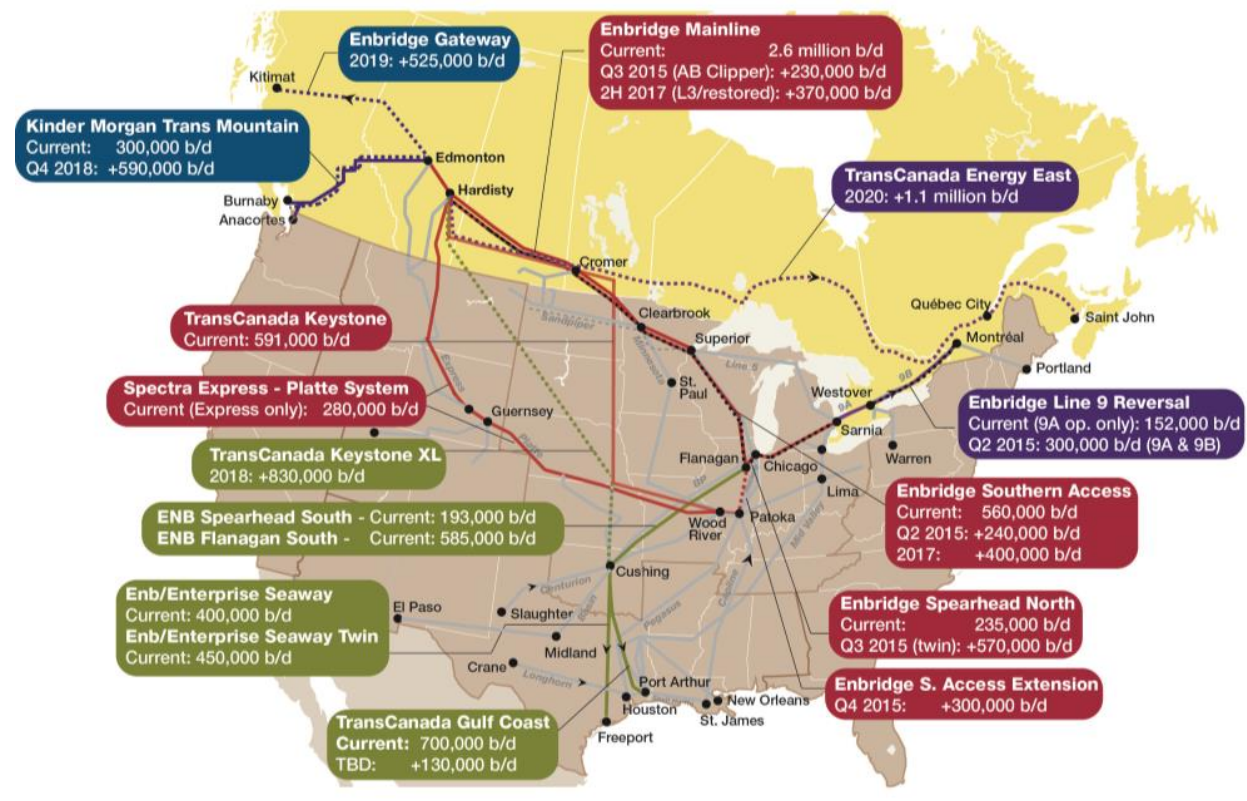

Source: Canadian Association of Petroleum Producers (2015).

TABLE 3: WCSB CRUDE OIL EXITING PIPELINE CAPACITY

\begin{tabular}{|c|c|c|c|c|c|}
\hline in thousand bpd & US Midwest & US Gulf Coast & CAN-US W. Coast & CAN E. Coast & Total Egress \\
\hline \multicolumn{6}{|l|}{ Current } \\
\hline Enbridge & 2,851 & - & & & 2,851 \\
\hline TransCanada & 591 & - & - & - & 591 \\
\hline Kinder Morgan & & - & 300 & - & 300 \\
\hline Spectra & 280 & - & & - & 280 \\
\hline Current Total & 3,722 & - & 300 & - & 4,022 \\
\hline \multicolumn{6}{|l|}{ Proposed } \\
\hline Proposed Total & 370 & 830 & 1,115 & 1,100 & 3,415 \\
\hline
\end{tabular}

Sources: CAPP and Enbridge.

Over 3.4 million bpd in exit capacity from Alberta is proposed across four major new-build projects, while further expansion is planned downstream by TransCanada and Enbridge in the US (see Table 3

${ }^{67}$ Canadian Fuels Association and Canadian Association of Petroleum Producers (CAPP)

February 2016 - The Future of the Canadian Oil Sands: Growth potential of a unique resource 
and Figure 5 above). Major WCSB exit proposals include Enbridge's Northern Gateway and Kinder Morgan's Trans Mountain Expansion, both aimed at reaching Asian markets, and two TransCanada projects: the famous Keystone XL to connect to the Gulf of Mexico refinery complex, and the Energy East line to supply crude to Eastern Canadian refineries and European markets.

\section{FIGURE 6: WCSB SUPPLY AND BAKKEN MOVEMENTS VS. EGRESS CAPACITY}

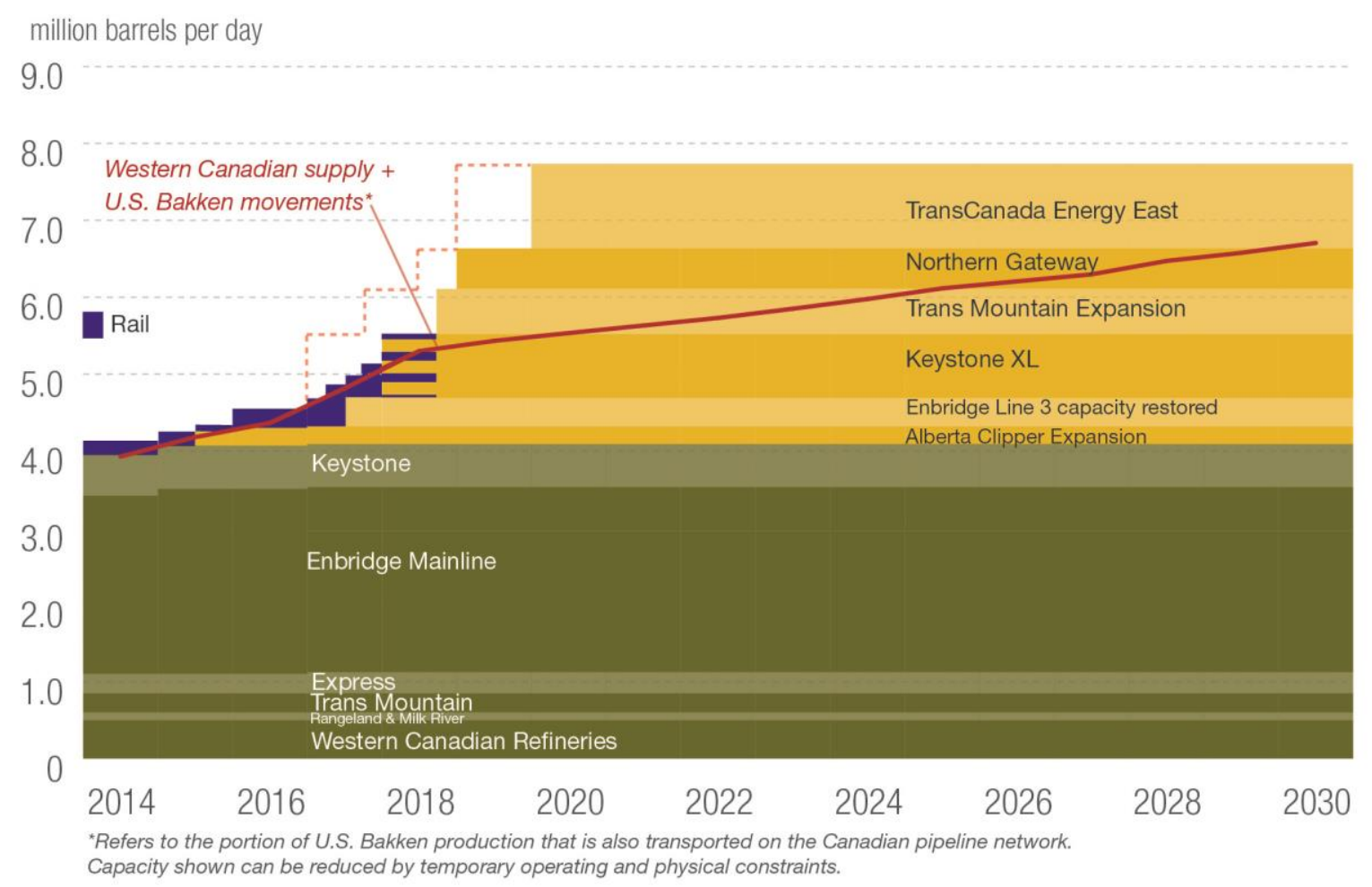

Source: Canadian Association of Petroleum Producers (2015).

Substantial delays and opposition exist for each project, creating heavy price discounts for Western Canadian heavy crude and uncertainty among upstream operators and investors. This has led to an increase in oil sands crude being shipped by rail transport (shown in Figure 6), reaching an estimated 185 thousand bpd in 2014 (conventional, light tight oil, and oil sands). ${ }^{68}$ Rail transport, however, is the most expensive method of shipping and has limits given current infrastructure.

\subsection{WCS vs. Global oil}

Western Canadian crude oil has suffered from multiple price discounts compared with the globally traded, seaborne Brent oil price. First, the well-known North American West Texas Intermediate (WTI) to global Brent differential, driven primarily by the advent of LTO and the US ban on crude exports to countries other than Canada. Second, the price between light sweet crude at Edmonton and WTI, driven by transport costs and the lack of egress from the WCSB. Third, the oil sands' heavy oil standard grade Western Canadian Select (WCS), a blend of bitumen and diluent, is further discounted due to its sour nature and low API of 20.5.69

Accordingly, WCS has at times been the lowest-priced crude oil in the world. Figure 7 shows the extent of the differentials: the gap between WTI and WCS averaged around \$15-20 per barrel over the past decade, while the gap between Brent and WCS has exceeded $\$ 50$ per barrel on several occasions in the last five years. On such occasions, the term 'bitumen bubble' was prevalent within the oil industry and Canadian politics. Current discounts between WCS and WTI (as of January 2016)

\footnotetext{
${ }^{68}$ CAPP (2015)

${ }^{69}$ WCS was defined in 2004 by CNRL, Cenovus, Suncor and Talisman Energy to consolidate a variety of supply streams and create a price benchmark within North American for heavy oil from the oil sands
} 
have lowered to around $\$ 13-15$. And fortunately for Canadian producers, the WTI-Brent differential has mostly disappeared due to the US government now permitting exports of crude oil.

\section{FIGURE 7: WESTERN CANADIAN SELECT (WCS) CRUDE PRICES SINCE 2005}

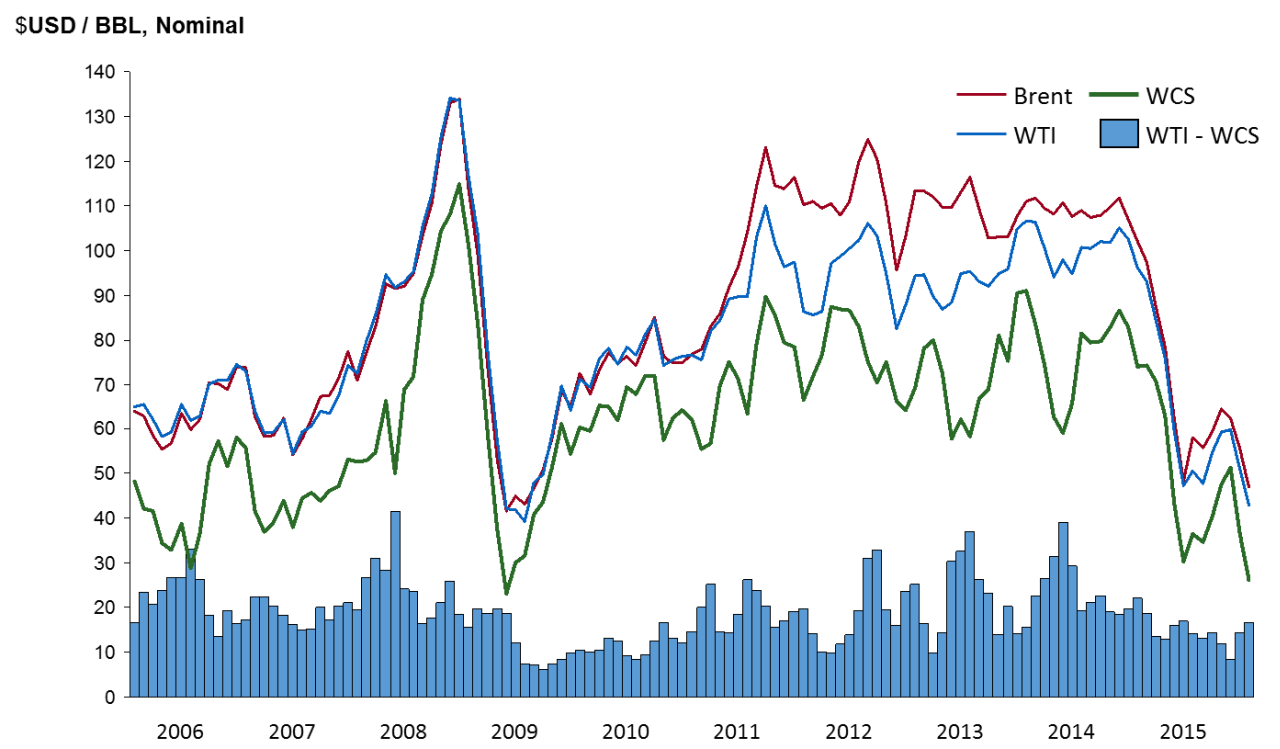

Source: Oil Sands Magazine (2015).

\section{The Mexican Maya comparable}

Light tight oil coming the Bakken shale play (mostly located in the US but straddling the Canadian border) also suffers from discounted prices due to the extent that WCS does. More telling is that the government price-controlled Mexican Maya crude, the largest direct heavy oil competitor stream that WCS faces in the US Gulf Coast, has historically managed to maintain smaller differentials to WTI and until recently, now that pipelines transport is opening up, has been priced higher than WCS (see Figure 8 for a freight on board comparison).

\section{Retooling for heavy oil}

Starting in the early nineties, out of fear of dwindling domestic light oil supplies and then with projections of rapid growth in Canada's oil sands, US Gulf Coast refineries have spent more than $\$ 85$ billion retooling themselves to accept a higher portion of heavy crude (US Midwestern refineries added another $\$ 15$ billion). ${ }^{70}$ The idea was that their refining spreads would be higher with low-cost, plentiful heavy oil from Canada, Mexico, and Venezuela than ever increasing light and medium crudes imported at Brent prices. Ironically, due to the unforeseen upsurge in US light tight oil, producers of heavy crudes such as Pemex's Maya have been able to charge refiners near WTI prices because of the large refining capacity for heavy crudes. In fact, between 2011 and 2013, Maya heavy commanded a higher price than the lighter and less sour WTI grade by an average of more than $\$ 6$ per barrel - the refiners had built up too much heavy capacity. During that same period, oil sands producers $3,000 \mathrm{~km}$ to the north grumbled that their bottlenecked Maya crude competitor WCS could only garner a price discounted by an average of $\$ 20$ per barrel against WTI (\$26 per barrel versus Maya). These discounts reduced oil sands revenues by roughly CAD $\$ 5-15$ billion annually. Fortunately for oil sands producers, improved access to pipeline transport to the Gulf Coast, at least in the US south of Cushing, has lowered the WCS discount to around \$13-15 as of December 2015. The remaining difference in WCS price from Maya crude can now then be attributed to the fact that oil sands heavy crude is of lower quality - with a higher total acid number (TAN) and presence of diluent.

\footnotetext{
${ }^{70}$ Birn, Kevin, and Jeff Meyer. Why the Oil Sands? Oil Sand Dialogue. IHS Energy, 2015.
} 
FIGURE 8: FOB WCS VS. MEXICO’S FOB MAYA CRUDE (\$ PER BBL, NOMINAL)

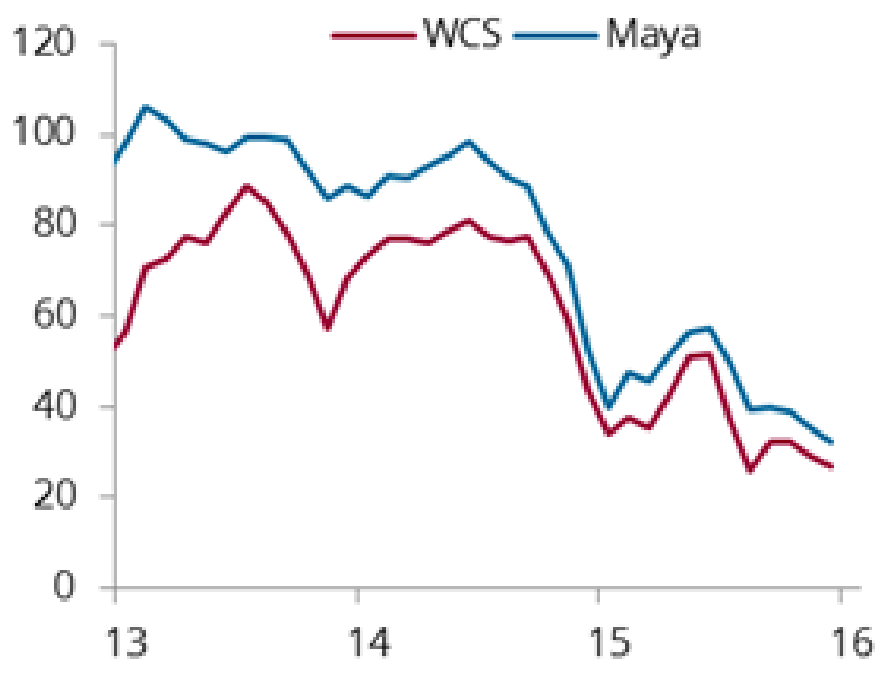

Source: Energy Aspects, Reuters.

\subsection{Increasing the value of Canadian crude oil}

Three major North American midstream players have proposed four pipeline projects to move WCS and SCO to North American and overseas markets. However, each of these have environmental and political challenges to confront, and many opponents claim that granting approvals is akin to giving oil sands production and its associated carbon emissions a green light. (Recall that current oil sands production constitutes around 0.17 per cent of global emissions.)

\section{Keystone XL (TransCanada)}

Even with a casual following of international energy news, or US or Canadian politics, in recent years, one will surely have heard mention of the Keystone XL pipeline. ${ }^{71}$ The proposed pipeline is the fourth phase of TransCanada's Keystone project, slated to carry 830 thousand bpd of crude from Alberta to the Midwestern state of Nebraska. Though not the first major new pipeline to be announced (that honour belongs to Enbridge's Northern Gateway), it is the best known and was considered the most likely to be completed given the technical review hurdles it had cleared. It is one of the few single pipelines to have multiple books written about it, and its approval will be a key debate topic during the US presidential election of 2016. Though Keystone-related concerns about the danger of spills and sensitive ecosystem protection are at times legitimate, they are mostly overblown with respect to past and ongoing pipeline approvals and acceptable levels of risk among energy sources in modern American society.

Keystone $\mathrm{XL}$ was held up for almost the entirety of the Obama presidency by the US approval system, first with environmental and legal reviews, and more recently used as a tool of political leverage.${ }^{72}$ Although it seemed likely that Keystone's fate would be in the hands of the newly elected president, not to be reconsidered until 2017, President Obama decided to respond to TransCanada's request for a delay with a swift rejection of the pipeline, claiming that it hurt the US's global climate

\footnotetext{
${ }^{71}$ Keystone XL has been termed by renowned oil historian Daniel Yergin as 'the most famous pipeline in the history of the world, even without being built yet.' Globe Editorial, 'Premier Redford and the World's Most Famous Unbuilt Pipeline', The Globe and Mail, 2013.

${ }^{72}$ Despite 63 per cent support for a bill approving construction of the pipeline in both the US Senate and House of Representatives in early 2015, and US government reports stating that Keystone's construction would have a negligible effect on global emissions, President Obama vetoed the bill claiming it interfered with the executive branch's authority. At the time, his administration stated that he would decide on the pipeline with a few weeks following more reviews. In retrospect, it is interesting to note this institute remarked on Obama dodging the issue bowing to political pressure in 2011 and punting his decision to beyond the 2012 election. - Michael D. Shear and Coral Davenport, 'Obama Vetoes Bill Pushing Pipeline Approval', The New York Times, 2015, http://www.nytimes.com/2015/02/25/us/politics/as-expected-obama-vetoes-keystone-xl-pipelinebill.html.
} 
change reputation and was not in the best interest of the country. A rejection on such tenuous environmental grounds contravenes the North American Free Trade Agreement with Canada however, and a legal challenge has come from TransCanada seeking $\$ 15$ billion in costs and damages.

The pipeline does have further hope - if the victorious 2016 president-elect is from the Republican Party, the pipeline will likely be approved in early $2017 .{ }^{73}$ Since the favoured and most pro-business Democratic presidential candidate Hillary Clinton has declared she will reject the pipeline, Keystone XL's existence hangs for the most part on the outcome of the US presidential race in November $2016 .{ }^{74}$

From a geopolitical perspective, few American leaders historically would target a strategy aimed at blocking trade routes to Canada, a NAFTA free-trade partner and ally. However, this trade distortion is precisely the most impactful outcome of blocking Canadian heavy crude access to the US Gulf Coast, rather than the stated goal of reduced carbon emissions and environmental progressivism, for which a rejection of Keystone XL has little impact. In reality, the resulting increased use of lessefficient rail transport will likely raise emissions.

\section{Northern Gateway (Enbridge)}

Few pipelines stay in the planning stages for as long as the Northern Gateway. The project was formally launched in 2004 and as of January 2016 seems maybe a decade away from being completed, if ever. The proposal would build twin pipelines between a terminal near Edmonton and the Canadian west coast at Kitimat, British Columbia, also the proposed site of a world-scale LNG terminal. One pipeline would send $525 \mathrm{Mbpd}$ of crude to the coast, to be shipped via tanker to Asia, while the other would return diluent eastward to blend with newly mined bitumen in Alberta.

Enbridge suffered delays in starting the project's review by a Joint Review Panel (JRP), consisting of the National Energy Board (NEB) and the Canadian Environmental Assessment Agency (CEAA) in 2010. Once the JRP process started, Enbridge was confronted publicly about not providing enough detail to the regulators. The contentious element of the Northern Gateway is the increased supertanker traffic into the narrow, windy, wavy, snowy, and wildlife-abundant inlet of Kitimat. Enbridge is aware of these challenges and has designed advanced risk reduction systems that have won the approval of Transport Canada. However, opposition is especially intense given the strong environmental focus of voters and Aboriginal groups in Canada's western province of British Columbia. In total, 45 Aboriginal groups are impacted by the pipeline, and only 26 currently support the initiative. ${ }^{75,76}$

The JRP finally released its report in 2013 and highlighted 209 issues of concern to be addressed, and the federal Conservative government followed suit by approving the pipeline in 2014, subject to Enbridge addressing those concerns. Given the cost and complexity around meeting these conditions that address Aboriginal engagement, marine wildlife, land mammals, pipeline integrity, and rigorous reporting, Enbridge has become rather silent on the project. Public anxiety of having oil tankers sail from the northwest coast, despite evidence showing the risks are acceptable, has led to newly elected Liberal Prime Minister Justin Trudeau banning the practice, effectively halting the Northern Gateway pipeline process until at least 2019 , when the next federal elections take place.

\section{TransMountain Expansion (Kinder Morgan)}

Similar to the Northern Gateway, the more recently proposed TransMountain Expansion would add 590 thousand bpd of pipeline capacity from Edmonton, this time going to the west coast Port of Metro

\footnotetext{
${ }^{73}$ Quicksilver Republican presidential candidate Donald Trump (the leader in polls as of January 2016) is running on a platform of economic nationalism and has claimed he would demand profit from TransCanada before approving the pipeline

${ }^{74}$ Anne Gearan and Steven Mufson, 'Hillary Clinton Says She Opposes Keystone Pipeline', The Washington Post, 2015.

75 Tracy Johnson, 'Is Northern Gateway Quietly Being Shelved?', Cbc.Ca, 2015, http://www.cbc.ca/news/business/is-northerngateway-quietly-being-shelved-1.2965355.

${ }^{76}$ Activists have at times singled out Enbridge because of the company's spilling of diluted bitumen into Michigan's Kalamazoo River in 2010. This was the costliest inland pipeline spill in US history at more than $\$ 1$ billion. Though such major incidents are infrequent and a somewhat unfortunate result of probability, as well as the fact that Enbridge has since made major improvements to its integrity management and operating procedures, activist opposition remains ardent. See Steven Mufson, 'NTSB Blames Enbridge, 'Weak' Regulations in Kalamazoo Oil Spill', The Washington Post, 2015.
} 
Vancouver in Burnaby. The proposal comprises of the twinning of Kinder Morgan's legacy EdmontonVancouver TransMountain pipeline built in 1953 (safely operating with multiple expansions, most recently in 2008) and increasing tanker frequency through the inlet from approximately five to 34 trips per month. The proposal is currently being reviewed by the NEB and, given that new pipeline and marine routes are not needed, is more likely to meet regulator requests than the Northern Gateway.

The challenge in getting the pipeline built will come from municipal and environmental opposition. The port to be used for export is located within Greater Vancouver, picturesquely nestled between the Coast Mountains and a straight leading to the Pacific Ocean, and accordingly one of the world's most desired and expensive cities in which to live. The city is a hub for wealthy Canadians and international real-estate investors, as well as an epicentre of environmental activism. ${ }^{77}$ The municipal government prides itself on its efforts to build the world's 'Greenest City' and cites reports that Vancouver's 'green brand' is worth CAD $\$ 31$ billion. A vociferous opponent, Vancouver Mayor Gregor Robertson reacted to the results of a study commissioned by his own office in 2015 in no uncertain terms:

Today we heard overwhelming evidence that the Kinder Morgan pipeline proposal and the oil tankers associated with it are incredibly disastrous for Vancouver. ${ }^{78}$

In an effort to plead the case for the expansion, Kinder Morgan's chairman and CEO has highlighted how the protests against the pipeline are politically driven and that it comes down to a decision by the federal government:

\begin{abstract}
I am sure there are legitimate concerns about any mega infrastructure development, but a lot of this is [about] the pipeline as a choke point to get at production of the oil sands, which there are people in Canada and the U.S. who want to strangle that altogether....I believe that Canada, like the U.S., has the rule of law, and I think if you have a valid federal decision to go forward, the project will go forward... I think we will get this permitted. We intend to get it built. And we hope to see it in service in the third quarter of $2018 .{ }^{79}$
\end{abstract}

This quote came before the announcement from Trudeau's Liberal government in January 2016 that the process would be delayed by four additional months to determine the pipeline's (indirect) effect on Canada's GHG emissions, such that the earliest a Federal approval could come, would be in December 2016. This corresponds to a 2019 on-stream date, barring further delays.

\title{
Energy East (TransCanada)
}

Last to the game, but certainly not least in magnitude, the Energy East pipeline proposal, that would transport 1.1 million bpd of WCSB crude to Eastern Canada, was announced publicly by TransCanada in 2013, and is currently being reviewed by the NEB. The proposal would transport oil from Alberta and Saskatchewan over 4,600 km to refineries and terminals in the eastern provinces of Quebec and New Brunswick, where there is port access to the Atlantic Ocean. The benefits include a less environmentally contentious path than the Northern Gateway or TransMountain Expansion, without the need for US governmental approval to which the Keystone XL is beholden. The crude will flow to Canadian refineries and terminals, improving regional and local economies throughout the country.

The pipeline is unique in that support will be required from a multitude of Canadian provinces, with Quebec being the most averse to its construction. Concerns about an export terminal impacting the breeding habits of the Beluga Whale off the coast of Quebec has TransCanada looking for another location to build an export terminal, likely in another maritime province due to opposition from the Quebecois people, who are traditionally more hostile to industrial projects. This hiccup is causing the project to be delayed by over two years, with a completion date being extended until at least $2020 .{ }^{80}$

\footnotetext{
77 Greenpeace was founded in Vancouver in 1971

${ }^{78}$ Laura Kane, 'Trans Mountain Pipeline Expansion 'Disastrous,' Says Mayor Gregor Robertson', CBC.CA, 2015,

http://www.cbc.ca/news/canada/calgary/trans-mountain-pipeline-expansion-disastrous-says-mayor-gregor-robertson1.3090501

${ }^{79}$ Claudia Cattaneo, 'Transmountain Pipeline 'Will Go Forward' If Approved, Kinder Morgan Inc CEO Says', The National Post, 2015.

${ }^{80}$ Geoffrey Morgan, 'Transcanada Corp'S Decision To Shelve Quebec Oil Terminal Plans May Delay Energy East Pipeline By Two Years', The National Post, 2015.
} 
Further to that, Mayor Denis Coderre of Montreal, a city on the proposed pipeline route, has come out vehemently against the project:
We are against it because it still represents significant environmental threats and too few economic benefits for greater Montreal. ${ }^{81}$

Albertans are becoming frustrated with other provinces restricting export access for their products, while Alberta has historically paid a disproportionately large amount of 'equalization payments' that poorer Canadian provinces receive (Quebec is by far the largest recipient of these payments historically). In January 2016, the Alberta government's political opposition leader vociferously attacked Montreal's environmental record when rejecting the Energy East pipeline:

\begin{abstract}
While Mr. Coderre dumps a billion litres of raw sewage directly into his waterways and benefits from billions in equalization payments [CAD\$9.5 billion in 2015], his opposition to the Energy East pipeline is nothing short of hypocritical. ${ }^{81,82}$
\end{abstract}

The debate is likely to become more acrimonious in the coming months and years, as the oil sands require the approval of at least one major pipeline in order to grow. Prime Minister Justin Trudeau ran a successful election campaign on the promise that he could help get oil sands oil to tidewater, while guaranteeing any project that is approved must first earn a 'social license'. The ill-defined term is a dangerous one and Trudeau has his work cut out for him. Contentious debates and potentially major delays are ahead for both the Energy East and the TransMountain pipelines; as a result of the Liberal government's newly announced inclusion of climate change impact on the approval of pipelines, Energy East will suffer a further 9 month delay for a total regulatory review period of 27 months. Few countries in the world impose such scrutiny and delays before approving energy infrastructure.

\title{
Rail
}

US light tight oil and the Canadian oil sands have together added around 5 million bpd of production in the past five years, but the largely unforeseen nature of this boom means that there is now an unsurprising shortage of pipeline infrastructure across North American continent. For the first time since the late 1800s, when the first crude pipelines in the US came online to avoid the overly unionized and costly railroad companies, rail has re-emerged to become a competitive alternative for shipping crude around Canada and the US. Research firm IHS predicts rail in North America will transport more than 1,400 thousand bpd in 2015, up from 20 thousand bpd in 2009.83 The biggest users are producers in the light tight oil Bakken formation, centred on the US state of North Dakota. As the largest oil-producing shale basin outside Texas, the Bakken struggles with acute egress challenges, not unlike Canada's oil sands in recent years with the delays of major pipeline proposals. Though safety is a major concern for transport of crude by rail, as those in the town of Lac-Mégantic in Quebec can well attest to, it is less of a concern for diluted bitumen which is much less flammable than the very light oil extracted in the Bakken. ${ }^{84}$

For bitumen producers, rail provides geographic flexibility and frees them from the necessity of adding costly diluent. Because closely located bitumen can be loaded onto railcars without the need for diluent to reduce its viscosity for pipeline transport, some operators are building Diluent Recovery Units (DRUs) that remove excess diluent from the crude ensuring that what is transported by rail is only the bitumen they produced.

Though the price of shipping by rail from the WCSB to the US Gulf Coast is substantially more expensive compared with pipeline transport (IHS estimates this premium to average $\$ 8$ per barrel), the WTI-WCS discount has in the past five years justified this expense for surplus barrels that cannot get past the pipeline bottleneck. Over the longer term, however, with oil prices driving down netbacks for producers, rail is unlikely to act as much more than a last resort, or used to ship insignificant

\footnotetext{
${ }^{81}$ Cbc.ca,. "Montreal Mayor Denis Coderre Says Energy East Pipeline Too Risky", 2016.

http://www.cbc.ca/news/canada/montreal/montreal-mayor-denis-coderre-energy-east-opposition-1.3413117

82 Montreal has been forced to release toxic sewage into the Saint Lawrence Seaway due to poor planning. See Perreaux,

Les. "Montreal's Sewage Dump Plan Reveals Common Misconceptions". The Globe and Mail, 2016.

83 (IHS Energy 2014)

84 The Lac-Mégantic Rail Disaster occurred on July $6^{\text {th }}, 2013$. Multiple rail cars exploded, killing 47 people and destroying 30 buildings.
} 

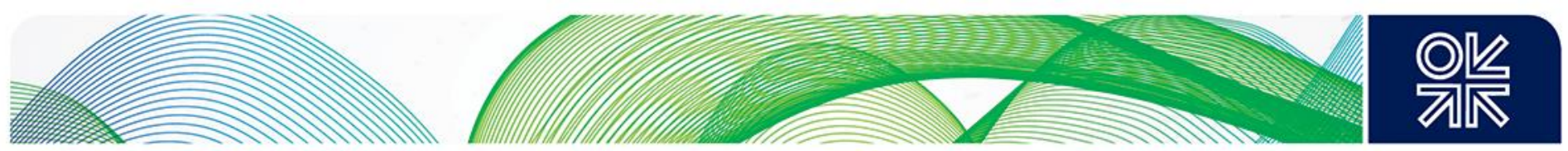

volumes to geographical regions that lack pipeline connectivity. Shipping by rail will not itself have a great effect on lowering the WCS discount, though it will continue to protect the discount from getting out of hand.

\subsection{The egress problem: A wall or an obstacle?}

Though politicians, environmentalists, and industry groups seem to fight many of their battles over the approval of pipelines, egress challenges alone are unlikely to block the growth of oil sands production. The massive increase in rail transport in the past five years is testament to this. With the economic implications at stake, especially during times of higher global crude prices, major pipelines and marine transport pathways for Canadian oil sands crude will be found sooner or later, as long as the profitability incentive to produce is there.

Pipeline opponents concerned about the impact of greenhouse gases from oil sands production who demand that this be taken into consideration before pipeline approval are misguided. Their concerns should be refocused not just on oil sands producers, but other industrial players and consumer endusers alike, and on deciding whether to generate emissions based on economic utility and a government regulated carbon constraint (pricing or otherwise). The onus for oil sands GHG emissions reductions will not, and should not, be on the pipeline operator, who oversees a very small portion of the total well-to-wheels emissions. 


\section{Can oil sands projects better compete on cost?}

\subsection{A brief history of oil sands supply cost}

In many respects, Canada's oil sands have a reputation similar to deep-water and several other sources of difficult oil - considered slow-moving, complicated, and costly. The cumbersome process of extracting entrapped bitumen from sand in a remote geography while attempting to minimize environmental impact, blending it with premium-priced diluent, and transporting it thousands of kilometres to faraway markets is indeed fraught with complexity and expense. One is left to wonder how the early oil sands endeavours at Syncrude and Suncor stayed afloat, and why Shell, Cenovus and other followers rushed quickly to grow production in the early 2000s, with only modest price increases at the time.

We can gain some insight to this question from Figure 9, which shows past estimates of the supply cost (also called the break-even price) for greenfield oil sands production projects against WTI and WCS prices. ${ }^{85}$ The supply costs shown estimate the required price of pure bitumen (not SCO or even WCS) required to cover capital costs, operating costs including fuel, working capital, royalties, taxes, regulatory liabilities, and a 12.5 per cent rate of return profit. ${ }^{86}$

\section{FIGURE 9: REAL OIL SANDS SUPPLY COST OF BITUMEN VS. CRUDE PRICE 2015 USD\$ / BBL}

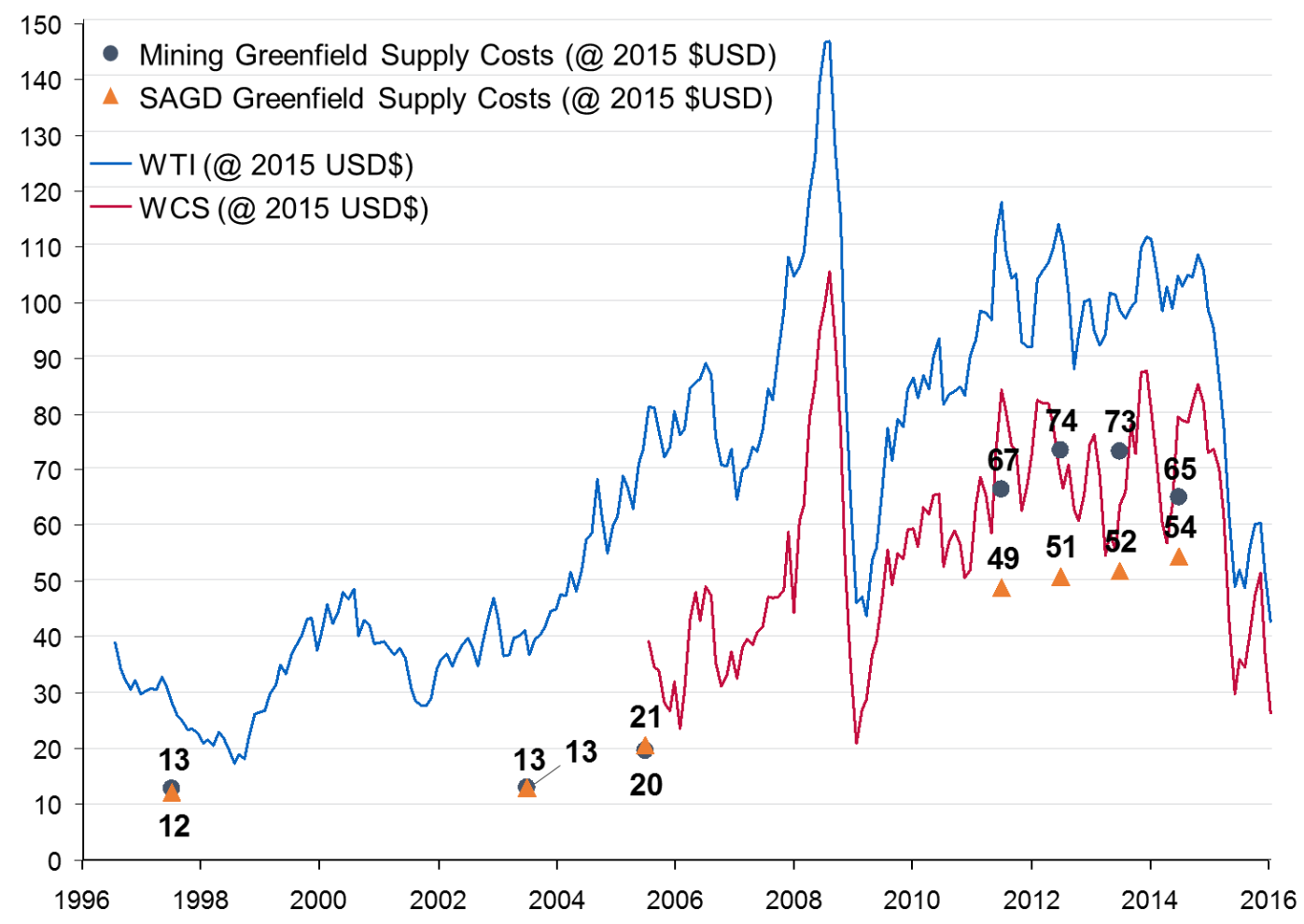

Source: National Energy Board, CERI, Oil Sands Magazine.

Note: Per barrel supply costs, as well as WTI and WCS prices, are shown in 2015 dollars, with an assumption of Alberta's rather high level of inflation used to adjust the historic estimates.

Making the comparison in real currency, an industrial or commercial operation with costs per unit of production that increase only with inflation would show as a flat line. Furthermore, industrial

\footnotetext{
85 Supply costs shown are those estimated by CERI (2010-2014) and NEB (1997-2006). An additional data point from CERI was made public for 2003: USD \$14 for SAGD and USD\$14 for Mining. This is similar to USD \$13 and USD \$13 from the NEB for that year.

${ }^{86} 2.5 \%$ inflation is assumed by CERI and NEB in making these calculations to give a real rate of return of 10 per cent over a period of 30 years from the 12.5 per cent nominal estimate.
} 
processes that have shown dramatic improvements in efficiency and effectiveness, such as shale gas and LTO extraction in the US, would appear as declining rather rapidly. What is profound about this recent cost history of the oil sands is that despite the massive increase in scale (roughly 2 million bpd of added capacity between 2001 and 2015) and the often touted improvements of processes and technology, the oil sands overall project and production life-cycle has become strikingly less efficient. Certainly, Figure 18 only shows an estimated average supply cost for new projects, and these costs vary significantly among the producers - for example, the most attractive and competitive SAGD project proposals might produce bitumen for as low as $\$ 40-50$. However, these are the exceptions. Looking at the average, it almost seems as if the supply cost for new projects is driven solely by market price, affirming marginal supply economics and the basin's reputation as the world's highest price, incremental barrel of oil. ${ }^{87}$

Indeed, there are multiple explanations for this cost increase, such as the fact that Alberta's wages have inflated higher than its overall consumer price index (not dissimilar to producing basins in the rest of the world); labour shortages in the remote producing regions of Fort McMurray and Cold Lake have been especially problematic. Another major challenge, common to all upstream oil producers, is the practice of 'high-grading' - producing the best geologies first. Analysts warn investors that as development continues, the reservoirs produced are decreasingly prolific. That said, one would expect this to be somewhat offset by the substantial decrease in Alberta natural gas price and incremental improvements in mining and SAGD technology.

It is also notable that the supply costs shown in Figure 18 are for bitumen production only, and they do not include the substantial costs of blending and transport. ${ }^{88}$ When those full-cycle costs are considered, including the strain of the WTI-WCS discount, most greenfield SAGD projects have supply costs requiring a WTI price of $\$ 70-80$ per barrel, while greenfield mining projects will likely need \$85-100 (Table 4). With current pricing of WTI in the \$30-40 range and forward curves to 2023 below $\$ 60$, approval of new projects in the near term is unlikely without clear visibility to major cost reductions.

TABLE 4: SUPPLY COSTS OF NEW OIL SANDS PROJECTS (2015)

\begin{tabular}{|c|c|c|c|c|}
\hline Project & Company & $\begin{array}{c}\text { New Production } \\
(M b p d)\end{array}$ & $\begin{array}{l}\text { WTI Equivalent } \\
\text { Supply Cost } \\
\text { (USD } \$ \text { / Bbl) }\end{array}$ & $\begin{array}{c}\text { Capex per } \\
\text { flowing Bbl } \\
(C A D \$ / b p d)\end{array}$ \\
\hline Mining & & & Average = \$91 & \\
\hline Kearl with Debottleneck & Imperial Oil & 235 & $\$ 85$ & $\$ 56,915$ \\
\hline Horizon Expansion & CNRL & 127 & $\$ 90$ & $\$ 91,200$ \\
\hline Kearl Expansion & Imperial Oil & 110 & $\$ 95$ & $\$ 81,818$ \\
\hline Fort Hills & Suncor / Total & 164 & $\$ 96$ & $\$ 82,317$ \\
\hline CERI Estimate & N/A (Averaged) & & $\$ 90$ & \\
\hline In-Situ & & & Average $=\$ 74$ & \\
\hline Christina Lake (F,G) & Cenovus & 122 & $\$ 68$ & $\$ 32,000$ \\
\hline Foster Creek (F,G, \& H) & Cenovus & 120 & $\$ 73$ & $\$ 38,000$ \\
\hline Jackfish Phase 3 & Devon Energy & 35 & $\$ 76$ & $\$ 37,142$ \\
\hline Surmount Phase II & ConocoPhillips / Total & 125 & $\$ 76$ & $\$ 44,037$ \\
\hline Nabiye & Imperial Oil & 40 & $\$ 70$ & $\$ 55,000$ \\
\hline Kirby North & CNRL & 40 & $\$ 80$ & $\$ 40,000$ \\
\hline Sunrise & Husky & 60 & $\$ 82$ & $\$ 53,333$ \\
\hline CERI Estimate & $N / A$ (Averaged) & & $\$ 80$ & \\
\hline
\end{tabular}

Sources: Citi Research; The National Post'9; CERI (2015).

\footnotetext{
87 Andrew Leach of the University of Alberta discussed this supply cost following price effect in 2013 (Leach, Andrew. 'Cheap Oil Sands Crude Production?'. Maclean's, 2013.)

88 Natural gas in Alberta as of September 2015 is trading around USD\$2.15 per MMbtu, a decrease of 60-80\% from the high prices of 2002-2008, even without counting for inflation. Natural gas is used as the primary fuel for oil sands production, especially in-situ operations.

${ }^{89}$ Hussain, Yadullah. 2015. 'How High Break-Even Costs Are Challenging New Oilsands Projects'. The National Post.
} 


\subsection{Examining cost increases across the value chain}

With the price collapse that bought WCS from highs of over $\$ 90$ in August 2013 to roughly $\$ 15$ in January 2016, oil sands producers are confronted with the reality shown in Figure 9 and, for the first time since the late 1990s, forced to truly shift their internal focus from growth to efficiency. Based on CERI analyses, Figure 10 summarizes the cost drivers for the 2014 supply cost against those in 2003 , with a 12.5 per cent nominal return for the producer included in the costs. Again, note that this diagram is in real currency and that a process that improves cost efficiency over time, like most manufacturing processes in other industries, should show a decline.

\section{FIGURE 10: REAL (INFLATION ADJUSTED) GREENFIELD PROJECT SUPPLY COST BUILD-UP}
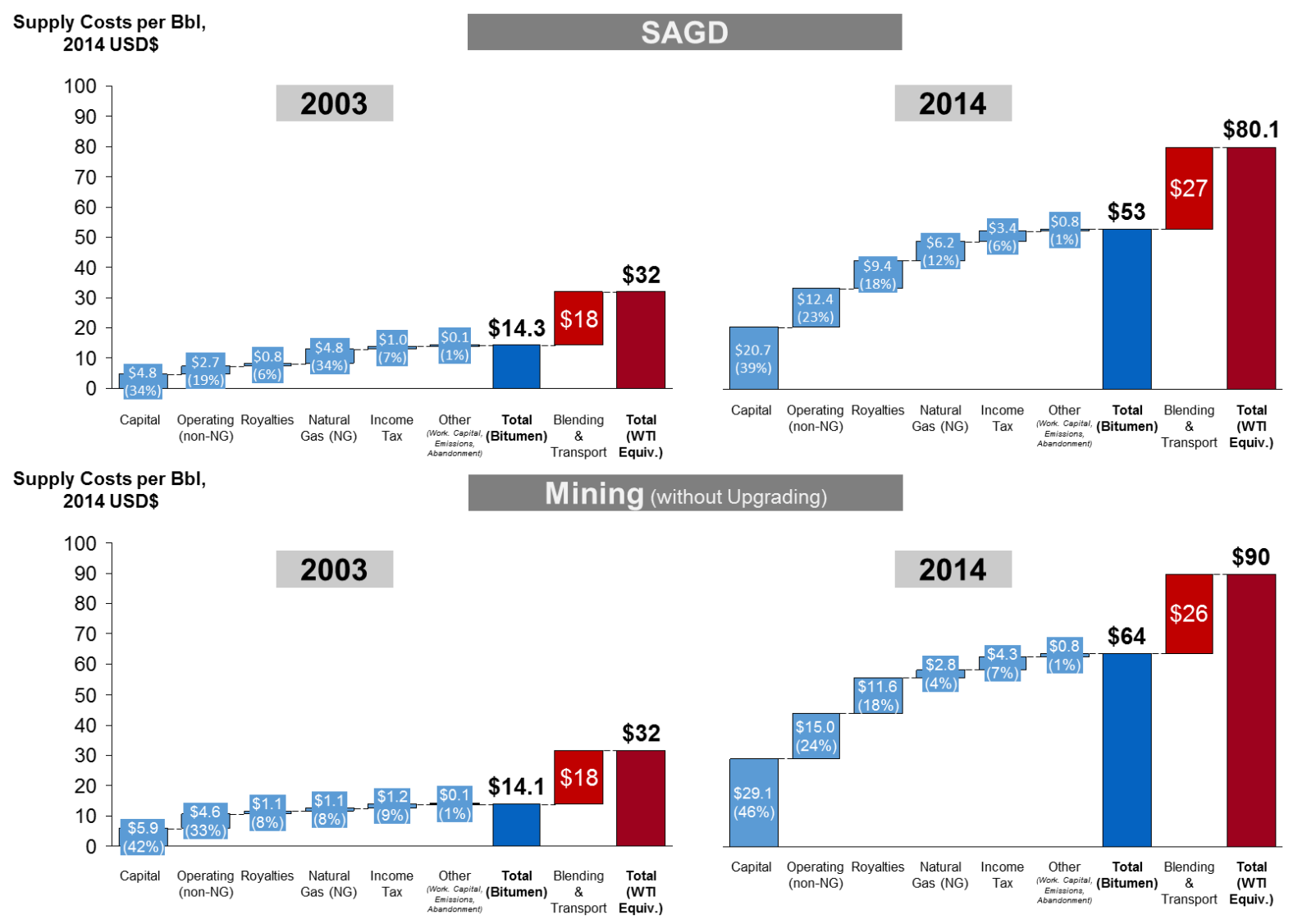

Source: CERI (2015). ${ }^{90}$

How can it be that in just over a decade the inflation adjusted cost of many of these projects has tripled or quadrupled? Capital and operating costs account for roughly two-thirds of the supply cost, estimated in 2014 at $\$ 33$ per barrel for SAGD and \$44 per barrel for mining. This represents a substantial increase from the 2003 inflation-adjusted costs of $\$ 7.50$ and $\$ 10.50$ for SAGD and mining, respectively. Admittedly, these are rough external estimates, but they are taken as industry averages and the methodology in arriving at them did not change from 2003 to 2014 . What, then, is driving these cost increases and how can they be addressed to the oil sands more globally competitive? 


\title{
High-grading and decreased productivity
}

In-situ

Though oil sands reserves may seem endless (170 billion barrels of estimated recoverable reserves with today's technology and roughly 2 trillion total barrels in place), all oil sands ore that is either at the surface to be mined, or in the subsurface to be heated and flowed, was not created equal. Detailed geological understanding of how in-situ reservoirs produce typically separates profitable projects from those that bleed capital. Reflecting on his early experiences in trying to make in-situ projects profitable, SAGD pioneer and Cenovus Executive Vice-President Harbir Chhina highlighted:

\begin{abstract}
...the lesson I learned was that you don't go around building oil sands projects if you haven't delineated the resource. You have to know what you have and what the quality is before you start spending big dollars and building these plants. ${ }^{91}$
\end{abstract}

SAGD operations have undoubtedly advanced in the past 20 years, though the technology still requires substantial tailoring for each unique geology. In fact, many operators have shown themselves unable to estimate the necessary steam-to-oil ratios during project planning - even Suncor's otherwise successful and highly prolific Firebag project uses an estimated 40 per cent more steam than it was initially designed for. ${ }^{92}$

Subsurface uncertainty and the need to show attractive economics lead to the common oilfield practice of high-grading, producing the most attractive portions of the reservoir first. The result is that production economics per barrel can become less attractive as producers drill or mine their way through their assets. In SAGD specifically, it means higher steam-to-oil (SOR) ratios as well as higher gathering and piping costs to reach wells that are further from the steam plants. Increased SOR values require not only higher natural gas costs in making steam but also increased capital costs for steam production, while decreasing per-well productivity rates requires additional wells to be drilled just to maintain the same level of production.

\section{FIGURE 11: HISTORY OF IN-SITU PRODUCTION STEAM-TO-OIL RATIO}

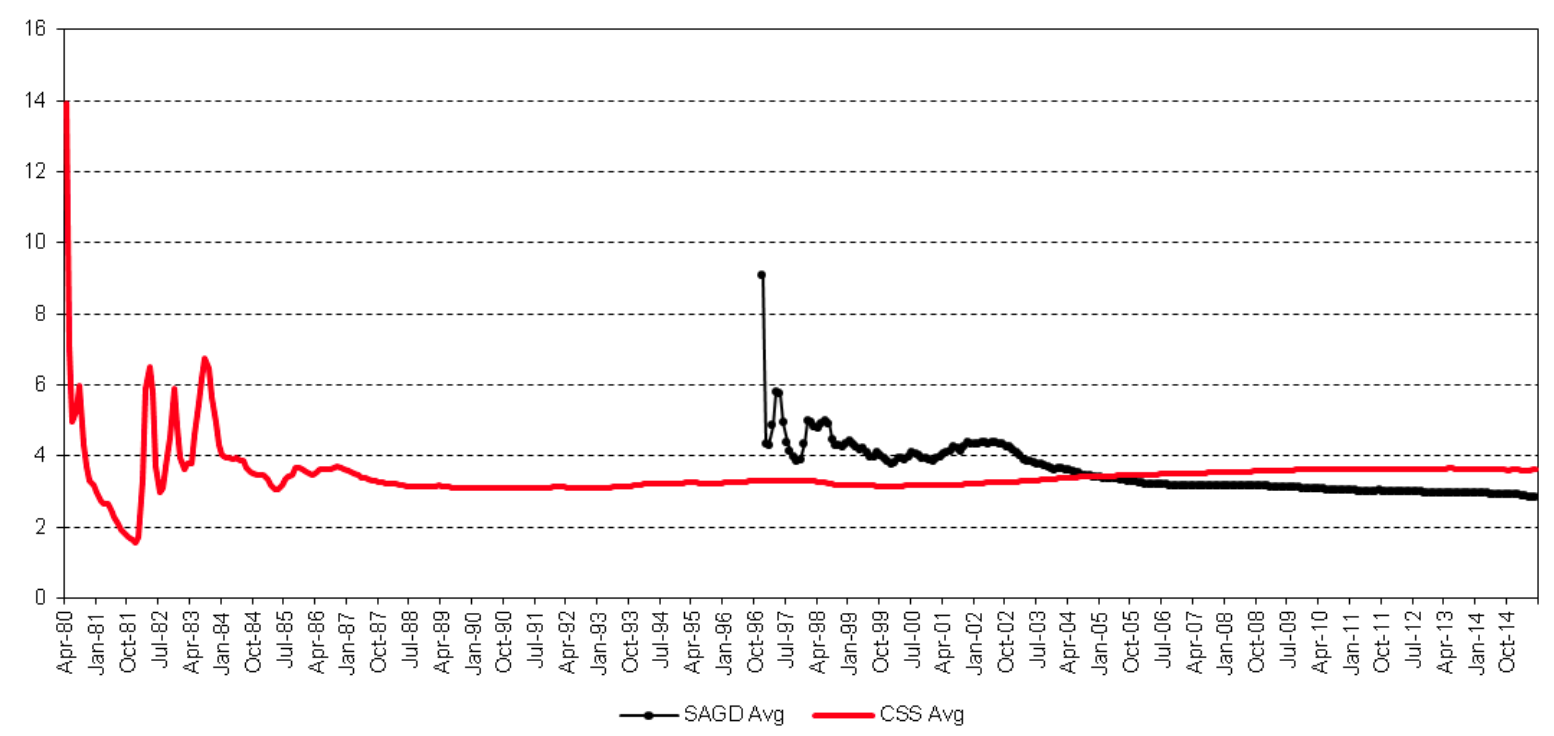

Source: BMO Capital Markets Oil Sands Monthly, September 2015.

Figure 11 and Figure 12 show the evolution of in-situ productivity and demonstrate rather clearly why the technology is surpassing the traditional huff-and-puff CSS method. However, there has been only nominal improvement in both average SOR and well rates within the last decade for SAGD, which has underwhelmed investors given it is still touted as a new technology with a bright future. Some of this

\footnotetext{
${ }^{91}$ Harbir Chhina, Oil Sands Oral History Project, interview by Peter McKenzie-Brown (Cenovus Energy, Calgary, 2011).

${ }^{92}$ Reference from Dawson, Chester. 'Falling Crude Prices Upend Canada's Oil Sands Projects'. Wall Street Journal, 2015 , and Peter's \& Co. Research Reports
} 
tepid improvement being demonstrated is due to less attractive geologies being drilled by less experienced operators - few of the new players have been able to match the productivity of Cenovus Energy's Christina Lake or Suncor's Firebag plays. MEG Energy's Christina Lake project for example, like most others, has less than half the productivity per well.

\section{FIGURE 12: HISTORY OF IN-SITU PRODUCTION PER WELL (BPD)}

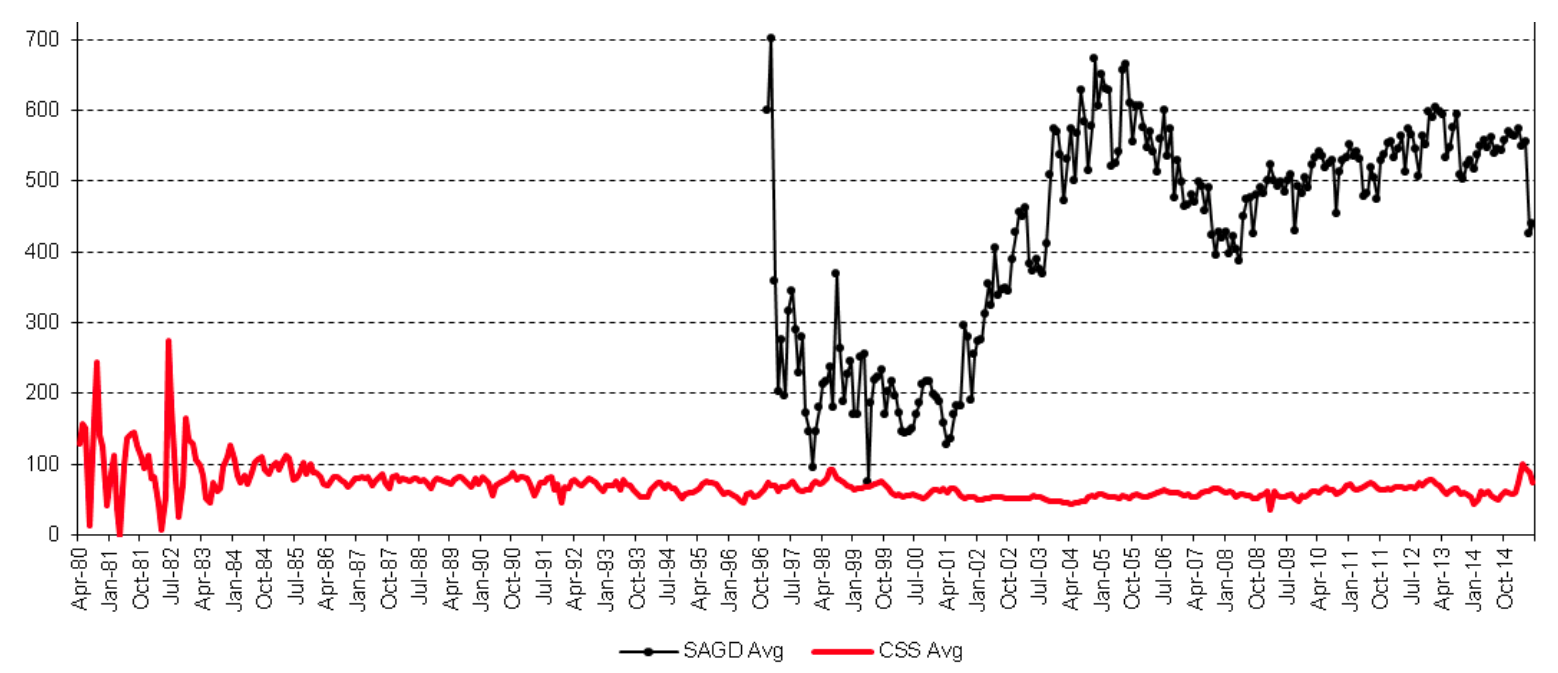

Source: BMO Capital Markets Oil Sands Monthly, September 2015

Though SAGD technology has added, and will continue to add, incremental productivity and energy efficiency gains, it seems unlikely from recent history that major improvements will be made without fundamental alterations to the extraction technology (further discussed in subsection 3.3).

\section{Mining}

With recovery rates for oil sands mines already reaching up to 95 per cent, large gains in production for a given amount of ore are unlikely. Economic analysis of mining uses the TV:BIP ratio to understand how much mining activity is needed to extract bitumen. The ratio is defined as the 'total volume of oil sands ore removed' (TV), which includes both 'oil sands volume mined' (OSv) and 'overburden volume removed' $\left(\mathrm{OB}_{\mathrm{v}}\right)$, divided by the volume of constituent bitumen within that volume. The calculation also includes the bitumen grade, in per cent, of oil sands ore (G). Using approximate densities for oil sands ore and bitumen, the ratio can be calculated as:

$$
T V / B I P=\frac{O B_{v} / O S_{v}+1}{2.1 \times G}
$$

The economic incentive of high-grading pushes operators to desire lower TV:BIP ratios as highlighted by Imperial Oil's touting of its proposed Kearl mine back in 2006 (see Figure 13 on the next page). The figure also shows an IHS CERA analysis that demonstrates the increasingly poorer quality of proposed mines. Unlike SAGD, however, high-grading is somewhat limited in mining by government regulation. The province does not want mines with large portions of the bitumen deposits left untapped as this leads to high levels of land disruption - the Alberta Energy Regulator mandates that all areas with a TV:BIP ratio of 12 or less must be mined. Though this restriction is effectively irrelevant with WTI prices around $\$ 100$ per barrel (when TV:BIP ratios of 16 or higher can still be attractive to producers), at the current WTI prices of $\$ 30$ per barrel, some operators are essentially forced to extract and process unprofitable ore. At the macro-level of the mineable resource, there is less high-grade, lightly overburdened ore to be extracted. This decrease in reservoir quality acts to offset capital delivery and operating efficiency improvements. 


\section{FIGURE 13: COMPARISON OF TV:BIP RATIOS WITH \% GRADE}
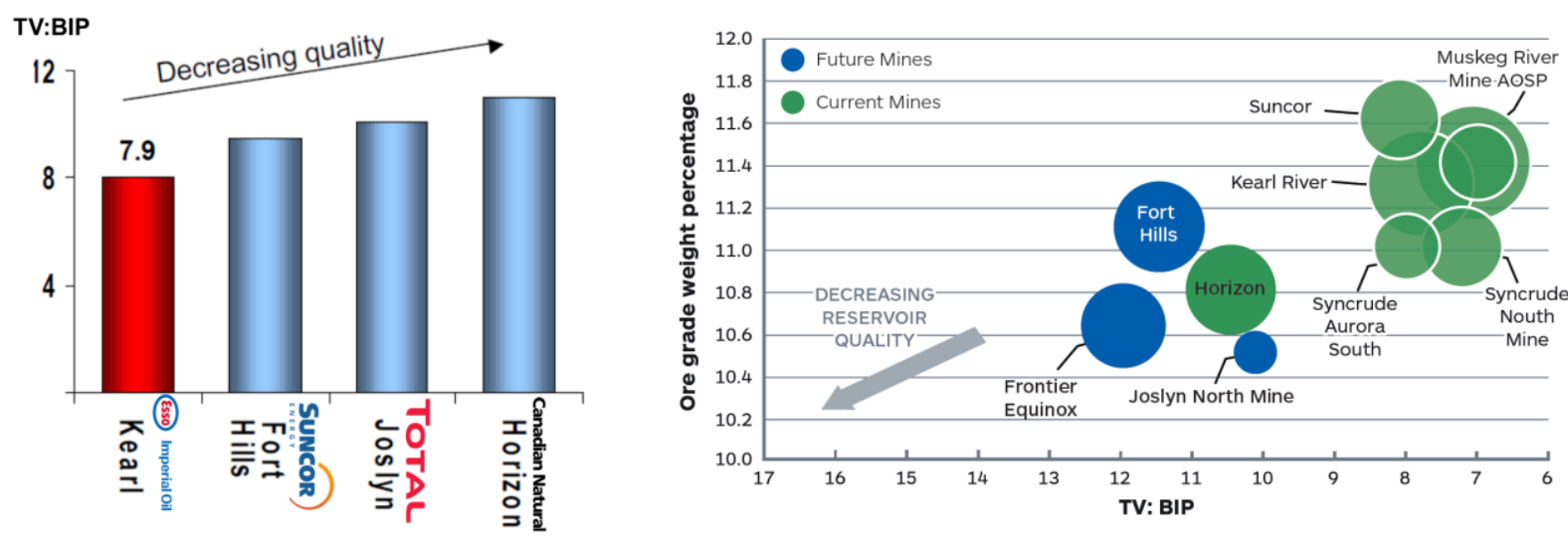

Sources: Imperial Oil Corporate Presentation; IHS CERA.

\section{Capital efficiency and the mega-project}

Estimated supply costs are based on future budgeting for capital costs that are far from certain. In fact, many oil sands projects have greatly exceeded budgeted capital costs due to an inability to scale up efficiently, which ironically is intended to lower per unit costs. Capital expenditures have tended to exceed budget more often than not (and by a much larger magnitude); since 2006, oil sands projects have on average delivered a poor return on capital versus what was touted to investors (see Section 4).

\section{FIGURE 14: LABOUR EFFICIENCY OF OIL \& GAS CONSTRUCTION IN ALBERTA}

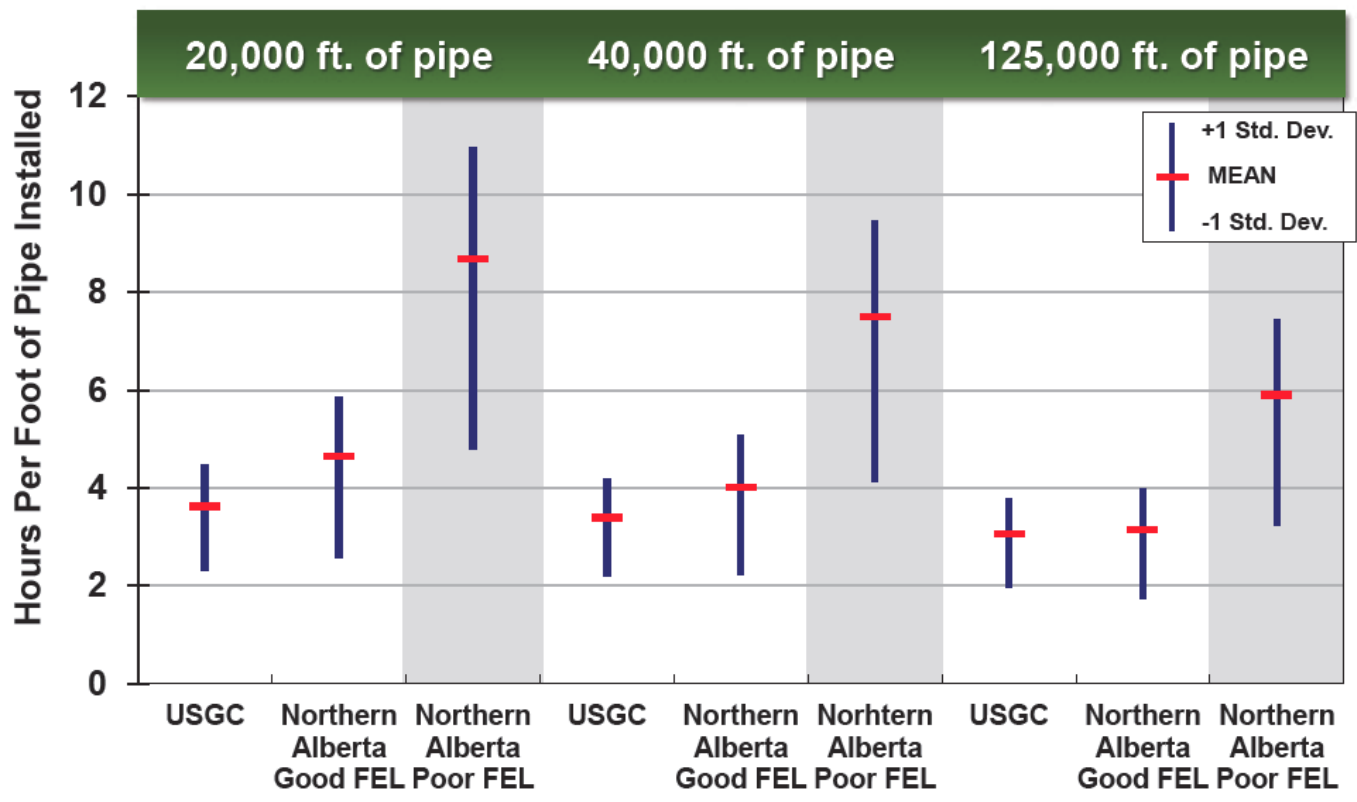

Source: Independent Project Analysis Inc. ${ }^{93}$

During the boom, many of the rapidly growing Calgary-based companies struggled to establish and maintain human resources, operating excellence and capital efficiency best practices amid a general talent shortage and shareholder growth pressure. Even though majors like ExxonMobil's Imperial Oil, Shell, Chevron, Total, and ConocoPhillips were able to leverage experience from their global heavy

${ }^{93}$ Labour efficiency chart shown was part of a presentation delivered by Ed Murrow in 2015 to the Construction Owners Association of Alberta Best Practices Conference. 
oil networks, they themselves struggled adapting to northern Alberta's unique challenges and were forced to pay substantial premiums for talented workers, services, and products. Alberta has demonstrated its ability to build projects competitively when proper preparation and planning is done (termed 'Front-End Loading' or FEL by Independent Projects Analysis Inc., a consultancy, in Figure 14). However, oil sands 'mega-projects' have an appalling history of exceeding budgets when FEL was not practised.

The oil sands is at an interesting crossroads in its history with regards to project planning - will producers continue the decades-old trend of building massive, multi-billion dollar growth projects in an attempt to leverage scale against the costs of producing bitumen? Or, will they look to limit risk and increase responsiveness by building smaller, modular growth projects, focusing on 'brownfield' expansions to already operating installations? Recent activity shows the latter trend is more likely the 'mega-project' approach, almost a requirement to reach scale in mining projects, has been fraught with substantial cost overruns and scheduling delays. Rarely have these projects brought the scale advantages promised and producers are looking to smaller scale projects for return on their capital.

\section{The push for operational excellence}

The uncertainty around geology and technology that is inherent to the oil industry, added to a history of massive swings in commodity prices that continue today, have made oil and gas exploration and production a relatively inefficient industry. Producers focusing on delivering volume rather than value to the market were especially common during the 15-year upswing in global prices from 1999 to 2014 . Meanwhile, major operating advances in the automobile and other industries such as 'Six Sigma' and 'Lean Manufacturing' process improvement (including organizational elements such as talent management), 'Just-in-Time' inventory management, and advanced strategic sourcing methodologies, have become standard in manufacturing. These practices have had slow penetration into the upstream oil and gas world, especially beyond the majors. Certainly, the process of producing oil from highly variable rock is different than fabricating consumer goods, especially with so much spend skewed towards capital investment. That said, there is undoubtedly room to improve how projects are constructed and operated in the oil sands given its manufacturing-like operations, and sub $\$ 50 \mathrm{WTI}$ crude is a strong impetus to overcome internal resistance to change.

Because much of the operations and construction efforts are outsourced, oil sands producers essentially take their whole supply chain to market when competing with each other and against other global sources of oil. Therefore, it is this integrated supply chain that must generate savings collaboratively and competitively, and not just the producers who own the assets and mineral rights.

\section{The SAGD 'manufacturing' of oil sands}

SAGD focused operators are increasingly discussing their oil sands production as a 'manufacturing' operation, talking of new plans for 'modularization', where construction of major plant components become repeatable and take place offsite, even as far away as Asia. Pad drilling of many co-located well heads is the standard. The intent is to standardize wells and pads, which can drive cost efficiencies in processing plants and gathering infrastructure. However, processes that are dependent on the local geology, such as optimizing steam-to-oil ratios in SAGD, are more difficult to replicate at scale, and true 'manufacturing' SAGD processes remain aspirational at this point. Survival is a compelling motivator, however, and producers do realize that they need to rapidly improve operating practices or remain uncompetitive for investment.

\section{Mining challenges}

All five large mining producers have shown efficiency improvements in extraction and processing starting decades back with the shift towards hydrotransport from the field and replacing the bucketwheels with large earthmovers (also discussed in the oil sands primer in the Appendix). However, it is unclear how much further these operators can go to reduce costs given they have already been fighting to catch up to the less expensive SAGD projects and are burdened with increasing environmental regulatory costs. Initiatives are being developed to automate and improve efficiencies, such as driverless mining trucks (to replace drivers whom cost operators in the neighbourhood of CAD $\$ 200,000$ or more per year) could result in hundreds of millions in annual savings for an operator, though their large-scale implementation is still years away. 


\section{Natural gas fuel prices}

Though producers can rightly blame regulatory burden, a lack of cost-efficient transportation, and wage inflation for their ballooning costs, their fuel costs have dropped sharply since 2008. Significantly discounted from Henry Hub prices by roughly $\$ 0.50 /$ per MMbtu, itself one of the cheaper trading points of natural gas in the world due to the advent of economic shale gas, Alberta natural gas prices (AECO, shown inflation-adjusted in Figure 15) are at their lowest level in decades. This boon has allowed many producers (especially those using SAGD) to maintain some level of profitability due to a substantial gap between global crude and Alberta natural gas prices. Since 2008, voices calling for the building of nuclear power plants to generate steam in the oil sands regions have been mostly muted due to this inexpensive gas. Despite the likely addition of one or more world-scale LNG liquefaction plants on Canada's west coast, and a potential, if unlikely, environmentally driven ban of hydraulic fracturing, Western Canadian natural gas prices look set to stay low for the foreseeable future.

\section{FIGURE 15: ALBERTA NATURAL GAS PRICE (AECO) VERSUS HENRY HUB AND WTI}

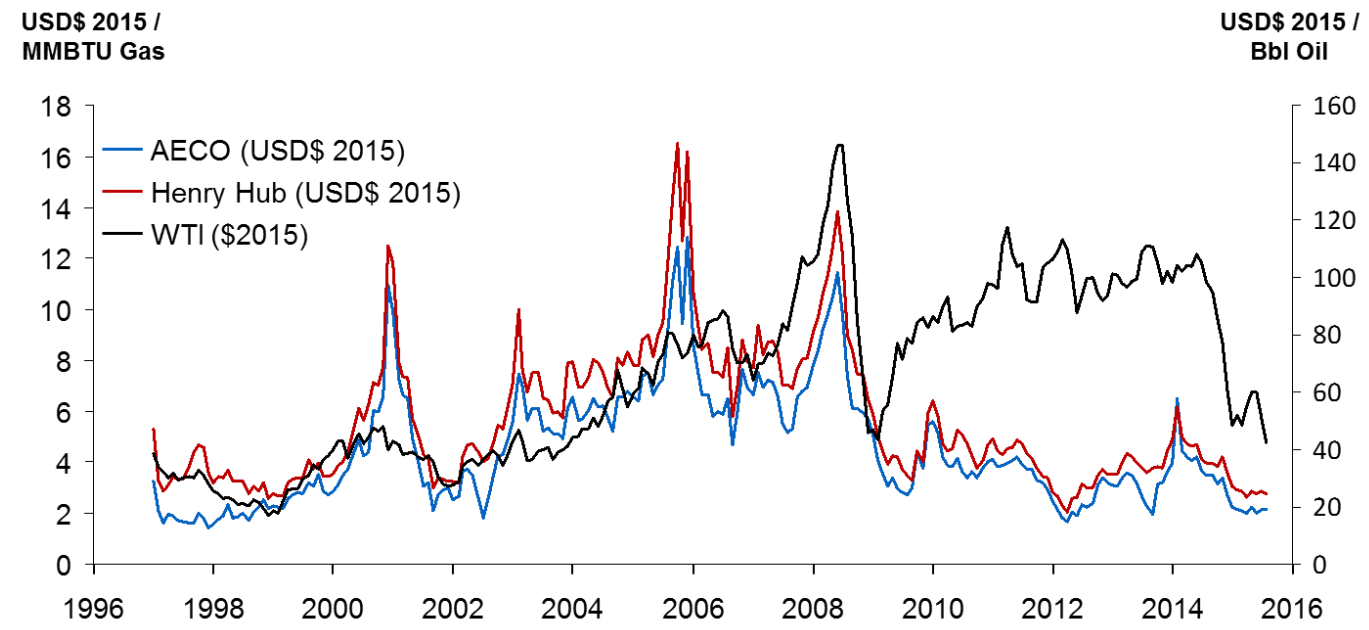

Sources: EIA; Bloomberg; and CanadianForex.

\section{Cogeneration}

With current processes, both in-situ and mining operations require massive amounts of gas-derived heat to separate bitumen from oil sands, either in the subsurface or a surface processing facility. Given that production facilities also have considerable electricity needs, the economics of cogeneration plants that produce both heat and power efficiently, are quite favourable. Their usage is growing among SAGD and mining producers alike, and with the Albertan grid looking to replace endof-life, high-emission coal power plants, there are calls for oil sands cogeneration units to grow in capacity and sell substantially more electricity back into the grid. This could greatly lower the province's overall carbon footprint.

\section{Contractors, talent shortages, and wage inflation}

A major contributor to the cost increase has been wage inflation within Alberta in general, and the oil and gas industry more acutely, as depicted in Figure 16. Alberta's 2000-15 economic boom witnessed 2 million bpd of added oil sands production capacity with its complicated extraction methods and processing plants, combined with accelerated investment in natural gas production (at least until 2008), LTO production (more recently), and substantial midstream capacity. Much of this investment was aimed at remote geographies in an already sparsely populated province. Moreover, the oil and gas industry holds less allure for many younger workers due to its perceived environmental reputation (whether deserved or not). The resulting crippling shortage of talented workers is therefore little surprise. 


\section{FIGURE 16: CANADIAN OIL AND GAS WAGES VS. OTHER INDUSTRIES}

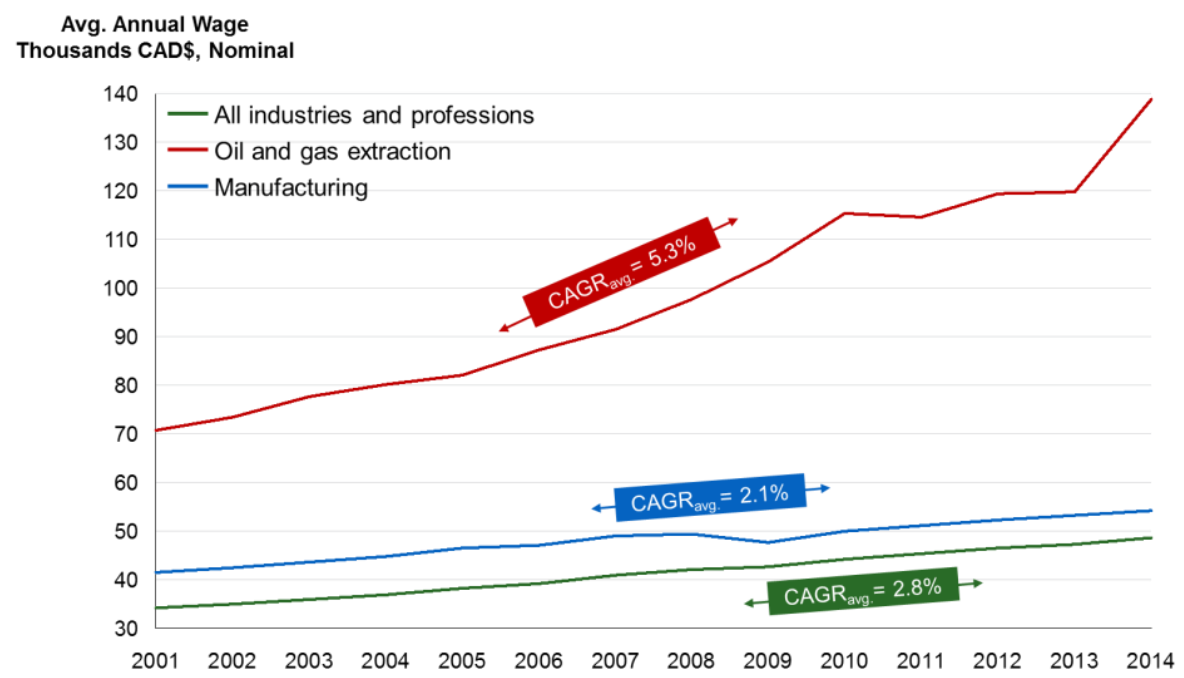

Source: Statistics Canada.

The oil and gas wage premium has been especially acute for the skilled trades such as welders and pipefitters, who until the recent price crash had been in high demand, commanding annual compensation on the order of CAD\$300-400 thousand per year in remote areas. In addition, producers are forced to pay for costly living allowances and bi-weekly or monthly transportation for many of these workers, as many prefer not to live in remote cities like Fort McMurray where housing, school, and hospital shortages have been dire. Oil field service companies grew to focus on growth and meeting their producing client's timelines and technical expectations rather than controlling costs.

\section{FIGURE 17: ALBERTA SAFETY PERFORMANCE - LOST TIME INJURY RATE}

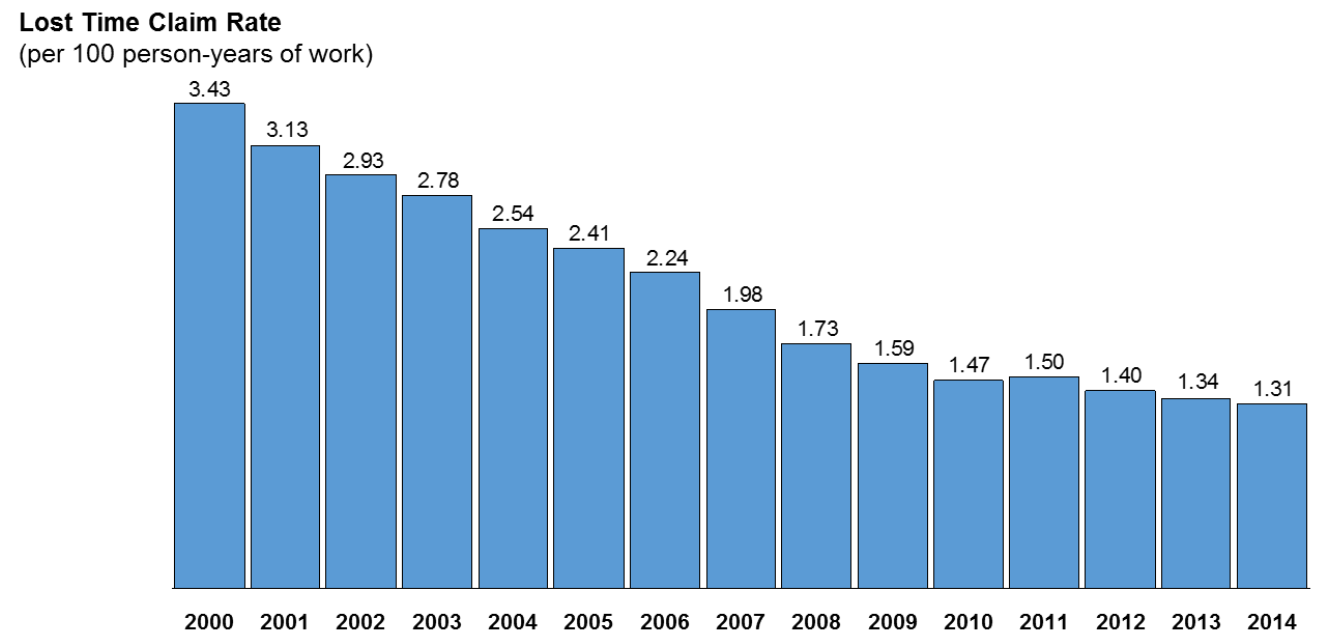

Source: Government of Alberta.

As labour shortages became exacerbated, producers and operators began to implement a rather systematic, if unheralded, practice of 'lowering the bar'. Operating positions that might once have been required to have a two-year post-secondary technical degree were filled with workers who only had maybe one year of post-secondary training, or none at all. Capable and reliable contractors (where much of the capital and operating expenses flow) were in high demand and were able to charge substantial annual price increases. Combining less experienced workers with safety standards that are ever more stringent (and justifiably so given producer focus on employee well-being) did little 
to allay rising labour costs. Fortunately, working in the oil sands became markedly safer as the boom period progressed, largely thanks to the efforts led by producers and contractors (Figure 17).

It will always be expensive to entice tradespeople to work and live in such a remote area. That said, contractor cost escalation was hardly limited to Northern Alberta - it was pervasive throughout the global upstream industry during the 2000-14commodity price ascension. Wages in Alberta have just been much slower to drop, as Harbir Chhina of Cenovus noted in November 2015:

\begin{abstract}
My way of judging how inflation is going, I just look at welder rates, because everything else is going to be escalated if they are getting paid that much. They vary anywhere between $\$ 800$ per day to $\$ 1,800$ per day. Last year they were getting $\$ 1,700$; today they're still getting $\$ 1,400$ per day. We still have to see those costs come down. ${ }^{94}$
\end{abstract}

Seasoned and knowledgeable professional talent in engineering, geology, and project management was spread thin among the multitude of new projects that arose each year, especially with highly attractive compensation packages aimed at poaching talent from the pioneering producers to new entrants. More senior talent was attracted to early retirement armed with sizeable bonuses and stock option pay-outs.

With the price crash of 2014 now lasting beyond 2015, and likely into the next few years, the flip-side of this inherent oil production boom-and-bust economic cycle on workers, well known to those who have the studied oil industry history since the 1800 s, is showing its ugly face once more. Layoffs have spread from contractors, the first to be hit by price slumps, to producers, who find themselves under unfamiliar scrutiny from shareholders. An abundance of under-employed contractors indeed helps lower producer costs in the near term, but will somewhat ironically lead to a shortage of workers for the next growth cycle. Alas, the undeniable inefficiency that arises from the boom-bust cycle looks to continue.

\title{
Overhead and benefits reduction
}

Generous compensation, benefits, and bonus packages for virtually all levels of employees have become the expectation for oil workers in Calgary, and are justified in periods of high commodity prices as a necessity to attract top talent. With poor financial returns amid recent low commodity prices and an estimated 40-60 thousand direct workers laid off in Alberta since the beginning of the price crash (many more indirect workers), shareholders are now growing sceptical of the level of compensation. Well before the crash, ExxonMobil's Imperial Oil chose to relocate from downtown to the less costly suburbs. Suncor, Shell, Husky, and Cenovus have already cut substantial portions of their workforce, while CNRL, who has the reputation of running rather lean, has chosen to impose a salary reduction of upwards of 10 per cent rather than invoking mass layoffs.

\section{Royalties, taxes, and regulatory costs}

Royalties are one of the major increases in supply cost since 2003, increasing roughly 1,000 per cent on a real basis for a new project (see the numbers back in Figure 10). With rapidly accelerating global crude prices, and a provincial infrastructure shortage due to rapid population growth (spearheaded primarily by the oil and gas industry), the Alberta government moved in 2008 to change the royalty structure and collect more revenue.

\section{TABLE 5: ALBERTA OIL SANDS ROYALTY CALCULATION (2015)}

\begin{tabular}{|c|c|c|c|c|c|c|}
\hline & \multicolumn{3}{|c|}{ Before 1 January 2009} & \multicolumn{3}{|c|}{ After 1 January 2009} \\
\hline WTI Price & Pre-Payout & Po & teater of & Pre-Payout & & $\begin{array}{c}\text { Post-Payout } \\
\text { Greater of }\end{array}$ \\
\hline WTI $<\$ 55$ & $1 \% \times$ Gross Rev & & $25 \% \times$ Net Rev. & $1 \% \times$ Gross Rev & & $25 \% \times$ Net Rev. \\
\hline$\$ 55<\mathrm{WTI}<\$ 120$ & $1 \% \times$ Gross Rev & $\begin{array}{l}\text { Payout } \\
\text { Rates }\end{array}$ & $25 \% \times$ Net Rev. & $\begin{array}{c}1 \%+0.123 \%{ }^{*}(\mathrm{WTI}-\$ 55) \\
{ }^{*} \text { Gross Revenue }\end{array}$ & $\begin{array}{l}\text { Payout } \\
\text { Rates }\end{array}$ & $\begin{array}{c}25 \%+0.231 \%{ }^{*}(\mathrm{WTI} \text { - } \$ 55) \\
{ }^{*} \text { Net Revenue } \\
\end{array}$ \\
\hline WTI $>\$ 120$ & $1 \% \times$ Gross Rev & & $25 \%$ x Net Rev. & $9 \% \times$ Gross Rev. & & $40 \% \times$ Net Rev. \\
\hline
\end{tabular}

Source: Alberta Oil Sands Royalty Guidelines (October 2012). 
The nature of the structure (both before and after the change), is that royalties potentially switch to a higher rate once the projects reach 'payout status' - defined as the date when its cumulative revenues first exceed its cumulative costs, including an acceptable interim return. After that date, the project will pay the greater of a royalty calculation based on gross revenues and a royalty calculation based on net revenue (revenues minus costs) as shown in Table 5. Rather ironically, though the Alberta government increased the royalty rate in 2008 to garner some of the windfall profits producers were receiving due to a rapid acceleration of WTI price, capital and operating costs were escalating so rapidly that much of the windfall was eaten away, and the producers were saddled only with the increased royalty and reduced overall earnings.

A new royalty review is currently underway in the Alberta, emanating from a platform promise of the recently elected NDP party to ensure producers were paying their 'fair share'. Given the economic stakes involved, it is most likely that royalties and corporate taxation will remain roughly similar to today's levels in order to both satisfy diminishing public coffers and incentivize investment. That said, royalties are unlikely to decrease, especially at higher prices of WTI or WCS, given the NDP'S pronounced willingness to increase government revenue at the expense of corporate profit. For example, adding to the foreboding forecasts of royalty increases, oil sands producers worry about the NDP's increase in corporate provincial tax rate from 10-12 per cent. ${ }^{95}$ With the above royalty structure, producers get substantial relief from these low WTI prices in the $\$ 30-50$ range (on the order of \$3-5 per barrel) compared to when WTI hovered around \$100 from 2010 to 2013.

\section{Exchange rate}

The Canadian-US exchange rate can have profound effects on oil sands profitability. It would seem that producers desire a lower Canadian dollar as they are paid revenue in US dollars (or the Canadian equivalent driven by US markets), while much of their cost base rests with Canadian suppliers and employees. For example, assuming that the cost fundamentals driving CERl's 2014 price estimates remain unchanged, the fall of the Canadian dollar from its 2014 average of USD $\$ 0.91$ to the current value of USD $\$ 0.75$ effectively cuts the cost to produce bitumen by more than 15 per cent. Although this may seem like a boon to producers, this drop in the Canadian dollar is primarily a result of lower global oil prices. Indeed, the correlation between the Canadian dollar and the oil price is remarkable, as illustrated in Figure 18.

\section{FIGURE 18: THE STRENGTH OF THE CANADIAN DOLLAR AS A FUNCTION OF CRUDE PRICE}

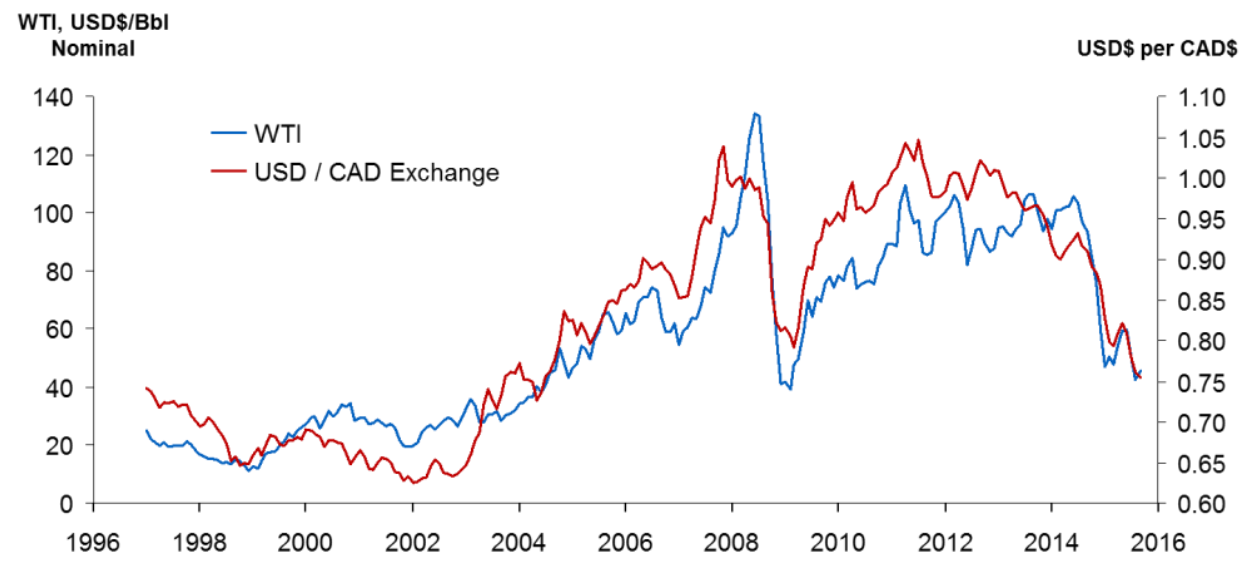

Sources: EIA; CanadianForex.

\footnotetext{
${ }^{95}$ Currently producers only pay $\$ 15$ / tonne on emissions beyond a 12\% reduction from a 2007 (or later) baseline as part of the Specified Gas Emitters Regulation. This fee was set by the NDP to double by 2017. The currently on-going comprehensive review of the province's climate change policy will likely apply carbon pricing to all emissions in the province, increasing costs for producers and consumers alike in all emitting industries and consumption.
} 
It follows, then, that the exchange rate acts as a buffer for producers, reducing costs in low-price environments to offset losses but accelerating cost inflation at boom times of high-price, curbing profits. Based on the price histories of the past 20 years, changes in crude price typically outweigh the resulting exchange rate effects on cost, and producers naturally prefer high prices, despite the higher dollar. This is antithetical to many of Canada's other exporters, who struggle with high exchange rates for which they have blamed high crude prices and the Canadian energy industry. With roughly twothirds of Canada's population residing in the manufacturing-heavy provinces of Ontario and Quebec, oil and gas producers have reduced political clout and little ability to influence policy at the federal level compared with Canada's more labour-intensive, populist, and trade-protected auto and aerospace industries.

\title{
3.3 Technology as both a competitive necessity and investor promotion tool
}

As with any energy source or technology whose adoption takes decades (think, for example, solar energy, small modular nuclear fission reactors, arctic offshore oil, electric cars, or industrial-scale batteries), extracting Canada's oil sands will continue to be an uphill battle, likely requiring almost perpetual technological advancement. Former Syncrude CEO Eric Newell described the challenge optimistically in 2013:

We're not a mature industry. We're still by comparison very young. The advantage to that is that there are technology breakthroughs to be made. It was technology that got us to where we are today. It will be technology that gets us to where we need to be tomorrow. ${ }^{96}$

\section{SAGD as Oil Sands 2.0}

The development of the oil sands mine, which came to commercialization in the late $1960 \mathrm{~s}$, is the pioneering method of oil sands production; in-situ production using SAGD technology might be considered 'Oil Sands 2.0'. If defined this way, Oil Sands 2.0 came to life in 1987, with the first successful SAGD well producing at the government sponsored AOSTRA Underground Test Facility, coincidentally the same year the Microsoft Windows 2.0 operating system was released for personal computers. The software analogy ends there, however, as oil sands technology development might seem like a turtle racing a cheetah in comparison. Mining technology took roughly five decades from the defining patent to have it its first commercial project payout, while SAGD took more than three. AOSTRA SAGD pioneer Harbir Chhina at Cenovus likes to use the analogy that if oil sands production, especially in-situ, was a baseball game, 'we've just finished the first inning [of a nineinning game]'. Given the wide variety of potential technologies to apply and the vastness of the resource, the statement is likely true. It is difficult to ascertain, however, how long the next inning will last, not to mention the rest of the proverbial baseball game. Sales pitches to potential oil sands investors boasting of the 'best thing since sliced bread' in extraction technology have been around for almost 90 years; back in 2011, the OIES promoted a sceptical view: ${ }^{97}$

\begin{abstract}
Any company that claims its technology programme will yield efficiency gains/emissions reductions beyond a modest, few percentage points within ten years - and they have yet to put steel in the ground to test their technologies - is simply naïve or attempting to mislead someone. It can take more than three years just to get regulatory approval, two to build, one to three to ramp up, monitor and measure and perhaps a couple more to analyse - and that is only for a pilot, not a full-scale commercial project: that can take another four to six years to produce initial results. And if the history of piloting is any guide, the analysis often concludes there were insufficient observation wells and measurements of the right parameters to provide conclusive data. ${ }^{98}$
\end{abstract}

This challenge rings true today, especially given that the stomach-wrenching price crash for investors may lead to less capital available for research and development and make it harder for technologically advanced start-ups to stay afloat. What's more, substantial variation in geological characteristics (such as varying thickness, high water-saturation, and impermeable rock formations) in oil sands

\footnotetext{
${ }^{96}$ Dan Barnes, 'Alberta's Oilsands Epic Stretches Back More Than A Century', The Edmonton Journal, 2013.

${ }^{97}$ Sliced bread was first produced and sold at commercial scale in the United States in 1928. Robert Fitzsimmons started the International Bitumen Company in 1927 at his Bitumount site, proclaiming a novel method of separating bitumen from oil sands that could change the economics of the petroleum industry.

98 'Robert Skinner Assesses The Technological Challenge Of Producing Heavy Oil', The Oxford Energy Forum, no. 86 (2011): Pages 20-23.
} 
reservoirs often leads to a lack of repeatable applicability for newly developed in-situ production technologies, lessening the motivation to develop them.

\title{
Incremental improvements
}

Internal combustion, diesel, and gas turbine engines have core designs that have remained fundamentally unchanged for 70 years or more, though have slowly but surely produced efficiency improvements by leveraging mechanical, thermodynamic, and material advancements. In a similar fashion, mining, CSS, and SAGD operations will continue to produce bitumen with increasing efficiency through technological enhancements for at least the next two or three decades. Imperial's modern Kearl oil sands mine may not look a lot like the early Bitumount or Abasands plants of the 1930s, but its extraction and separation processes of oil sands ore follow the same underlying physical principles. Technological advances in field extraction and processing for mining, and steam production, well delivery, and reservoir engineering for in-situ, will continue to improve margins for producers. For example, SAGD well delivery has benefited from advancements in horizontal drilling and 'logging while drilling' (LWD) capabilities. Reservoirs are exploited more effectively with the help of 3D reservoir modelling, 4D seismic monitoring of steam chambers, gas injection after steaming, and 'electrical submersible pumps' (ESPs). Additional competitive patents have arisen, such as Cenovus' 'WedgeWell' arrangement for well spacing, which has helped it maintain a competitive advantage in SOR.

The challenge for current and proposed mining and SAGD projects is to develop technological improvements to a magnitude that meet, and ideally exceed, the detriment of decreasingly prolific rock, a result of high-grading. Judging by the escalating per barrel capital and operating costs in past decade, just meeting this challenge has been very demanding - the combined effect of incremental improvements only typically measures a few dollars per barrel in cost savings.

\section{In-situ potential game-changers}

Research departments of majors and large independents, pilot projects of a few entrepreneurial startups, and government-funded academic bodies, such as the research consortium Alberta Innovates, have engineers and geologists working to bring disruptive in-situ production technologies to commercial feasibility. The following families of in-situ extractive technologies are currently under development, though they are yet to generate material commercial success and are likely at least five years away from doing so. The common underlying theme among them is the shift away from steam heating, where most of the heat remains wastefully in the sands, rather than the bitumen.

\begin{abstract}
Use of Solvents. Diluents, typically natural gas liquids, are added to the subsurface reservoir in order to produce bitumen with less energy usage than production with steam. This has the added benefit of providing substantial reductions in GHG intensity. Another bonus is that solvents can even 'upgrade' the bitumen insitu to some extent. The drawback is that these diluents are expensive, trading at substantial price premiums to bitumen (and certainty steam), and recovery rates of both bitumen and the diluent itself need to be high enough to justify their usage. Due to solvent demand just for blending and transporting growing oil sands bitumen production, condensate in Alberta trades at a premium to light, sweet crude, making it even more expensive. Propane however, seems to be more than ample supply in Alberta for the foreseeable future - in 2015 it even traded below zero for a few months. Its usage as a solvent might be increased due to its low cost.
\end{abstract}

Solvent injection methods include VAPEX (injecting gaseous state solvents), injecting warm liquid solvents, and co-injecting solvents with steam. Most in-situ producers are developing solvent technology to some extent (most commonly co-injection) and tinkering with it to optimize the economics. The start-up $\mathrm{N}$-Solv is leading the charge in warm liquid solvents, touting itself as a 'clean-tech' leader in its ability to reduce SAGD GHG emissions by 80 per cent. It is working with Suncor to expand its pilot project that has produced 40,000 barrels as of January 2015. ${ }^{99}$

Combustion. The two relevant technologies are Toe-to-Heel Air Injection (THAI) and Combustion Overhead Gravity Drainage (COGD). THAI was developed by Petrobank Energy \& Resources (now Touchstone Exploration) and generates downhole combustion and energy release by injecting air in a separate vertical well at the toe of the bitumen-producing well. COGD generates combustion in vertical wells above the

${ }^{99}$ See the N-Solv website for more details as https://www.nsolv.ca. 
producing horizontal wells such that reduced-viscosity bitumen flows with gravity, similar to SAGD. The idea of combustion to release bitumen is attractive as upgrading can happen in-situ (roughly 5 degrees API anyway) and require much less energy than SAGD or CSS. However, preliminary testing of the technologies has not demonstrated the potential to be economic - THAI has essentially been shelved after years of Petrobank touting its potential. ${ }^{100,101}$ That said, the Canadian government continues to perform more fundamental physical research on bitumen combustion that may lead to commercial technologies.

Electrical Heating. Two processes under development leverage thermal heating rather than steam to produce in-situ. Electro-Thermal Dynamic Stripping Process (ET-DSP) leverages a matrix configuration of vertical wellbores with electric current passing through water-saturated reservoirs that work to lower the viscosity of bitumen and produce through vertical wells. Thermal-Assisted Gravity Drainage (TAGD) is similar to SAGD in subsurface geometry, though the thermal conduction of electric resistance heaters replaces the steam injection in the upper well, rendering the process essentially waterless, and eliminating the need for costly steam plants and related infrastructure. TAGD is suited to developing bitumen in the carbonates of the oil sands area which represent almost 500 billion of the approximately 1.8 trillion barrels of bitumen reserves not presently considered recoverable. These plentiful reserves are too deep to mine and too shallow to steam with SAGD. ${ }^{102}$

\section{Research and development costs: Who pays?}

Costly game-changing technology investments have been a tough sell for producers due to such long development times. This is true in times of high crude prices, when the focus is on capacity building, and in crude's current low-price environment, amid across-the-board cost cutting efforts and layoffs. ${ }^{103}$ Producers often tout their large research and development (R\&D) budgets - CNRL leads the pack with CAD $\$ 450$ million spent in 2014, while Suncor, Syncrude, Imperial Oil, and Cenovus each spend roughly CA $\$ 100-200$ million annually. ${ }^{104}$ Nevertheless, not unlike other oil and gas producers worldwide including supermajors, the portion of revenue reinvested into R\&D for oil sands producers is somewhat paltry - around $0.5-1$ per cent. ${ }^{105}$ Many of Canada's other major companies spend substantially more - the country's technology, aerospace, and pharmaceutical firms invest roughly 7-20 per cent of annual revenue into R\&D. Even Canada's two largest telecommunications firms Rogers and Bell, with a combined annual revenue of roughly CAD $\$ 34$ billion, spend around 3 per cent each on R\&D.

\section{Overstressing the ' $D$ ' in $R \& D$}

Much of the oil sands stated R\&D investment is skewed towards development, rather than the more primary research needed to make long-term major cost reductions. If producers can demonstrate that an element of a new project, even if it is for direct commercial use, is in some way experimental, the associated costs can qualify for federal Scientific Research and Experimental Development (SHRED) tax credits. It is therefore in the producers' best interests to amplify their claim of R\&D spend as much as possible. For this reason, stated annual R\&D totals are overrepresented with the costs of tweaking established technologies (development), rather than the costs of innovating novel ones (research).

\section{Environment takes priority}

Viewing regulatory and political obstruction as a potential barrier to growth and even continued operation, producers have been coerced to spend much of their R\&D investment on reducing their environmental footprint rather than their break-even costs. Certainly, these goals are not mutually exclusive - a more effective SAGD process that lowers the SOR reduces greenhouse gas usage, after all. Nonetheless, many of the footprint reduction efforts that are primarily advanced collaboratively through COSIA and other research groups have been costly to develop (77 technologies have been shared to-date, totalling roughly CAD $\$ 1$ billion) and do not necessarily lower capital and operating costs. If anything, reducing the far from trivial impacts on water, air, land, and

\footnotetext{
100 Tait, Carrie. 'The Tangled Tale of Petrobank's THAI Extraction Technology'. The Globe and Mail, 2013.

${ }^{101}$ Healing, Dan. 'Asset Sales Signal Patience Short For Disappointing THAI Heavy Oil Technology'. The Calgary Herald, 2015

102 Sebastian Gault, 'An In-Depth Look At How In Situ Oil Sands Development Has Evolved', Alberta Oil: The Business Of Energy, 2014

${ }^{103}$ Lewis, Jeff. 'Oil Patch Takes Aim At R\&D Spending To Make Way For More Cuts'. The Globe and Mail, 2015.

104 'Research Infosource', 2014. http://www.researchinfosource.com/top100_corp.php.

${ }^{105} \mathrm{CNRL}$ is the standout at roughly $2 \%$ of revenues, having almost quadrupled annual spend since 2009 . 'Canadian Natural Resources - Advancements in Technology', 2015. http://www.cnrl.com/corporate-responsibility/advancements-in-technology/.
} 

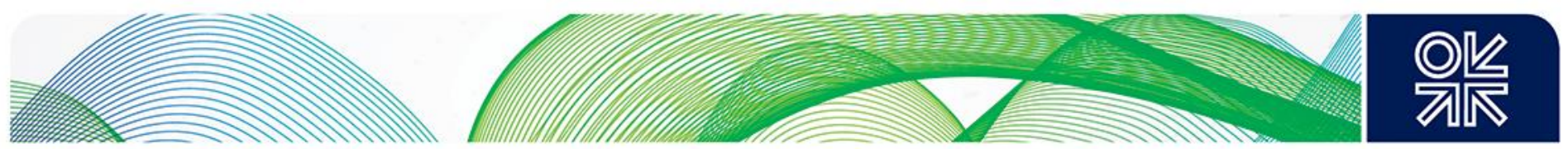

climate that are associated with bitumen production will likely add to supply costs due to the necessary and expensive new technology.

\section{Cooperation vs. competition}

In an effort to earn and maintain their social licence to operate, oil sands producers have adopted the practice of 'co-opetition', at least to some extent. The co-opetition neologism was born out of economic game theory, and it is defined by two or more competitive entities cooperating in order to grow the market with the fundamental premise that 'the whole is greater than the sum of its parts'. This practice led to collaboration between producers through the form of joint-funding for COSIA and other research groups such as Alberta Innovates and the Institute for Oil Sands Innovation at the University of Alberta, the province's largest university.

\section{FIGURE 19: SAGD PATENTS SINCE 1979}

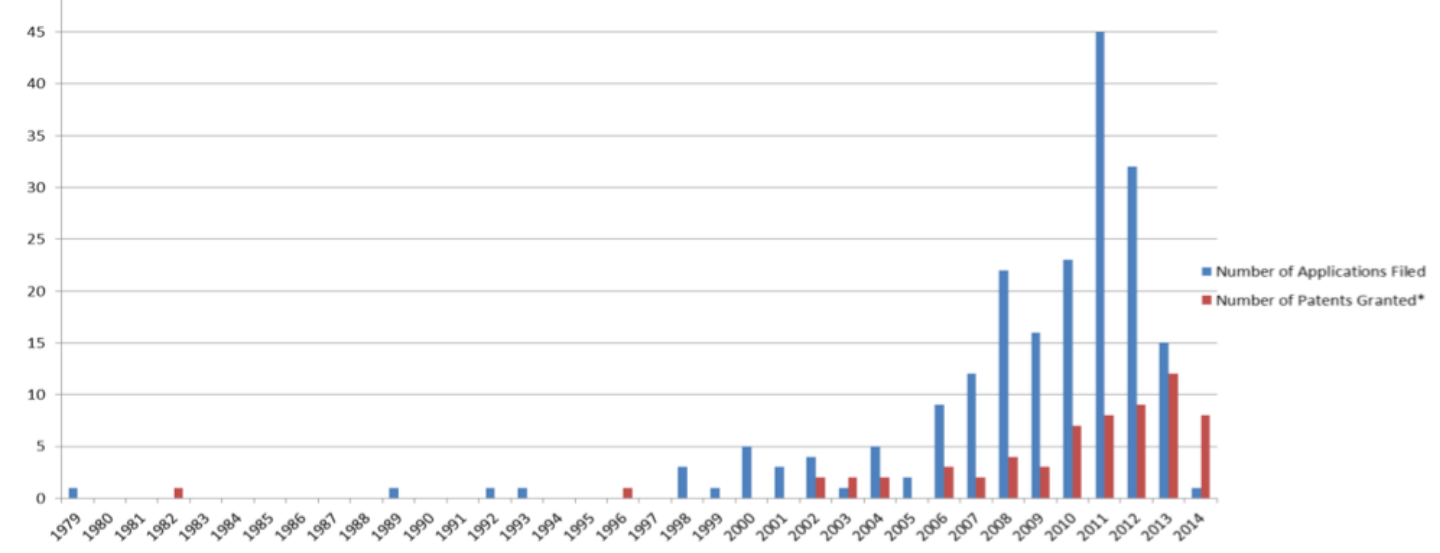

Source: McCarthy Tétrault LLP.

The problem is that critical production technologies require major funding efforts, such as SAGD that was first developed and patented by Imperial Oil in the 1970s. A full pilot facility is typically needed, such as the AOSTRA SAGD pilot in the 1980s, and producers, knowing that the patents will likely expire before commercial success arrives, are sceptical about making such major investments. (The gap between SAGD's first seminal patent and first commercial project payout was 30 years, though many smaller patents were granted once commercial production started, as seen in Figure 19.)

As a result, there are many potentially disruptive technologies, especially for in-situ production, developed by university researchers, entrepreneurial inventors, and oilfield service companies that go untested because of lack of access to pilot testing facilities.

\section{FIGURE 20: SAGD PATENT APPLICATIONS BY TYPE OF APPLICANT}

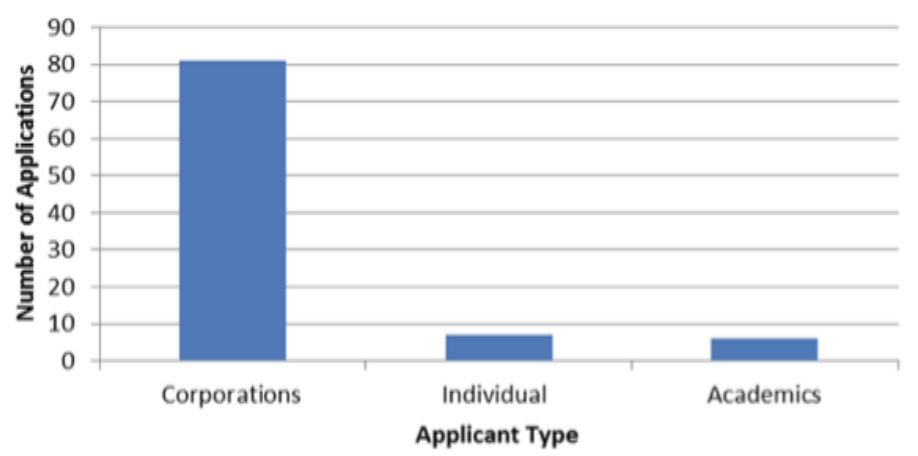

Source: McCarthy Tétrault LLP.

Consequently, it is the handful of larger producers, particularly majors such as Imperial Oil and Shell, who are financially backed by global assets and downstream diversification and thus capable of 
investing the magnitude of research funds necessary to make major breakthroughs. These large producers are unlikely to collaborate on subsurface production technology, because it is so critical to their perceived competitive advantage. Ironically, oil sands producers are seeing their competition arise more from lower-cost global basins (like LTO), than each other. The long timelines that seem inherent to the development of oil sands production technology look likely to continue.

\section{Oil sands 3.0 ?}

The profound, innovative engineering and technological applications that have followed modern man's landmark scientific discoveries in the twentieth century, such as the information technology revolution or genetic modification in agriculture, typically take decades to come to commercial fruition. In this light, researchers like Steven Bryant at the University of Calgary, who leads the Materials Engineering for Unconventional Oil Reservoirs research group, funded by the federal government through a Canada Excellence Research Chair, are rethinking how production from oil sands can be achieved. The core idea is to reinvent ore separation techniques that have remained fundamentally unchanged for more than 80 years, or the practice of creating process heat for in-situ production by simply boiling water, the same basic process that begot the first steam engines more than 200 years ago.

Researchers are developing radically new ideas in academic environments by leveraging budding applications from nanotechnology and microbiology. The central mission is to overcome oil sands' viscosity and release the massive reservoirs of bituminous chemical energy trapped in sand, with minimum environmental impact. Preliminary research has shown that incorporating micro/nanoparticles such as iron oxide into in-situ methods may act to substantially reduce bitumen viscosity. ${ }^{106}$ Suncor is moving forward with a small-scale pilot that leverages electromagnetic microwaves with nanoparticles, in combination with its solvent in-situ technology, to hopefully improve production economics and reduce emissions. Longer-term concepts look to harness the microbiome trapped within the oil sands to reduce bitumen viscosity by breaking down carbon-sulphur or carboncarbon bonds, or removing waste through chemical processes. ${ }^{107}$

Futuristic discussions of converting the chemical energy deposits to electrical energy or hydrogen, rather than following the traditional hydrocarbon value chain of transport, refining and combustion, are also ongoing in academic circles. Research at the University of Calgary looks to leverage nanoparticles and the microbiome to create the following:

i. Direct conversion of petroleum in an oil sands reservoir to hydrogen or electricity

ii. Integrated energy systems (oil/gas/power) with ultra-low energy input and emissions (potentially mediated through microbial organisms). ${ }^{108}$

Considering oil sands operators seem hesitant to commit sizeable funds to research for even nearterm production technologies, it is not a surprise that the majority of funding for these Oil Sands 3.0type ideas stems from government research grants. ${ }^{109}$ Researchers are lobbying the government for what they deem a 'moonshot' - substantial research funding of at least CAD $\$ 100$ million annually for a committed period of ten years or more, with the stated goal of transforming the hydrocarbon resources of the oil sands to produce useful energy for society while leaving the carbon in the ground. ${ }^{110}$

\footnotetext{
106 Shokrlu, Yousef Hamedi, and Tayfun Babadagli. 'Viscosity Reduction of Heavy Oil/Bitumen Using Micro- And Nano-Metal Particles during Aqueous and Non-Aqueous Thermal Applications'. Journal Of Petroleum Science And Engineering 119 (2014): 210-220.

107 A microbiome is composed of trillions of microbial organisms. An example is the microbiome in the human gut whose magnitude (of cell numbers) in the trillions has just recently come to the attention of researchers. Being close to the surface, the microbiome within the oil sands is well developed.

${ }^{108}$ From discussions with, and documentation from, the Canada Excellence Research Chair (CERC) in Materials Engineering for Unconventional Oil Reservoirs at the University of Calgary

${ }^{109}$ Somewhat of an exception to this is Cenovus' investments in General Fusion (a nuclear fusion technology company) and donations to the Perimeter Institute for Theoretical Physics in Ontario. Though these are not direct investments into production of oil sands chemical energy and could be perceived as corporate social responsibility efforts, technological breakthroughs from these investments could enable game-changing new methods applicable to the oil sands.

${ }^{110}$ Moonshot refers here to the US government program Project Apollo in the 1960s, famously announced by President John F. Kennedy with the objective of sending a man to the moon through heavy spending on research without a clear line of sight to success.
} 
The economic importance of the oil sands to Canadians today and in future decades is undeniable. Furthermore, the fact the province already spends roughly CAD $\$ 3$ billion annually on research and advanced education, while the federal government annually invests over CAD $\$ 10.3$ billion in science and technology, would indicate that such a funding commitment for a 'moonshot' would be a wise investment for the politicians in Edmonton and Ottawa. They could also refer back to how much provincial wealth has been generated out of the relatively meagre government investments made into SAGD in the 1980s. Nevertheless, rationality does not always prevail in democracies, and the public perception of supporting oil sands production with large amounts of government funds may be viewed a political landmine, even if the investment is aimed at removing the associated greenhouse gas emissions. Obstinate opponents of oil sands extraction from British Columbia's west coast to Quebec's east coast would be marching in the streets (likely in larger numbers than today).

\subsection{Cost competitiveness with LTO}

\section{Shale Gas \& LTO: Survival of the Fittest}

Just a decade ago, few (if any) experts within the US oil and gas industry anticipated the advent of such cheap shale gas in North America, at least at the volumes now being produced. Ingenuity, entrepreneurial nature, key technological advancements, and engineering iteration all accelerated the shale gas revolution from the early days of George Mitchell's Mitchell Energy (later Devon Energy). This continued through to the competitive landscape of shale producers that we know today, consisting mostly of small and medium players supported by an efficient and adaptable supply chain.

\section{FIGURE 21: ILLUSTRATION OF LEAN / JIT DRILL PLANNING FOR SHALE GAS / LTO}

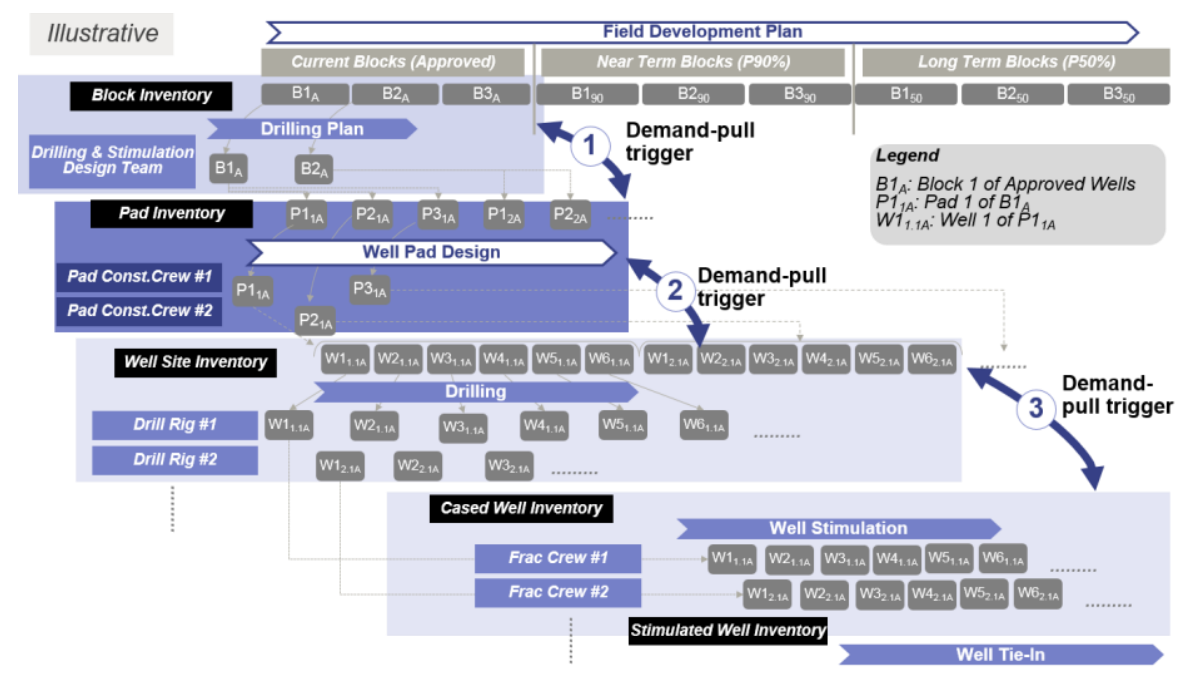

Source: Author.

Most impressive about the shale gas revolution is not the technology, which has developed rapidly, but the speed and adaptability of the production operations. After the Henry Hub price crash of 2008 ended the party for natural gas producers, many went bankrupt, hobbled along, or were gobbled up by competitors. Through this rather Darwinian process, the producers left standing were more efficient and prolific in their drilling efforts. Rather than 'grid drilling' producing areas for example, operators increased efforts to delineate the subsurface reservoirs though iterative data management and learning to ensure the more productive geologies were targeted. ${ }^{111}$ Drilling and completion teams decreased well delivery times and costs through 'Lean Manufacturing' and 'Just-in-Time' (JIT) type drill planning (see Figure 21 above) and further optimized well geometries and completion designs. Substantial reductions in break-even costs occurred for producers able to adapt despite continuing wage inflation and the increased practice of high-grading. This near market death created a highly competitive marketplace that was able to maintain some level of profitability producing gas. More

\footnotetext{
${ }^{11}$ Grid drilling involves drilling shale wells a unified grid rather than identifying sweet spots and optimizing productivity per well through reservoir management.
} 

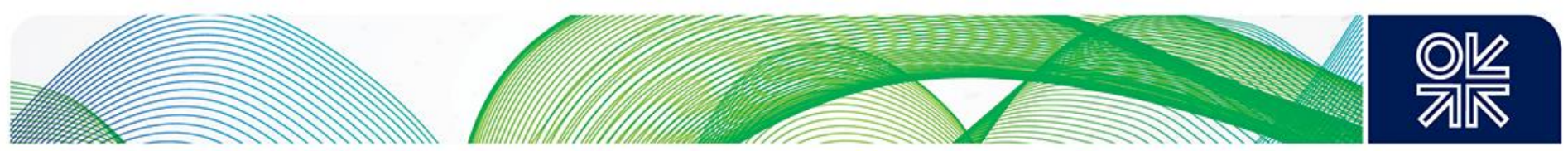

importantly, and detrimental to the oil sands, lessons learned from this shale gas market cycle have shifted into shale drilling for LTO, with a similar level of operating excellence.

\section{LTO producers are faster learners}

Most disturbing for oil sands executives is the pace at which LTO operators are improving their trade. Year over year, LTO producers are delivering lower drilling costs, longer laterals, and enhanced productivity that are all driving down supply costs. Plotting the WTI equivalent supply cost trends for the oil sands against LTO basins in Figure 22 reveals a stark contrast. The oil sands experienced rapid cost inflation through 2013 (roughly 10 per cent per year), while LTO costs are dropped sharply. The only reduction for oil sands projects came in 2014 (a larger drop will be seen in 2015) due primarily to the fall in the CAD to USD exchange rate. LTO operators in the US do not have the same buffer to protect them from low crude prices, but they have nevertheless managed to lower supply costs.

\section{FIGURE 22: SUPPLY COSTS OF OIL SANDS VS. LTO (WTI IN USD\$, NOMINAL)}

Canadian Oil Sands

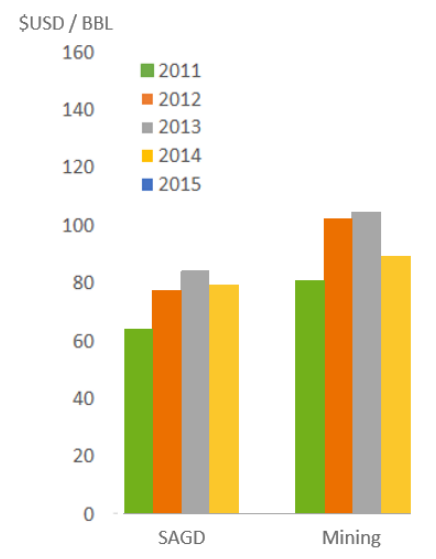

US Tight Oil

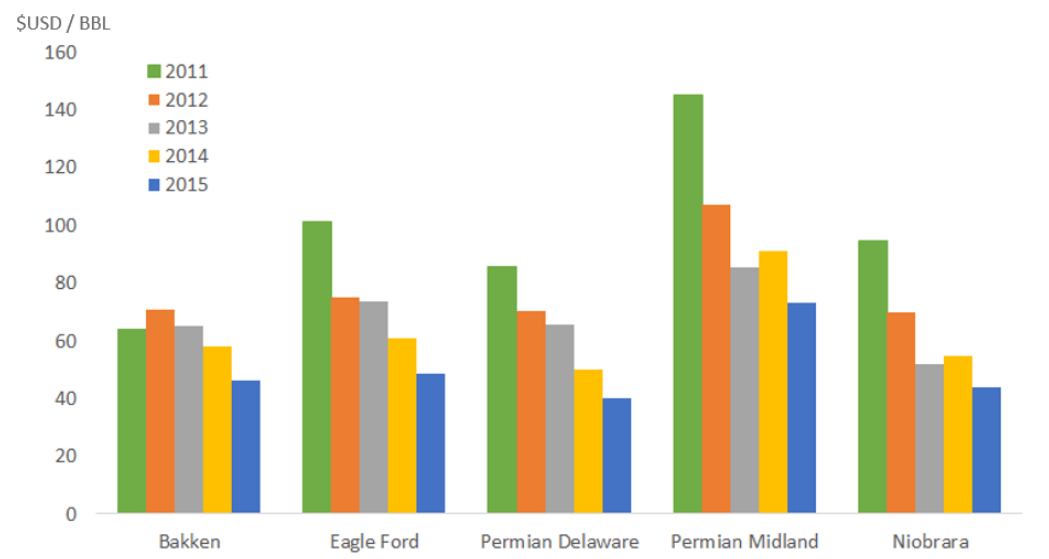

Sources: CERI; Oil and Gas Journal, July 2015. 


\section{Economic attractiveness and growth outlook}

\subsection{Fleeing investors}

After a bull run on oil sands stocks lasting from the early 2000s until the global financial collapse, oil sands investments have handed investors, on average, a substantial loss over the past nine or ten years. This is shown rather starkly in Figure 23, which compares the IShares Oil Sands Index, a weighted 'exchange traded fund' (ETF) of major producers (excluding conglomerate majors such as Shell and Total) against US (S\&P 500) and Canadian (TSX) stock market benchmarks. ${ }^{112}$ Investors have been fleeing oil sands stocks since 2011, well before the collapse of crude price in mid-2014. BlackRock Asset Management decided to close the oil sands ETF in August of 2015 in a tell-tale sign of investor disinterest in the commodity markets and the oil sands specifically.

\section{FIGURE 23: SHARE PRICE PERFORMANCE OF OIL SANDS STOCKS VS. MARKET INDICES \\ Share Price}

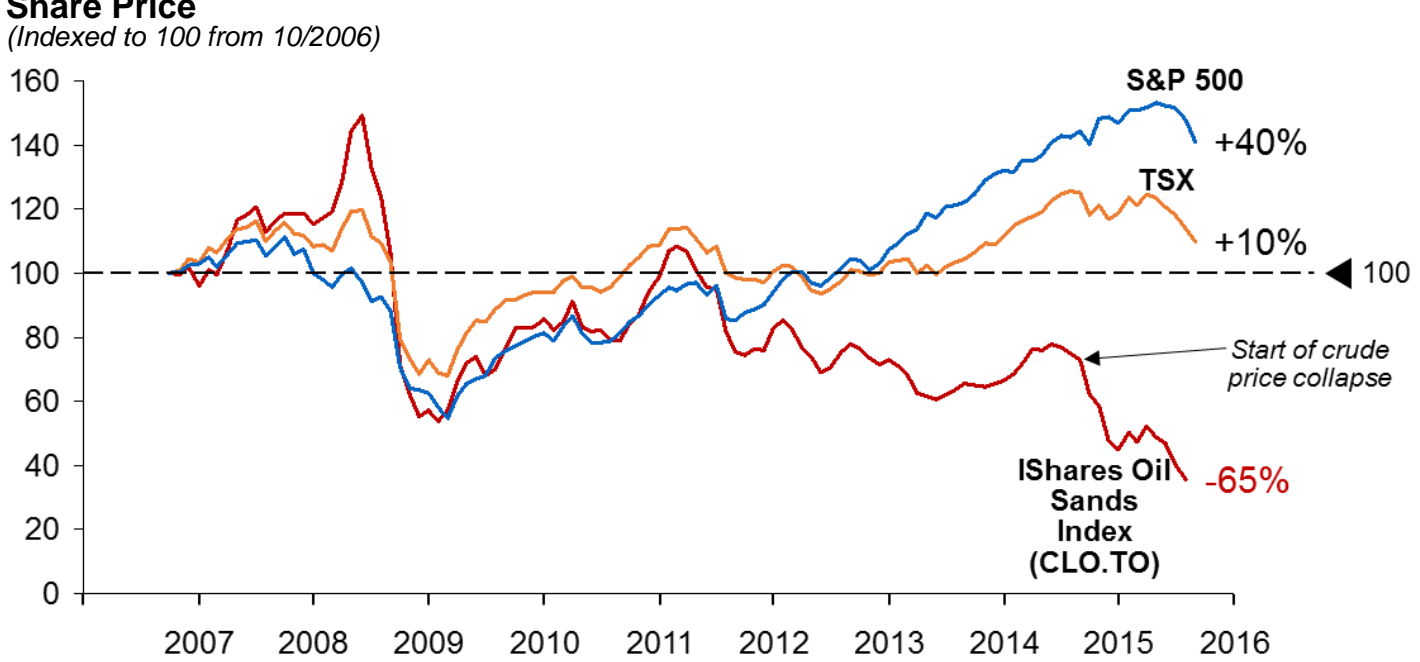

Sources: Bloomberg; IShares Canada, August 2015.

\section{Who invests in the oil sands?}

Markets are evermore interconnected as globalization and the information technology revolution continues relatively unabated - investors have many options of geographies and industries to choose from. One might ask, then, why would investors risk their capital on one of the highest-cost oilproducing basins in the world that sells crude to market for what is often the lowest crude price in the world?

\section{The long-game}

Oil sands investment is a long-term endeavour. Unlike conventional deposits of crude, increasingly challenging to discover in countries that allow private investment, the reserves of oil sands are well known and massive. The recoverable reserves, especially those to be produced in-situ through SAGD, appear inexhaustible in the minds of even long-term thinking investors, who are thinking decades in advance. This long-term certainty is attractive to large-magnitude sources of investment (often in the tens of billions of dollars) from pension funds who are attracted by dividend paying stocks, majors concerned about long-term reserves, and foreign governments (through their national oil companies) looking for crude oil energy security as their domestic needs grow. ${ }^{113}$ In addition, there

\footnotetext{
112 The IShares Oil Sands Index ETF is made up of 14\% Suncor, $12 \%$ CNRL, 11\% Imperial Oil, $9 \%$ Canadian Oil Sands, $9 \%$ Cenovus Energy, 8\% MEG Energy and portions of smaller players including Blackpearl Resources, Athabasca Oil, Bayex Energy and Husky Energy Canada. Though the IShares index shown is somewhat handicapped by the fact that dividend payments are not included (averaging around 1.6\% annually as of 2014), the contrast is nonetheless remarkable. Some individual stocks, such as Suncor, have performed much better than the index.

${ }^{113}$ A few oil sands producers and midstream companies, including Canadian Oil Sands (a major shareholder in Syncrude), were able to benefit from the Canadian 'Income Trust' structure until 2011. The structure allowed companies to pass profit directly to shareholders without paying corporate tax.
} 

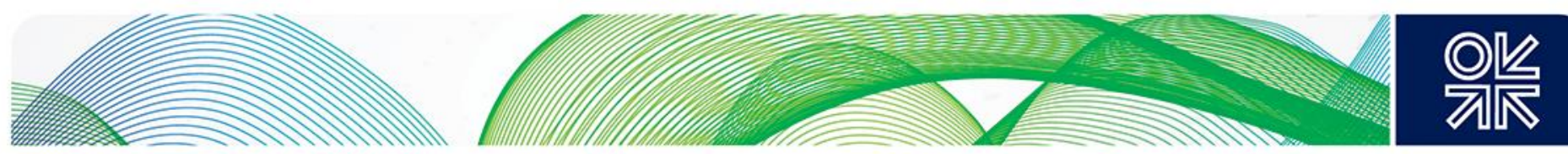

is the upside promise, whether realistic or not, that technology will change the game for oil sands production and that supply costs will sooner or later drop drastically. In this light, accumulating reserves makes a lot of sense for long-term investors. Even famed investing guru Warren Buffet, the CEO of Berkshire Hathaway who has a well-earned reputation for successful long-term investing strategies, has enlarged his company's ownership of Suncor Energy (now a little under 2 per cent).

Domestic vs. foreign

Investors from all over the world are attracted to Canada's political and legal stability, especially when compared to other major crude basins in South and Central America, Russia, Africa, and the Middle East. Canada is one of the least corrupt nations in the world (as judged by Transparency International and highlighted in Figure 24). Outside of Norway's declining North Sea basin, and the US, which will remain a net importer of crude for some time, Canada acts as a stable and ethical 'beacon of hope' for international oil investors looking to export. This reputation attracts investors who are averse to the risks inherent in less stable regions.

\section{FIGURE 24: GLOBAL CORRUPTION INDEX, HIGHLIGHTING MAJOR OIL EXPORTERS}

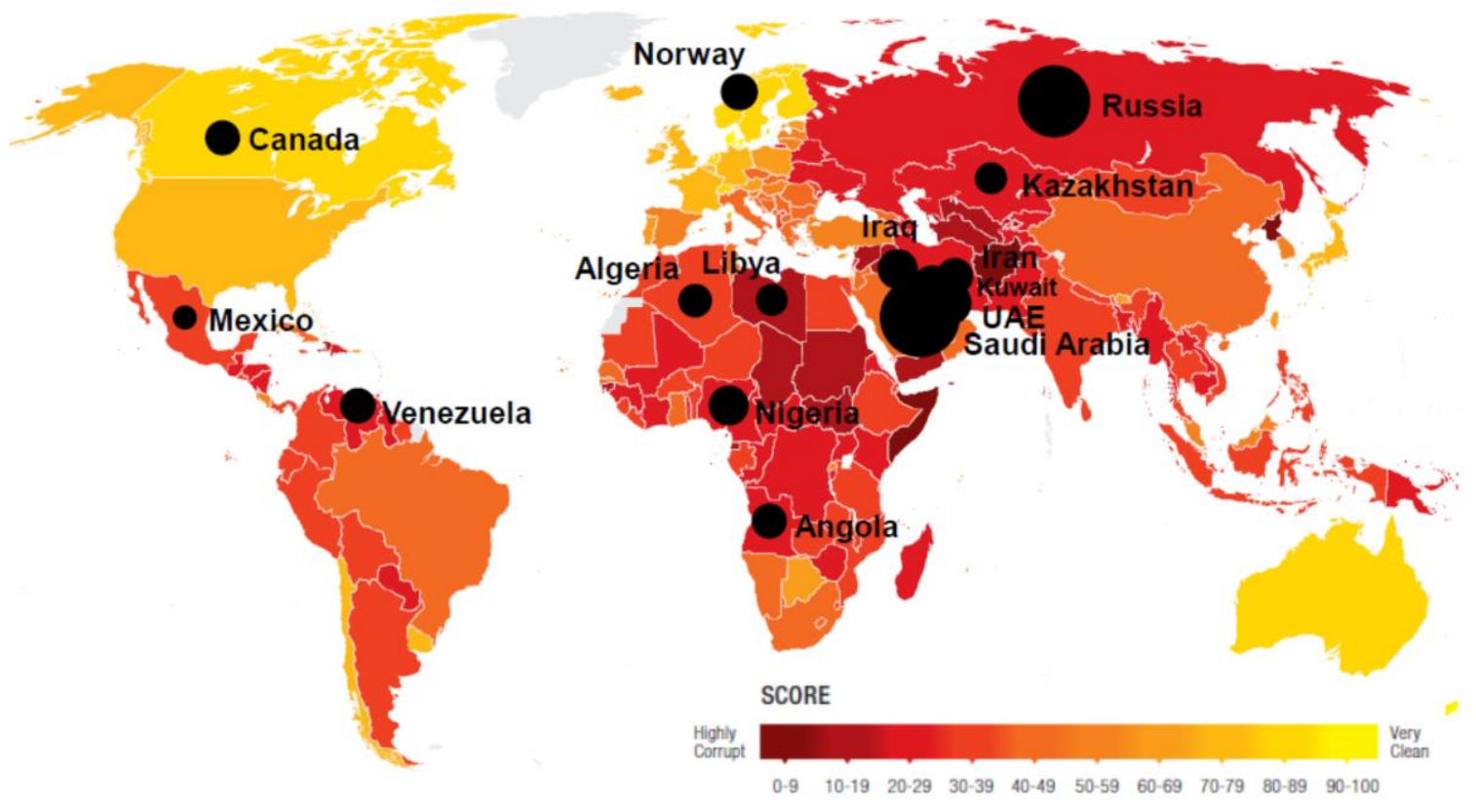

Sources: Transparency International; ARC Financial (black labelling).

In an effort to drive public opinion against growth, an oil sands opposition group concerned about protecting Alberta's forests estimated in 2012 that more than 70 per cent of the oil sands production ownership was foreign, though foreign entities only controlled 24 per cent. ${ }^{114}$ On the whole, however, much of the production ownership is as how it has traditionally been for decades - mostly split between investors based in Canada and the US (remember that mining pioneer Suncor was once a subsidiary of US energy firm Sun Co.).

Global majors such as Shell, Chevron, ConocoPhillips, and ExxonMobil (through Imperial Oil) began playing a bigger role through their Canadian offices as the projects became more attractive. European majors Total and Statoil jumped on the bandwagon a few years later as the global price of crude rose. Several have made quick exits however - Total, Statoil, and ConocoPhillips have all retreated to some extent in the past few years from their audacious initial plans.

More recently, Asian investors seem more bullish on the oil sands than anyone else. Following the financial crisis and amid uncertainty about global oil supply, Asian NOCs accounted for roughly onethird of acquisitions in 2009 and 2010. Much of this investment is from China, through its NOCs Sinopec, CNPC, and CNOOC. Their government mandates and strong financial backing allows them

114 De Souza, Mike. 'Majority Of Oil Sands Ownership And Profits Are Foreign, Says Analysis'. The National Post, 2015. 
to suffer through unprofitability for longer than the traditional majors and certainly longer than small capitalized Canadian companies. Worried about relinquishing the geopolitical advantages of its oil sands following CNOOC's CAD $\$ 15$ billion acquisition of Nexen in 2012, the Canadian government banned major controlling acquisitions of oil sands operators by foreign state-owned companies, especially those from non-democratic nations. This has caused Asian NOCs to take smaller, noncontrolling ownership stakes, purchase a number of smaller operators, and/or build up capacity organically with their own companies.

\title{
LTO is more attractive to investors
}

For much of the first decade of the twenty-first century, most major investments in North American oil were either aimed at Canada's oil sands or offshore of the US Gulf Coast, which are both costly and difficult sources of oil. This changed rapidly, however, with the emergence of US light tight oil (LTO). Never before has so much oil been added to global supply so quickly from a new source of oil.115 During arguably the fastest industrial expansion in Canadian history, the oil sands added roughly 1.5 million bpd over the last 10 years, while in just the last five years, the LTO revolution has added almost 5 million bpd to the US production total. Indeed, the oil sands have a formidable 'new kid on the block' competitor in US light tight oil, which is undoubtedly one of the factors behind the diminishing investor interest in the oil sands since 2011.

The ability to drill and complete wells rapidly (within weeks) and the inherent large production declines after the first year or two of operations, makes LTO production a much shorter term investment compared with long-life (and long construction period) oil sands projects. Producers and their investors have much more certainty in knowing that the bulk of their positive cash flow will arrive in a few months, rather than over the next ten to twenty years. Consequently, drilling into shale geologies has created a much more dynamic and nimble landscape of producers than those operating in the oil sands. This higher of level of competition among LTO producers drives further cost efficiencies and ingenuity. Without rapidly adapting, operators can go out of business very quickly - the efficiency of operations evolves at a much quicker pace for LTO than the oil sands.

\section{Risk vs. return}

Few other industries burden their investors' capital with as much risk as oil and gas production. A typical project economic analysis must confront the daunting uncertainty in subsurface reservoir characteristics, capital costs, scheduling delays, regulatory changes, and commodity price, each of which can make or break final investment decisions. As a result, investors expect higher rates of return than investing in less risky ventures such as a power plant or pipelines with a guaranteed rate structure and more standardized engineering designs.

Oil sands production endeavours can be even more risky than conventional production. Major mining and SAGD project builds must grapple with sizeable fluctuations in the labour markets, capital project delays and overruns, uncertain regulatory burden, bottleneck-related price discounts, volatile energy input costs (natural gas), and - worst of all - long project lifecycles. For example, predicting the future price of oil is always challenging, but it is certainly easier to forecast for the next 10 years, the most productive and relevant period for an LTO project, than for the next 25 years or more, the relevant lifecycle in an oil sands project. Oil sands projects can take five years or more to just come online, while this is just a few months for LTO. Shell CEO Ben van Beurden called attention to these risks after Shell suspended its 80 thousand bpd Carmon Creek SAGD project in October 2015, despite having already sunk CAD $\$ 2$ billion into the project:

\begin{abstract}
[Carmon Creek was subject to] a very, very wide range of outcomes... It was basically a clear, straightforward economical decision. So many things had sort of moved against the project economically and so much uncertainty had crept into it on the financial outcomes, that with a tightening of the cash balances within the company, the more sensible thing was to shelve it. ${ }^{116}$
\end{abstract}

The question then becomes: even if the oil sands can reduce its supply cost enough to equal that of LTO, its continuously improving competitor (for a prescribed rate of return), why would investors

\footnotetext{
${ }^{115}$ Saudi Arabia rebuilt its production volumes starting in 1985, after massive productions cuts in the early 1980s when it played the role of the world's swing producer

${ }^{116}$ Lewis, Jeff. 'Shell Says It Halted Oil Sands Project Over Pipeline Uncertainty'. The Globe and Mail, 2015.
} 
choose the energy source with substantially more risk? Unless investors have a predisposed focus on energy security, unlikely in today's oversupplied global crude market, oil sands projects will need to become cheaper than LTO projects to be competitive.

\section{Shareholders losing patience}

The current low-price environment for oil and commodities in general is certainly a roadblock for operators throughout the world trying to raise capital and grow production. But even before the global price collapse, shareholders were becoming disenchanted with the performance of the oil and gas industry in Canada. Remember that the estimates of supply costs shown in this paper, as well as in financial research and public newspapers, are typically based on a 12.5 percent nominal rate of return, with the assumption that capital costs come in at the budgeted amount. Cost escalation and overruns are common, however, and this has led to disappointing returns on an industry-wide average.

In an effort to prevent further royalty and regulatory cost burdens on the oil and gas industry, CNRL president Steve Laut presented a version of Table 6 to the newly elected NDP provincial government in the summer of 2015. The poor performance of the oil and gas sector at returning capital is glaring, especially considering the high WTI prices in 2012 and 2013 versus today. The numbers will likely look significantly worse for 2014-15; although considered one of the better performers, CNRL notes that despite having a 10 per cent return on capital in 2014, it is forecasted to drop to negative 1.9 per cent in 2015. Laut made the case that because producers are already laden with high costs, and struggling to return the profits that shareholders expect, Alberta's oil and gas industry (in many ways driven by the oil sands) cannot both bear further costs and continue to be a major driver of job creation and government revenue for the province.

\section{TABLE 6: RETURN ON CAPITAL ACROSS INDUSTRIES IN THE CANADIAN ECONOMY}

\begin{tabular}{|l|l|l|}
\hline By Industry & 2012 & 2013 \\
\hline Arts, Entertainment \& Recreation & $39.2 \%$ & $30.7 \%$ \\
\hline Agencies / Brokers & $14.7 \%$ & $15.3 \%$ \\
\hline Alcohol \& Tobacco & $10.5 \%$ & $11.2 \%$ \\
\hline Insurance Companies & $12.8 \%$ & $10.6 \%$ \\
\hline Construction & $9.4 \%$ & $8.9 \%$ \\
\hline Agriculture & $8.3 \%$ & $8.0 \%$ \\
\hline Forestry & $7.4 \%$ & $7.4 \%$ \\
\hline Banking & $6.1 \%$ & $6.1 \%$ \\
\hline Mining & $3.3 \%$ & $2.9 \%$ \\
\hline Pharmaceuticals & $4.9 \%$ & $2.8 \%$ \\
\hline Canada / Alberta Oil and Gas & $\mathbf{1 . 4 \%}$ & $\mathbf{1 . 0 \%}$ \\
\hline (WTI Price, \$USD) & $\$ 94.19$ & $\$ 98.00$ \\
\hline All Canadian Based Industries & $\mathbf{6 . 3 \%}$ & $\mathbf{6 . 4 \%}$ \\
\hline
\end{tabular}

Source: Statistics Canada.

Larger operators like Suncor, Husky, and Cenovus have attracted investors with their downstream asset diversification, creating a buffer of refining profits in periods of low oil price and losses on the production side. The recent cost cutting and operational improvement efforts of operators is also applauded by investors, though they cannot seem to come fast enough. Major M\&A activity will likely continue such as the initially hostile, but eventually mutually agreeable, takeover of Canadian Oil Sands' interest in Syncrude by Suncor. ${ }^{117}$

\section{The divestment movement}

Newspaper headlines have somewhat exaggerated a growing movement among universities, churches, family trust funds, and other groups to divest from all fossil-fuel investments, especially

\footnotetext{
117 The finalized takeover bid will give Suncor 49\% control of Syncrude (making it by far the largest shareholder), allowing it to better implement its cost cutting and operational improvement capabilities.
} 

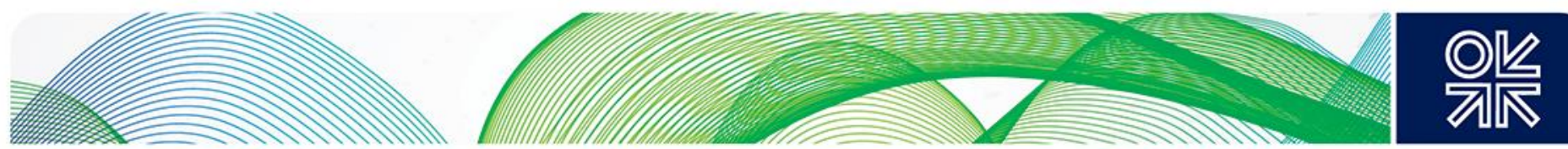

those in the oil sands - at times decried as harmful as coal by the activists. The movement has had relatively little effect to date outside independent groups and Hollywood celebrities; major groups to make divestment declarations so far include the University of California, Oxford University and, more notably, the Rockefeller Brothers fund, a family financial legacy from oilman John D. Rockefeller. However, these multibillion-dollar funds had very little of their capital invested in the oil sands in the first place, and though the student activist fervour continues to try to sway the fund managers of major endowments at Harvard, MIT, and the University of Toronto, the movement overall is unlikely to create measurable impact when compared to the underlying economics of oil sands production.

\subsection{Projects in development}

\section{Announced projects}

Wanting to demonstrate growth prospects to investors, oil sands producers tend to announce many more projects than they end up building. Figure 25 summarizes the in-situ dominated 5,212 thousand bpd of capacity in projects currently announced (not including those officially cancelled or shelved). Of these announced projects, only 479 thousand bpd are listed as under construction as of November 2015.

\section{FIGURE 25: OIL SANDS PRODUCTION CAPACITY (NEW AND PROPOSED)}
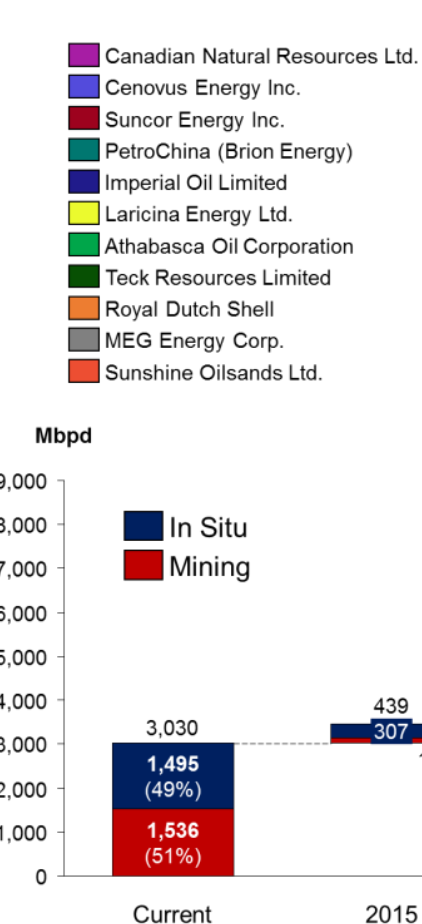

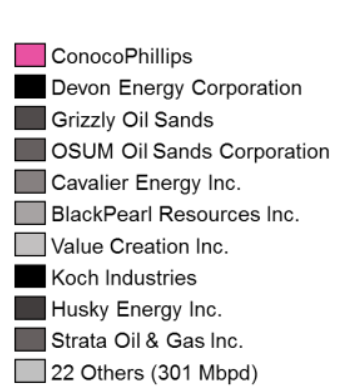

22 Others (301 Mbpd)
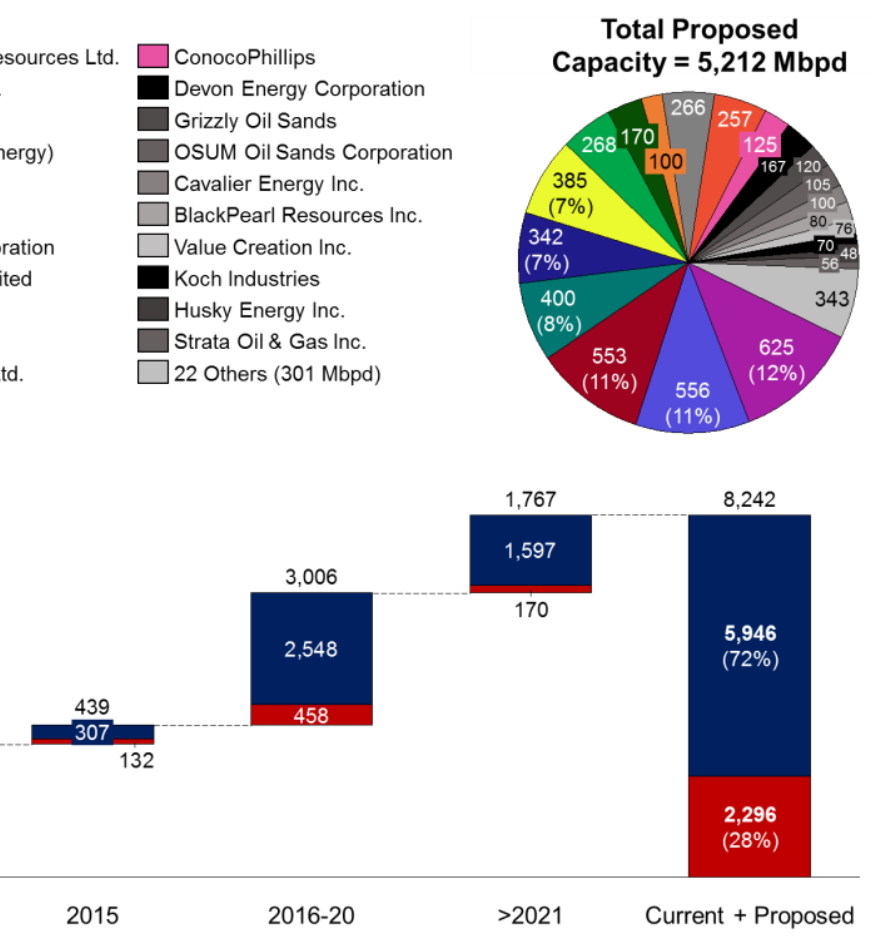

Announced Onstream Date

Source: Oilsands Review Datasets (November 2015).

The major additions proposed are from the current major players - CNRL, Cenovus, Suncor, and Imperial, with the notable addition of Brion Energy (owned by Chinese NOC PetroChina) which has high aspirations of SAGD growth. Some of these announcements, though not officially cancelled, have little chance of coming to fruition in the near term.

\section{Cancelled and shelved projects}

Major withdrawals have occurred both before and since the 2014 crash of crude prices, though project cancellations and suspensions are becoming more common (see Figure 26). Shell's shelving of Carmon Creek in October 2015 is the most recent example. As well, while 81 per cent of announced project capacity is for in-situ production, only 56 per cent of cancelled and suspended project capacity is - further evidence of how mining is becoming much less attractive in comparison. Many feel that Suncor's Fort Hills mine (of which Total and Teck Resources are partners) could be the 
last greenfield oil sands mine, especially if costs go as far over budget as previous mega-project mining endeavours. The future looks even grimmer for new upgraders. Economics for upgrading within Alberta remains highly unfavourable, and there are presently no upgrading project plans with an announced start date.

\section{FIGURE 26: SUSPENDED OR CANCELLED PRODUCTION PROJECTS (SINCE 2011)}

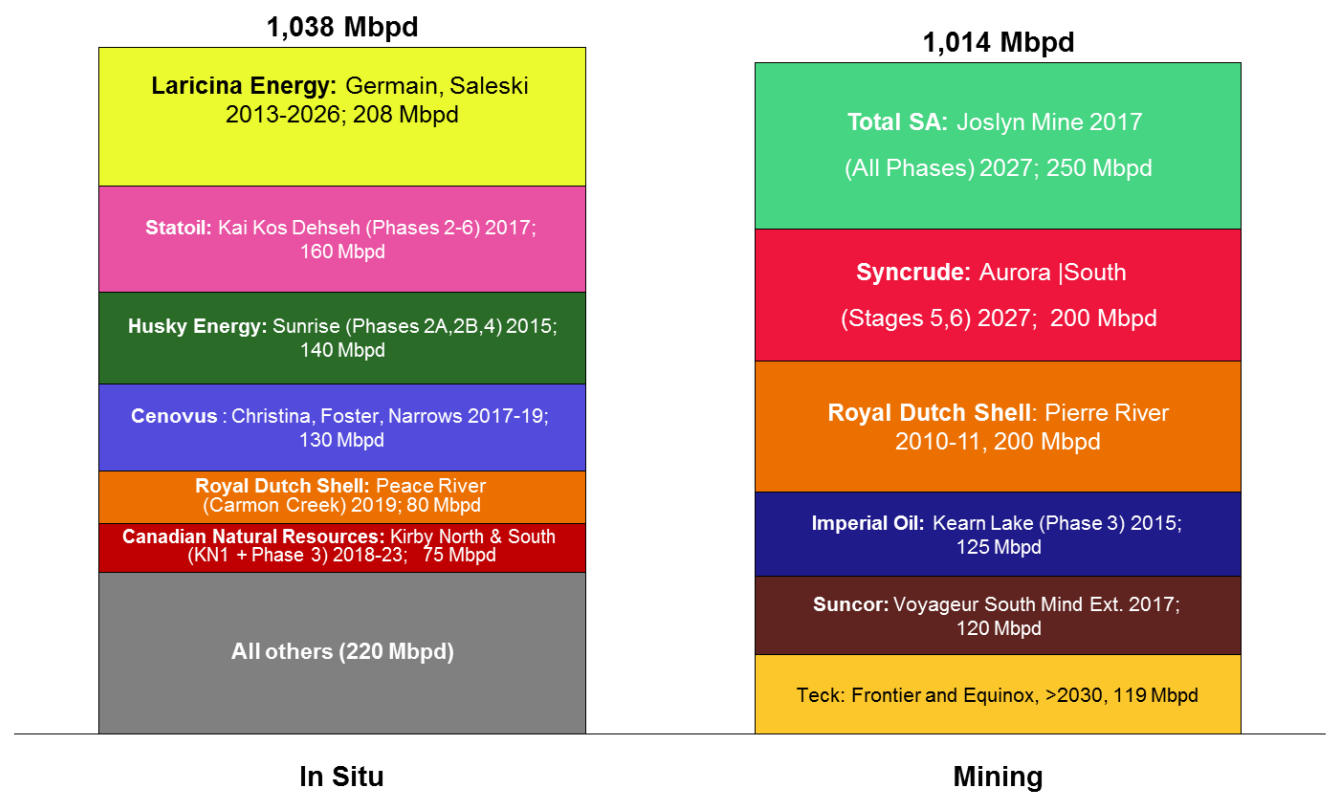

Source: Oilsands Review Datasets (November 2015), Author analysis.

\section{Fundamental changes are needed}

Barring a major oil price recovery to $\$ 80-100 \mathrm{WTI}$ in the next few years, major changes are needed to make many of these announced projects economically attractive enough to pass a final investment decision review:

1) Oil sands producers, service companies, and suppliers need to become drastically more cost-efficient in their operations through better processes and lower wages. This will likely arise out of a necessity for survival. Negotiating power needs to shift from contractors and suppliers back to where it sits in most industries with healthy economics: the buyer.

2) Technology needs to be developed and used effectively, yet judiciously, to improve reservoir productivity and production processes. An entrepreneurial, venture capital-type approach is needed within large producers and external technology developers to be able to compete with the continuing improvements of LTO projects. Research should be a major focus of both government and industry in dedicating resources to developing both near-term gains and longer-term game-changing technologies.

3) Certainty is needed around regulatory costs (royalties, carbon pricing, and other environmental controls) and access to markets through new pipelines. Producers and their shareholders will remain justifiably hesitant to go forward on new projects otherwise.

\subsection{A cautionary approach to growth predictions}

\section{Inherent uncertainty}

The oil sands future has always been blurry at best. Since the resource was first considered useful and exploitable by early European explorers and geologists, there have been fluctuating periods of high hopes and disappointment, boom and bust, audacity and anxiety. As it is rational to think these fluctuations will continue, the reader should take the production growth forecasts shown here, or elsewhere, with an ounce of scepticism. Each of the fundamental drivers of new production growth price, cost (including technology), egress, and regulation - are driven by a variety of underlying 
factors that can change within just a few months, so much so that evaluating each one more than five years in the future can seem futile.

\section{FIGURE 27: IN-SITU OIL SANDS PRODUCTION FORECAST BY THE NEB IN 2000, 000 B/D}

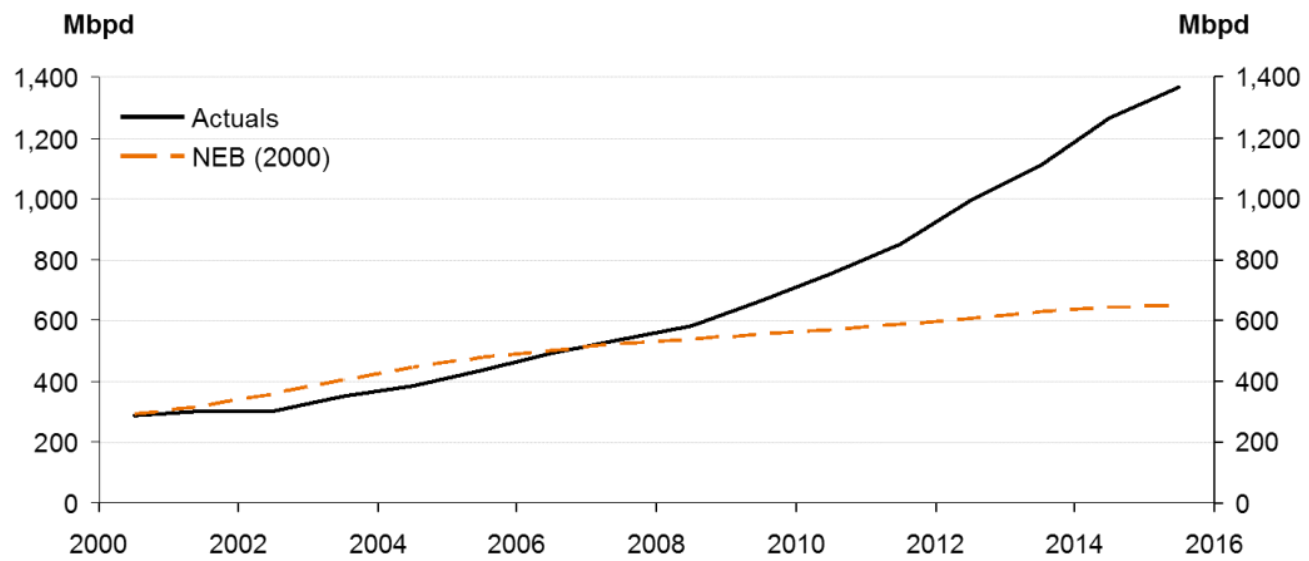

Sources: Alberta Energy Regulator; National Energy Board of Canada (2000).

FIGURE 28: OIL SANDS PRODUCTION FORECASTS AND ACTUALS, 000 B/D

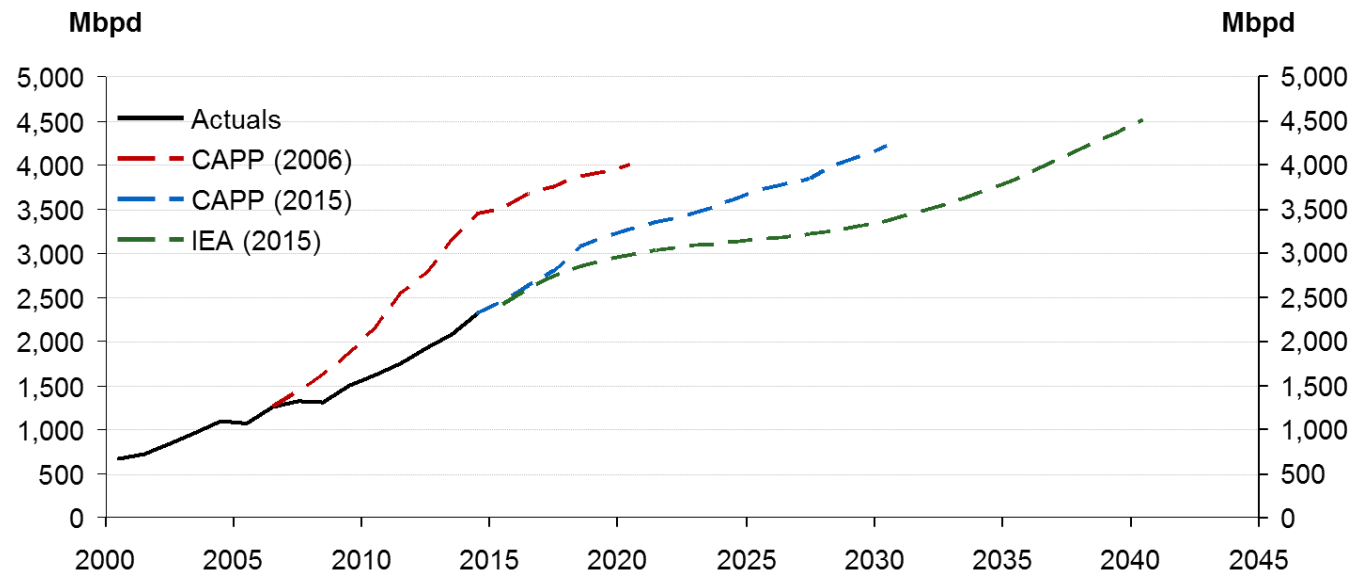

Sources: Alberta Energy Regulator; CAPP (2006, 2015); IEA (2015). ${ }^{118}$

Humbling examples of analysts' inability to forecast oil sands production are shown in both Figure 27 (an in-situ forecast from the National Energy Board in 2000 assuming oil price was to stay at $\$ 18$ per barrel) and Figure 28 (forecasts from CAPP and IEA going forward). For example, just within the past year, forecasts of oil sands production rates in 2030 have fallen by 1 million bpd or more due to the drop in crude prices.

It is interesting to note in Figure 28 that there seems to be a substantial difference between the CAPP and IEA 2015 forecasts: CAPP, like other industry groups or industry-funded consultancies, may have a bias towards a more bullish growth trajectory. It is also clear that the growth of LTO and resulting oversupply has greatly dampened oil sands production projections versus earlier predictions like CAPP's in 2006, for example. Accordingly, the IEA is rather dour on oil sands projects being built just after 2020, when those already under construction are completed. Nonetheless, the agency predicts a return to high growth rates from 2025-2040 when LTO production flattens out and declining global conventional supply needs to be supplemented.

\footnotetext{
118 Taken from the "New Policies Scenario"
} 

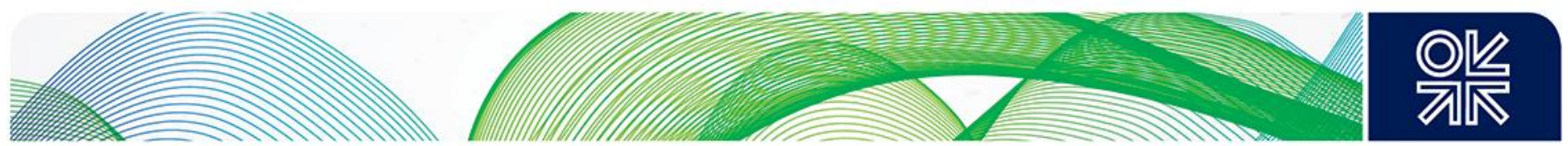

\subsection{Where will the oil sands fit in the global supply mix?}

With the above caveat of uncertainty, this paper will attempt to bring some foresight to oil sands production trends, if somewhat qualitative in nature. The sheer magnitude of the reserves contained in the oil sands is a recurring theme in this research, and this is what has fascinated oil futurists for more than 100 years. This fascination ebbs and flows with concerns about global supply and perceived technological breakthroughs - we are currently at the ebb portion of the analogy; the proverbial receding tide has washed much of the interest for rapid oil sands production growth out to sea. When and how much fervour returns among investors, supermajors, and NOCs to expand oil sands production is uncertain, but to some extent we can use what we have learned over the past 50 years of oil sands growth and, when combined with insights from near and long term economic drivers, make some high-level prognostications.

\section{FIGURE 29: CURRENT SUPPLY (BREAK-EVEN) COSTS OF NEW SOURCES OF OIL}

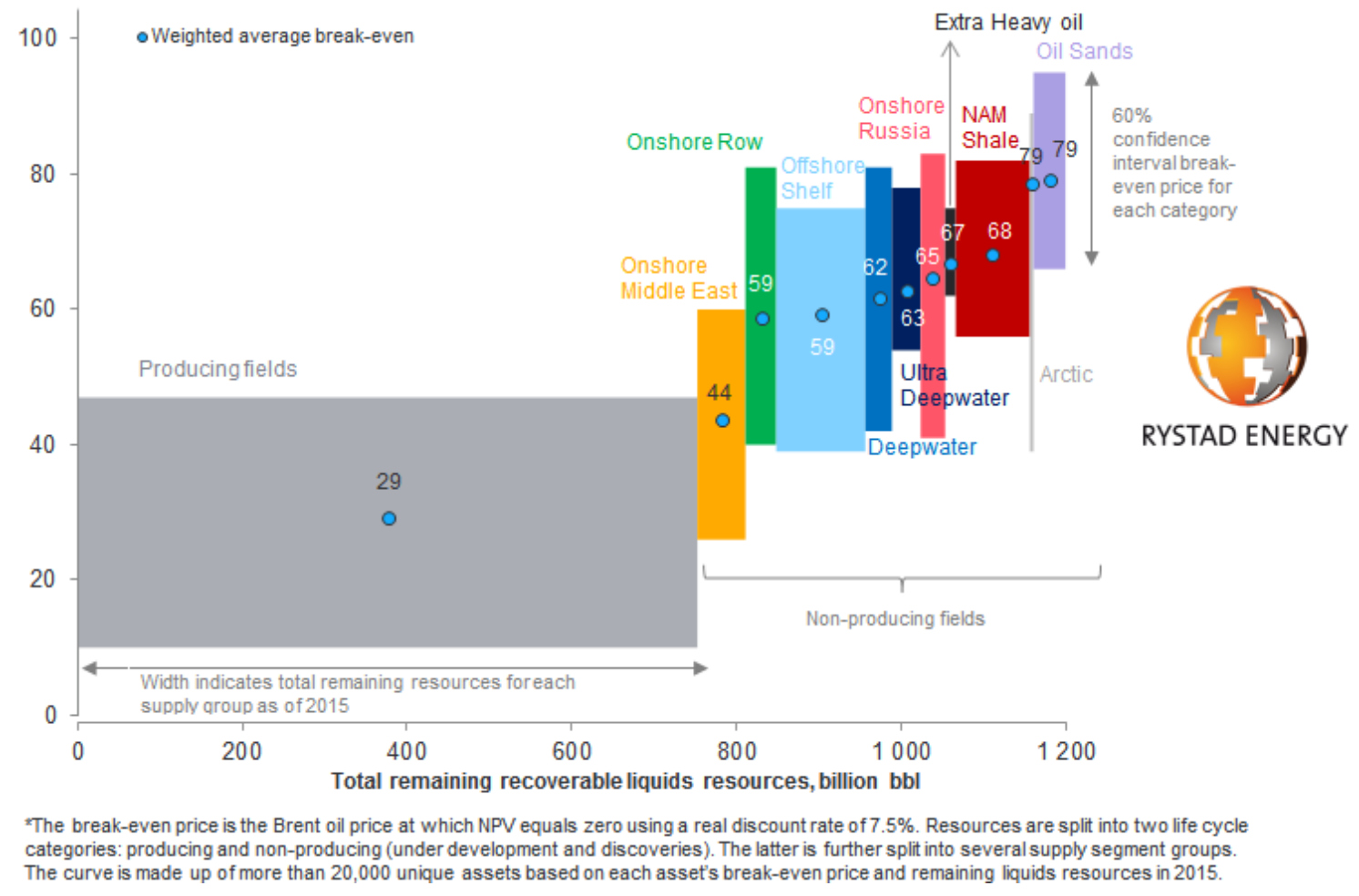

Sources: Rystad Energy UCube, September 2015.

The near term (until 2025)

Canada's oil sands are considered currently by many as the highest, large-scale source of global crude production (see Figure 29 for a September 2015 analysis, though costs are likely lower in January of 201 for a September 2015 analysis, though costs are likely lower now in January of 2016). This does not bode well for oil sands growth in the relatively oversupplied world of the next few years. Though there are clear-cut opportunities to substantially bring down production costs, other competing sources are also lowering costs and opening market access - US light tight oil and Iran's muzzled conventional production are two examples. Even costly deepwater projects are reducing their field development times from the traditional seven years down to three, especially in North America. ${ }^{119}$ 


\section{Unavoidable retrenchment}

Many are predicting, and this author agrees, a marked slowdown in capacity construction until either the global crude price returns to consistent levels at perhaps $\$ 80$ or above (forecast by the IEA to occur around 2020) or producers can demonstrate drastic and sustainable reductions to their costs structures. Investors and executives will likely need both given the poor economic performance of many of the projects built in the past decade, not to mention current projects under construction that planned for oil prices above $\$ 80$ or $\$ 90$. Regulatory and egress uncertainty adds additional burdens to already economically unattractive near-term growth opportunities.

Finding capital for oil sands projects, whether directly from public markets, or at the executive level of supermajors and NOCs, is harder now than just two years ago and much harder than it was 10 years ago during the expansion frenzy. Much of the capital spent on the oil sands in the coming years will be aimed at sustaining current levels of production rather than building new capacity, given that investors are now more acutely aware of uncertainty. Furthermore, the short lead-times for US light tight oil and Iraqi projects (highlighted by the IEA in Figure 30) are able to keep price increases buffered with rapidly responding supply, at least to a certain extent.

\section{FIGURE 30: LEAD TIMES FROM FID AND PRODUCTION OF VARIOUS SOURCES}

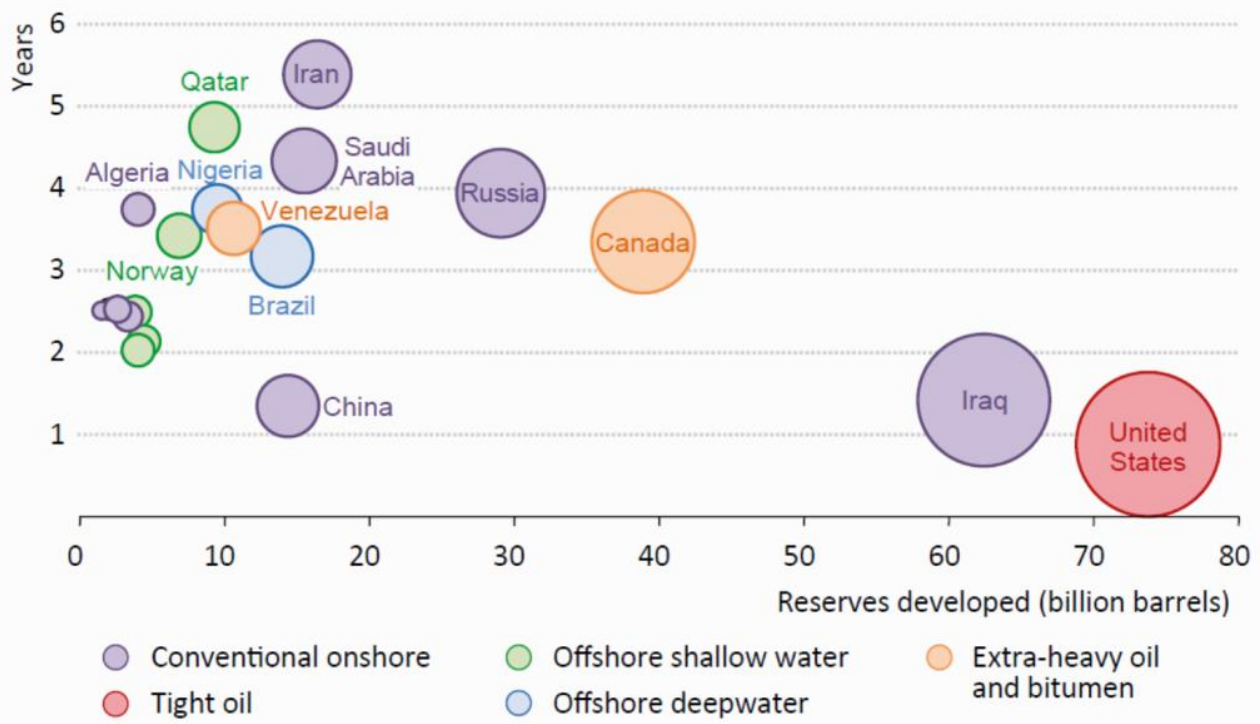

Source: International Energy Agency (2015).

\section{From ebb to flow}

However, beyond 2020 it is likely that oil sands production will ramp back up more quickly than the IEA has predicted in its base forecast. Near-term pain borne by producers and suppliers will translate to more competition and efficiency, and much lower costs. Production technologies and processes, especially in SAGD, will have to improve out of necessity for producer survival, though the outlook for mining growth still looks grim with high costs and tailings management challenges. Confronting major deficits and awakening to the economic importance of the oil sands, the Alberta and federal governments will bring regulatory certainty for carbon pricing and royalties. The egress problem will eventually be solved, with evidence-based scientific, engineering, and economic arguments outweighing those of the activists. More importantly, prices will likely begin to rebound as indicated by the IEA's Fatih Birol, who has cautioned over crude energy security:

It would be a grave mistake to index our attention to energy security to changes in the oil price... Now is not the time to relax. Quite the opposite: a period of low oil prices is the moment to reinforce our capacity to deal 
with future energy security threats. [The global oil industry needs to invest $\$ 630$ billion] just to compensate for declining production at existing fields and to keep future output flat at today's levels. ${ }^{120}$

Most importantly, with price likely to recover (at some point in the next ten years anyways), investors will be more likely to look at new growth projects.

\section{The long term (beyond 2025)}

\section{Price}

Like any energy source, sufficient demand through the form of relatively high prices, say above $\$ 70$ in today's dollars, will likely be a major driver of oil sands growth over the long term. Certainly, predicting crude prices for the next two or three decades are beyond the scope of this paper, though there are some fundamental themes underlying most of the published forecasts and analyses that are worth mentioning here.

From a demand standpoint, consumption savings through improved engine technology and a switch to natural gas and electrified transportation looks to be offset by the billions of new consumers joining the middle class, primarily in Asia, but also in Africa. Such a rise of income and global trade will surely require more demand for transportation fuels, not to mention petrochemical by-products. Accordingly, ExxonMobil and BP both estimate an average demand growth rate in the next two decades of around 0.8 per cent, while the IEA is less bullish on oil demand due to changing climate policies, but still has demand grow by 0.5 per cent annually. The emergence of these new Asian middle-class consumers is somewhat offset by the fact that they proportionately use less crude oil in their energy mix than traditional developed markets.

Not only are new sources of supply needed to meet this growing demand but also to offset declining production of the majority of the world's conventional fields. LTO production will likely level off at some point due to a dearth of new sweet spots to drill, and the world will look to heavier sources like the oil sands and more difficult sources like deepwater and the Arctic to fill the void. Barring a drastic and unlikely drop in demand, price increases will trend upwards to incentivize production.

To be sure, meaningful restrictions on greenhouse gas emissions will have a dampening effect on global demand, but given how much more costly and technically complicated it is to switch away from liquid fuel usage for transportation than it is to switch away from coal usage for electricity, demand for oil will likely still grow to some extent (before flattening). And with the majority of emissions arising from combustion at the tailpipe, emissions from oil sands production are only marginally more damaging than those from other producing basins around the world.

\section{Technology, process, and cost}

In addition to those who flocked to the early twentieth century first strike of oil near Calgary, the province of Alberta was settled by hard-working farmers and ranchers. Albertans, and especially those leading the charge in Canada's oil and gas industry in Calgary, have always prided themselves as an industrious, entrepreneurial, and resilient bunch. The Canadian oil industry has known boom and bust times like all global basins, but it is somewhat unique in its ability to re-invent itself - the development of the oil sands through advancements in process and technology is a strong testament to that.

Despite the current sluggish oil prices, there is every indication that producers committed to the oil sands in the long term will return to global competitiveness through operational improvements and technological advancements. The question is: how quickly and to what extent?

The biggest factor driving the long-term oil sands production outlook is likely technology. Both incremental improvements to current technologies, such as the addition of solvents to SAGD, and lower probability, but more disruptive, technologies such as the use of nanotechnology or microbial organisms, could have major impacts. Sustainable reductions to supply costs are indeed much more compelling to investors and decision makers than oil prices staying high for a decade or more, something that history shows us is inevitably fleeting.

\footnotetext{
${ }^{120}$ Hussain, Yadullah. "'Grave Mistake' To Be Complacent On Energy Security, International Energy Agency Warns". The National Post, 2016.
} 


\section{'Speed limits' to growth}

The past 15 years in Northern Alberta has taught us that there exist a number of limiting factors to how quickly Alberta's oil sands can grow production. As seen even with a seemingly efficient new technology like SAGD, cost escalation, egress challenges, and environmental impact can quickly dampen even the most promising growth scenarios. These burdens will continue to weigh down producers during future boom times in the coming decades, especially without collaborative forethought between industry and government into cost control, environmental considerations, and impact on Aboriginal groups. Without such critical planning, Canada continues to limit its ability to be a major global exporter.

\section{The ultimate marathon}

The magnitude of Canada's oil sands reserves is reiterated here, with the diagram in Figure 31. The acknowledgement that in-situ reserves can be produced through SAGD put Canada on the global radar in the late nineties as a major potential source of future crude production.

\section{FIGURE 31: OIL SANDS RESERVES AMID GLOBAL RESERVES (BILLIONS BBL)}

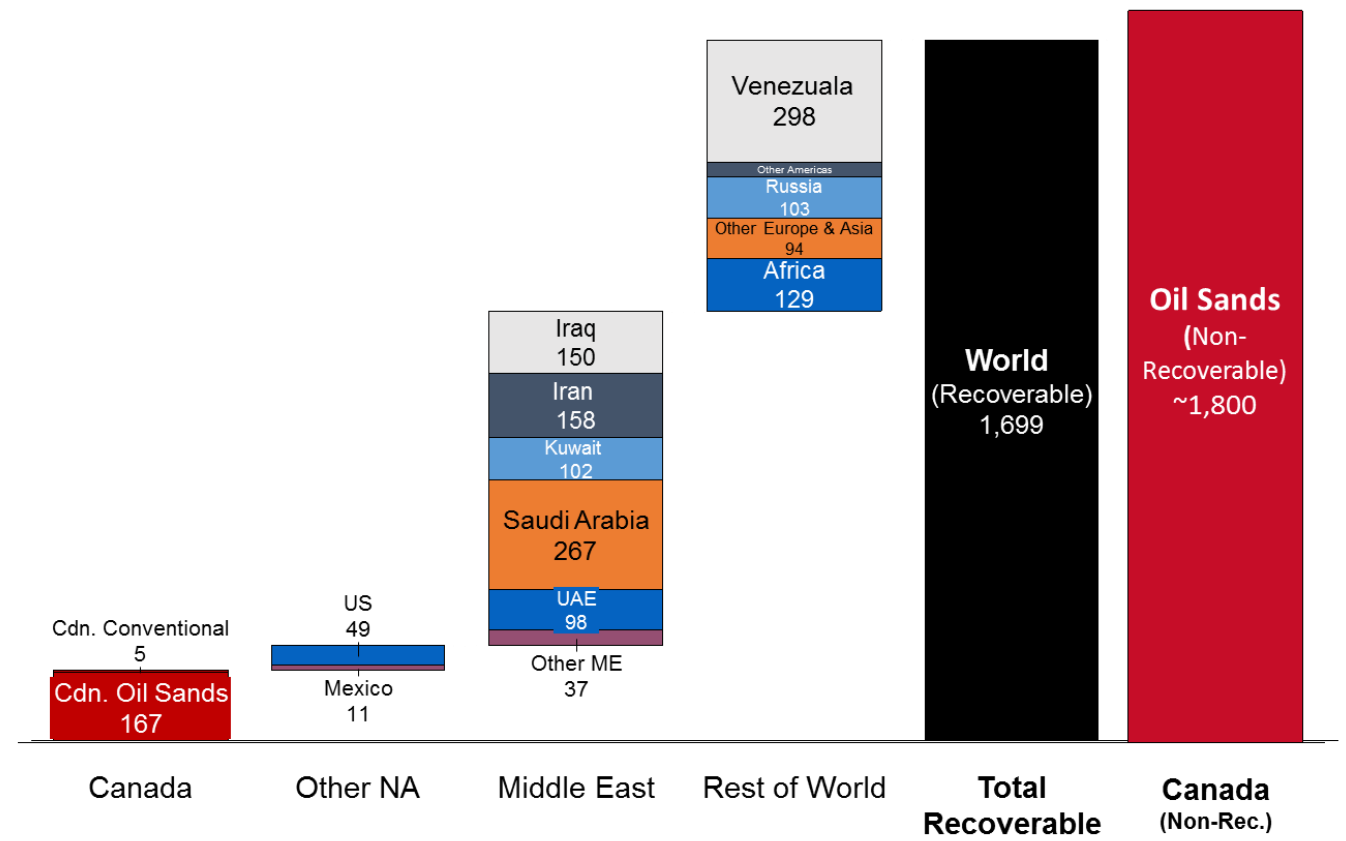

Source: BP Statistical Review, June 2015.

For domestic and foreign investors alike, Canada represents one of the most politically stable regions to place long-term capital. As technology is tweaked, processes improved, and transportation bottlenecks cleared, SAGD (or other in-situ) projects will slowly become more attractive again over the next decade. Technological breakthroughs, such as TAGD technology that uses thermal conduction heating from electrical resistance to produce in the now 'unrecoverable' oil sands carbonates, could very likely add another few hundred billion or so more reserves to Canada's recoverable tally.

In summary, the oil sands is a long-term bet for patient visionaries whose success depends both on the global crude supply and demand fundamentals, and the ability to improve production capability over time. Suncor's Steve Williams summarized the nature of the resource after taking over the CEO role in 2012:

The oil sands business is the ultimate marathon. It requires fitness, endurance, strategic pacing, and discipline. ${ }^{121}$

\footnotetext{
${ }^{121}$ Cattaneo, Claudia. 2015. 'King Of Pain: Steve Williams Seizes On Price Pangs To Prepare Suncor For Oilsands Dominance'. The National Post.
} 


\section{Appendix: Oil sands primer}

\section{A.1 What are 'oil sands?'}

\section{Geologic origins}

The oil constituent of the Canadian oil sands is believed to have been formed through similar processes to conventional oil traps. Research suggests that much of Alberta was covered with an ancient sea from which trillions of microorganisms from the ocean floor decomposed to produce kerogen, buried deeply under high temperatures and pressures. ${ }^{122}$ Tens of millions of years after this organic material was initially deposited in the middle Cretaceous age (approximately 115 million years ago), the tectonic activity that arose from the large Pacific Plate, of what is today the most western Canadian province of British Columbia, advanced westward and created the world-famous Rocky Mountains on the western edge of Alberta (the Banff and Jasper regions). The mountain-building process generated enormous subsurface pressures on the Cretaceous kerogen layers, converting the deeply buried organic material into massive deposits of light crude oil and natural gas. As geologic activity continued, the lighter hydrocarbon mixture moved towards the surface hydrostatically, and because of the existing geological structures including sand deposits that existed on the path of surface migration, the oil lost lighter hydrocarbons along the way and massive biodegradation occurred. The now volume-diminished, high-viscosity oil then came in contact with sands from ancient river beds (such as the Athabasca River), rendering an immobilized heavy oil, sand, water, and clay emulsion. ${ }^{123}$ The industry has now aligned to describe this emulsion as 'oil sands'. They exist in vast proportions in Alberta across the Peace River, Cold Lake, and Fort McMurray deposits as seen in Figure 32. Although oil sands deposits are known to exist in many countries of the world, by far the two largest reserves are in northern Alberta and the Venezuelan Orinoco Belt, each containing comparable volumes of around two trillion barrels of oil in place.

\section{FIGURE 32: THE CANADIAN OIL SANDS HIGHLIGHTED IN THE PROVINCE OF ALBERTA}

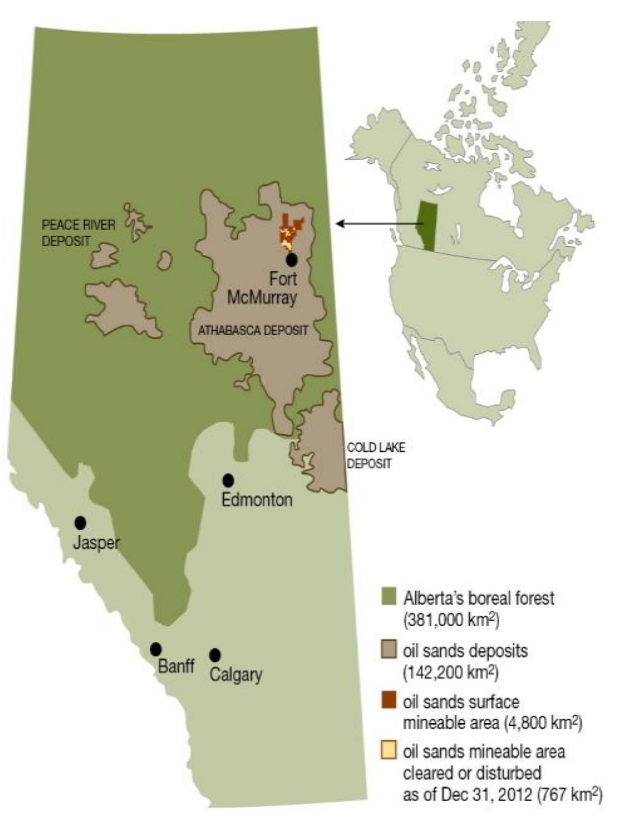

Source: Government of Alberta.

\footnotetext{
122 M.B. Dusseault, 'Comparing Venezuelan And Canadian Heavy Oil And Tar Sands', in Proceedings Of Petroleum Society's Canadian International Petroleum Conference, 2001, 61

${ }^{123}$ Fran Hein, Geology Of The Oil Sands (Association of Professional Engineers and Geoscientists of Alberta, 2013).
} 


\section{Composition}

A visually descriptive representation of oil sand composition can be seen in Figure 33, detailing the water-wet composition of the mixture. Triangular and highly abrasive sand grains composed mostly of quartz are covered with a water envelope containing clay minerals, known as fines. Engulfing this is a film of extra-heavy oil known as bitumen. With an API normally less than $10^{\circ}$, the bitumen that comprises between 1-18 per cent of the volume of oil sands is essentially immobile in the colder reservoirs of northern Alberta (though this is less of an issue in the warmer reservoirs of Venezuela). Increased compositions of fines are associated with more water and less bitumen to produce. However, a minimum concentration of the silt- and clay-based fines (around 3 per cent) is needed to produce commercially, as they act to aid the separation of bitumen and sand. ${ }^{124}$ The fundamental challenge with oil sands mining is that given the relatively low composition of bitumen in the sand, it takes an average of 2 tonnes of oil sands to produce approximately 1 barrel of synthetic or 'upgraded' crude oil with an API around $30^{\circ}$ (vs. Brent at $38^{\circ}$ and WTI at $39^{\circ}$ ).

\section{FIGURE 33: OIL SANDS COMPOSITION}

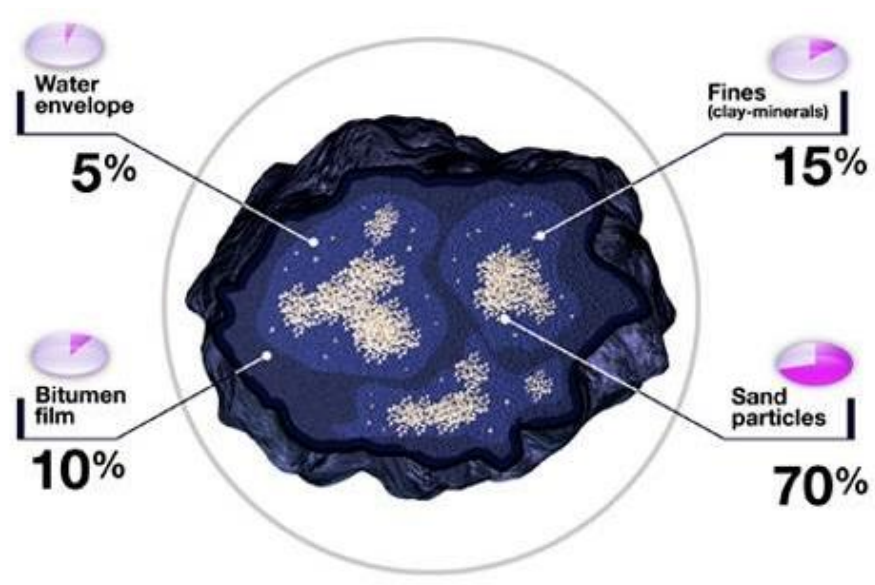

Source: Total Website

\section{Surface or subsurface?}

All three main oil sands deposits are located within Alberta (revisit Figure 32 on the previous page), though other areas of 'lighter' heavy oil with API levels above $10^{\circ}$ can be found within the province and into Saskatchewan, the contiguous province to the east. Well over half of the oil sands are located in the Athabasca deposit, the only portion that contains reserves close enough to surface to be mined - that is, where oil sands constituents are removed en masse and transported to a facility for the bitumen to be separated.

Across the deposits, mineable reserves make up about 20 per cent of the total at the most. Even if all of these reserves were to be produced in the coming decades, only $4,800 \mathrm{~km}^{2}$ of land would be disturbed (and eventually reclaimed). These near or at-surface reserves are essentially frozen solid in the winter months and soften up substantially in the summer with seasonal variations in air temperatures of up to $70^{\circ} \mathrm{C}$.

The remaining 80 per cent of recoverable reserves are at depths varying between 300 and 800 meters $(1,000-2,600$ feet) that require in-situ production - removing the bitumen in the subsurface while the remainder of the oil sand material stays in-place.

\section{A.2 History and technology: 'The Supergiant of the Future,' since 1906}

The anthropological uses of bitumen are thought to go back tens of thousands of years further than that of crude oil, with Neanderthals in what is modern day Syria using the substance as an adhesive 

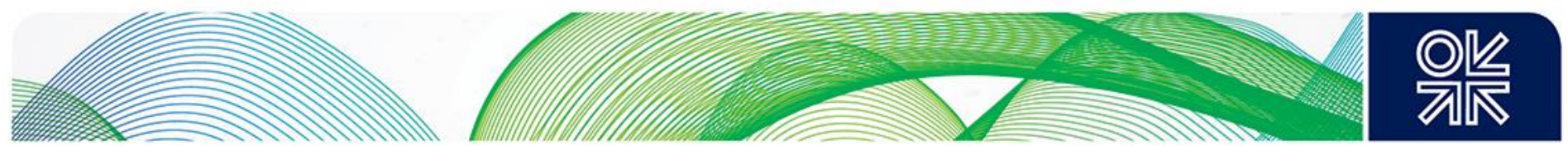

for hunting tools. ${ }^{125}$ Bitumen used for construction and other purposes continued extensively from ancient to more modern civilisations. In fact, well before crude oil became a major global commodity in the 1800s, oil sands were mined at Pechelbronn in Alsace, France in 1741 where heavy bitumen oil was separated from the surface sands using hot water and distillation. ${ }^{126}$

\title{
Aboriginal traditions and European encounters
}

For generations (it is unknown how long exactly), Aboriginal peoples of the Athabasca River region had used surface bitumen to caulk their canoes and to keep pesky mosquitos at bay. These First Nations groups used a basic boiling technique to separate the bitumen from the sands. ${ }^{127}$ Bitumen was considered valuable enough to the tribes that in 1719 an Aboriginal leader named Wa-Pa-Su (meaning 'the Swan') offered a sample of oil sand to the Hudson's Bay Company, a fur trading business and at the time the de-facto colonial government of unsettled Canadian territory. ${ }^{128}$

Later assessments of the region by British explorers peaked interest in the vast deposits that could be seen at the surface. Once a critical mass of settlement began in Alberta in the mid to late 1800s, and kerosene (from oil) became known as a valuable commodity for lighting, geological surveys were commissioned to the oil sands with auspicious findings. Renowned Canadian geologist Robert Bell noted in 1884:129

The banks of the Athabasca would furnish an in exhaustible supply of fuel... [They] have found it to contain from 12-15 per cent of bitumen. This proportion may appear small, yet the material occurs in such enormous quantities that a profitable means of extracting oil...may be found.

\section{Early hype and production endeavours}

On the heels of the promising results of the geological surveys, a couple of primitive wells were drilled. They were followed by further expeditions at the end of the nineteenth century that led to great expectations: 130

\begin{abstract}
That this region is stored with a substance of great economic value is beyond all doubt, and, when the hour of development comes, it will, I believe, prove to be one of the wonders of Northern Canada. We were all deeply impressed by this scene of Nature's chemistry, and realized what a vast storehouse of not only hidden but exposed resources we possess in this enormous country. What is unseen can only be conjectured; but what is seen would make any region famous.
\end{abstract}

The Canadian prairies were being rapidly settled with European immigrants and North American migrants in the early 1900s, attracted by enticing land giveaways from the federal government, and Alberta's population grew from 73,022 in 1901 to 374,943 in 1911. With Canada's federal government proving themselves inept at overseeing the development of domestic oil production, and amidst pressure from the British Empire's growing thirst for global oil supplies from the 'Dominions', lease rights to drill for oil in Alberta were made private. The resulting land boom in Calgary became legendary - in the two or three weeks following the famous strike of conventional oil in nearby Turner Valley, over 500 oil companies were formed. The race was on to make the oil sands commercial through private investment. Many geologists thought that the ground seepages of bitumen were indicative of massive oil pools below the surface. Twenty-four wells were drilled starting in 1906 with great expectations and disillusioning results. Subsequent and equally unsuccessful efforts were made to use the oil sands material in paving, in place of imported asphalt. Despite the failures, interest to

\footnotetext{
125 S. E. Churchill, 'Hand Morphology, Manipulation, And Tool Use In Neandertals And Early Modern Humans Of The Near East', Proceedings Of The National Academy Of Sciences 98, no. 6 (2001): 2953-2955, doi:10.1073/pnas.061032198. 126 Total.com, 'Total Global Homepage', 2015, http://www.total.com.

127 'First Nations' refers to status and non-status 'Indian' peoples in Canada, as was originally defined by the Federal government. Many communities also use the term "First Nation" in the name of their community. Currently, there are 617 First Nation communities, which represent more than 50 nations or cultural groups and 50 Aboriginal languages. - Aboriginal Affairs and Northern Development Canada

${ }^{128}$ The Hudson's Bay Company exists today as a retail department store and holds the claim of North America's oldest company.

129 (Selwyn and Bell 1885)

130 (Mair 1908)
} 

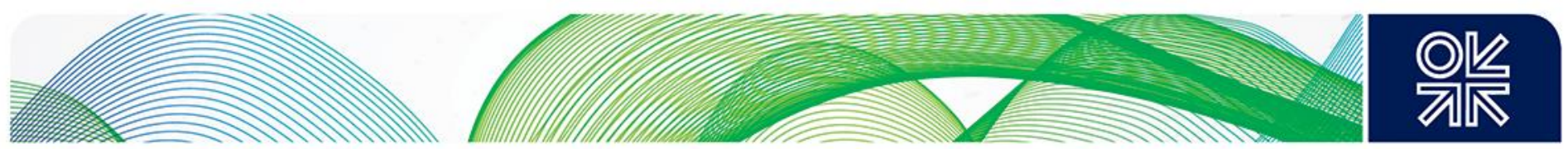

develop the resource did not wane due to local entrepreneurial spirit and government interest in growing domestic production. ${ }^{131}$

Farmer turned businessman Robert Fitzsimmons came to Fort McMurray in 1922 to make his fortune from the 'huge pools of oil', raising funds to purchase a site he named 'Bitumount' and drill what turned out (again) to be dry holes. Concurrently, the Albertan government setup a council to research oil sands viability and $\mathrm{Dr}$ Karl Clark began developing a process to separate bitumen from the sands through the addition of hot water. The process was patented in 1929 and Mr Fitzsimmons applied the process to his Bitumount site, now focused on mining and extraction of oil sands, rather than traditional drilling. With a primitive hot water separation plant, and extensive labour, Bitumount was soon able to produce 300 barrels per day. Though Fitzsimmons' 'International Bitumen Company' listed over 50 uses for its extra heavy oil product, the majority of it was being used only to waterproof roofs after being shipped to Edmonton. ${ }^{132}$

\section{FIGURE 34: FUTURISTIC ILLUSTRATIVE OF THE OIL SANDS VALUE CHAIN DURING WWII}

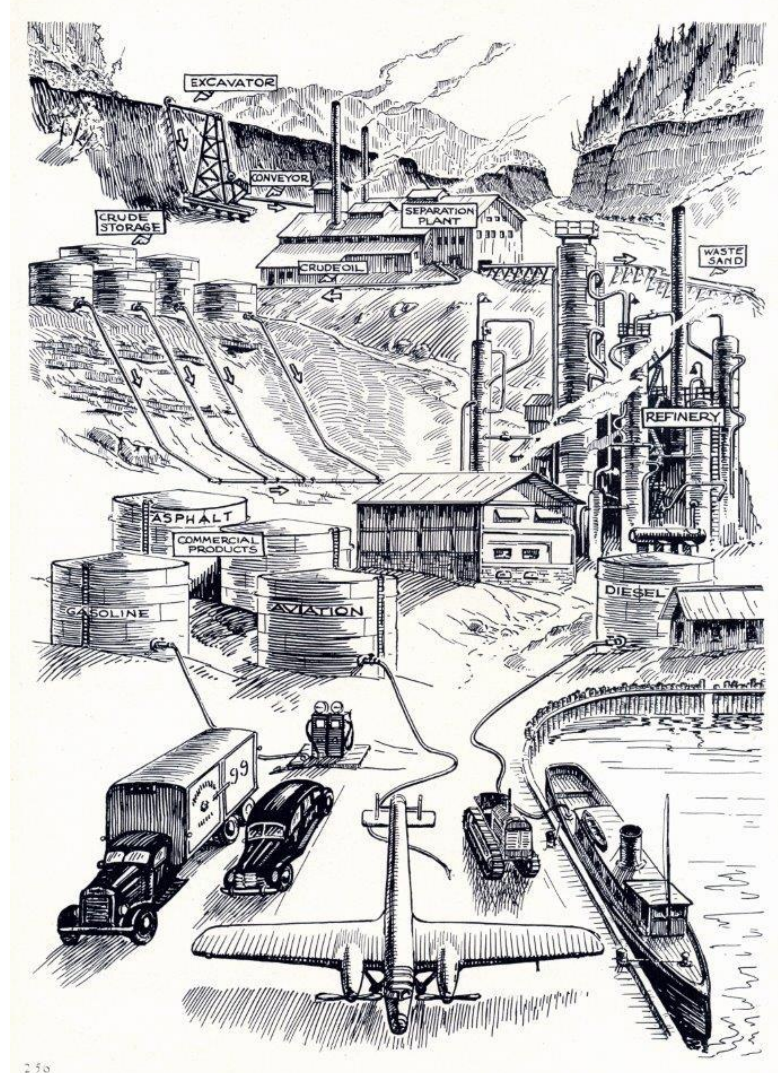

Source: S.C. Ells.

Concurrently during the 1930s, two American developers started the Abasands Oils Company, which was granted substantial land rights from the federal government, and despite economic hardships through the Great Depression in the1930s, they were able to commence production by 1941. During this period, Canada was importing more than 90 per cent of its oil consumption, and the Second World War led to further global pressure from the Allies' desire for energy security through 'synthetic fuels' (from substances other than conventional crude oil). Many proposed rapid growth of oil sands production to support Canada and the Allied war effort, as depicted in Figure 34, a cartoon drawing by engineer and oil sands proponent Sidney Ells during the Second World War.

132 The Government of Alberta, Facts About Alberta's Oil Sands And Its Industry (Edmonton, 2009). 
Despite this impetus to develop production, however, both the Bitumount and Abasands plants remained too uneconomic to continue production given the limited scale and primitive technology. Quarrels between the federal and provincial governments around natural resource development that began at the beginning of the century continued following the Second World War. This impeded proper investment and regulatory structure to enable oil sands growth. A major oil strike of conventional oil at Leduc (just outside Edmonton) further diverted attention, and oil sands production regressed until the 1960s. ${ }^{133}$

\section{The EROI hump}

With such a massive hydrocarbon deposit in place, scientists, engineers, civil servants, and visionary oilmen contemplated a wide variety of technological and operational schemes to reinvigorate an oil sands production push during the period following the Second World War. The challenge they faced remained the same - how can one improve process efficiency? Described more fundamentally, they needed to the raise the Energy Return on Investment (EROI). This somewhat conceptual ratio that undeniably and somewhat arbitrarily varies according to how the energy input denominator is defined, is nevertheless a driver of global energy economics. ${ }^{134}$ Economically attractive energy sources such as hydroelectric power, coal, and high-pressured conventional light oil tend to require little energy input for production $(E R O I>20)$ while higher cost, more cumbersome energy sources like biofuels and solar thermal $(E R O I<2)$ need substantial energy inputs as part of upfront and/or ongoing efforts.

Owing to the prolific Texas oil boom (of very 'conventional' oil), the EROI of US oil production in 1919 was estimated at $100 .{ }^{135}$ However, the diminishing discoveries of untapped giants in easy to reach areas has pushed the global EROI of oil production down to an estimated value of 20 , as of 2010 . The US crude EROI declined even further, with much faster depletion of 'easy oil' resources than global producers Russia, Norway, and Middle Eastern countries. (LTO is likely in the 2-4 range for EROI.) This substantial drop is in spite of the prodigious efficiency and technological advances made in the exploration and production industry over the last 100 years. ${ }^{134}$ Oil sands production effectively aims to 'reverse' geology, involving the energy-intensive practices of thermal cracking and re-saturation. Subsequent upgrading or diluting the product to resemble refiner-ready crude requires further energy when compared with conventional production. Geographical isolation and seasonal challenges of Canada's oil sands further exacerbates these challenges. EROI at the first large-scale mining operation in 1970 is estimated at 1.0, while EROI values at earlier, rudimentary production projects Bitumount and Abasands were almost certainly lower. ${ }^{136}$

The challenge of overcoming a poor EROI, viewed in light of the colossal magnitude of the hydrocarbon resource in place, led to some interesting ideas. A rather extreme, yet still intriguing, example of this was 'Project Oilsand' that proposed the detonation of nuclear bombs in the subsurface. The $400 \mathrm{~m}$ (1,300 feet) deep detonation plan was developed by Richfield Oil of California, already experienced in the heavy oil fields of the San Joaquin Valley. The idea was to use the energy release from approximately 100 atomic (fission) bombs to vaporize oil sand ore and create a cavernous well of less viscous liquid hydrocarbons that could be pumped conventionally. If the energy release from an atomic bomb can be considered 'useful', the detonation process would increase oil sands EROI by several orders of magnitude. Federal and provincial authorities approved a pilot using a single atomic bomb, slightly less forceful than those dropped on Japan in 1945, to be detonated just $64 \mathrm{~km}$ from Fort McMurray. The plans to have US-owned bombs detonated on Canadian soil were ultimately thwarted before the pilot testing. Ironically, rather than the obvious safety and

\footnotetext{
${ }^{33}$ Institute for Oilsands Innovation - University of Alberta, 'Oil Sands History And Development', accessed 15 September 2015, http://www.iosi.ualberta.ca/en/OilSands.aspx.

${ }^{134}$ Charles A.S. Hall, Jessica G. Lambert and Stephen B. Balogh, 'EROI Of Different Fuels And The Implications For Society', Energy Policy 64 (2014): 141-152, doi:10.1016/j.enpol.2013.05.049.

135 The famous Spindletop 'gusher' that trigged the Texas Oil Boom in 1901 had an initial production of around 100,000 bpd from the single well. In 1902, this well produced more than 17 million barrels, assuredly with a very high EROI, well into the thousands. Texas Oil and Gas Association (www.txoga.org)

${ }^{136}$ Adam R. Brandt, Jacob Englander and Sharad Bharadwaj, 'The Energy Efficiency Of Oil Sands Extraction: Energy Return Ratios From 1970 To 2010', Energy 55 (2013): 693-702, doi:10.1016/j.energy.2013.03.080.
} 
environmental concerns, it was Cold War-era fears of Soviet espionage and the nuclear nonproliferation climate of the 1960s that thwarted the proposal. ${ }^{137}$

Numerous oil sands technologies and schemes to reduce energy intensity and improve operating efficiency have reached dead ends over the decades. How then, have engineers and investors had the patience to overcome these tribulations and expand production? Former Suncor CEO Rick George has described the somewhat prophetic vision of exploiting the colossal reserves in the face of often unfavourable economics:

\begin{abstract}
The most appealing feature of the oil sands was the fact that they were there to be taken. Instead of cruising the world in search of oil hidden beneath ground and drilling 10 dry wells for every one that proved successful, why not focus on the largest known source of oil? A lot of minds went to work on the idea over the years. A lot of money was spent to make it happen and a lot of companies invested millions of dollars in the dream. ${ }^{138}$
\end{abstract}

\title{
Mining
}

With some 30 billion barrels of proved oil sands reserves at or near the surface, mining was the commercial extraction method of choice for most of the twentieth century. Despite fickle support from both provincial and federal governments, the dawn of the large-scale oil sands mining age was triggered by an audacious president of the US-based Sun Oil Company, J. Howard Pew. An early oil sands visionary, Pew aggressively lobbied Sun's board to look to northern Alberta for a long-term return and a first-mover advantage. ${ }^{139}$ In 1953, his company's backing led to the founding of the Great Canadian Oil Sands (GCOS) consortium, the precursor to Suncor, and eventually the first commercial production, starting in 1967. The GCOS plant was completed for a capital cost of approximately $\$ 220$ million at a production capacity of $45,000 \mathrm{bpd} .{ }^{140}$ The success of this endeavour and the growing concern over international energy security prompted other players to enter the game, as the Oil and Gas Journal illustrated in 1967:

The start of commercial production of synthetic crude from the Athabasca tar sands has been hailed as the dawn of a new era, the forerunner of vast new supplies of hydrocarbon energy, assurance of hemispheric self-sufficiency in petroleum, and a threat to conventional crude oil. It may turn out to be all of those things, but only time will tell. ${ }^{141}$

Although other large upstream players wanted a stake in the potentially large resource and started to assemble research teams, few were willing to take on the associated risks themselves with the GCOS plant still not demonstrating attractive returns. Syncrude was created as a consortium of investors who came and went during lengthy project approval and financing postponements. Construction of their plant, finally completed in 1978, required federal and provincial government investment to bail out the remaining three private investors: Imperial Oil, Gulf Oil Canada, and Cities Services. The oil price spikes of the 1970s buoyed the GCOS (renamed Suncor in 1979) and Syncrude plants to profitability. Soon after however, the fallout of low oil prices starting in the early to mid-1980s, combined with federal government overreach into the oil industry through the National Energy Program (NEP), rendered oil sands expansion projects economically unattractive for almost two decades. The turn of the millennium brought new investments for mining production growth at the Suncor and Syncrude sites, as well as new players like Shell and Canadian National Resources (CNRL) joining the field.

All oil sands mining projects, from the earliest Bitumount plant in the late 1920s to today's most modern operations, leverage the same basic bitumen separation process patented by Dr Karl Clark back in 1929. Mining is attractive as it recovers almost all of the bitumen present, but it must remove enormous amounts of ore in the process.

\footnotetext{
${ }^{137}$ Aaron Fitzpatrick, 'Project Oilsand', Canadian Institute Of Mining, Metallurgy And Petroleum, 2013,

https://magazine.cim.org/en/2013/August/mining-lore/Project-Oilsand.aspx.

138 (George and Reynolds 2012)

139 (Chastko 2004); Dan Barnes, 'Alberta's Oilsands Epic Stretches Back More Than A Century', The Edmonton Journal, 2013.

${ }^{140}$ Exchange rate taken in 1967 at $\$ 1$ USD = \$1.077 CAD; Suncor.com, 'The Oil Sands Story (1960S, 1970S \& 1980S) -

Suncor', 2015, http://www.suncor.com/en/about/744.aspx.

141 'Editorial', Oil \& Gas Journal, 1967.
} 


\section{Mining}

All oil sands mining is surface mining, otherwise known as open-pit, in which oil sands are removed directly from the surface, or near the surface, rather than by tunnelling through the earth. The technology and efficacy of this process has changed markedly as mining projects have worked to increase efficiency and profitability.

Before oil sands are mined, the removal of overburden (trees, vegetation, muskeg, and layers of soil) is conducted as needed, with the use of bulldozers, backhoes, loaders, water trucks, scrapers, side booms, and graders. ${ }^{142}$ Much of this overburden is stored for land reclamation, a long-term process that begins just after the mining process is complete. Images of oil sands production popularized in the media and by environmental groups, will typically show aerial views of the disturbed land with overburden removed. Postreclamation images are rarely shown, except by producers aiming to improve their public image.

For extraction, the 1967 GCOS plant leveraged a six-story tall, 773-ton bucket wheel excavator that was originally designed for the purpose of building an earthen dam. The excavator would remove the oil sands using its 10 buckets and deposit the ore onto massive conveyer belts to be carried to the processing plant. Syncrude decided to leverage large draglines to remove the oil sands, then smaller bucket wheels to transfer the piled ore to the conveyer belts. Syncrude, Suncor, and new mining ventures began using giant mining shovels (earthmovers) at the turn of the millennium and the world's largest purpose-designed trucks with carrying capacities of hundreds of tons to remove and transport oil sand ore. Suncor's Rick George has spoken about the mechanical complexities of mining:

Bucket wheels, and in particular Suncor bucket wheels, were ideal proof of a rule that every engineer understands instinctively: the more complex a piece of mechanical equipment, the greater the probability of its breaking down... I was convinced that replacing the bucket wheels with a more reliable system would produce an immediate leap in productivity. ${ }^{143}$

A single tire for one of the trucks weighs more than 5 tons, is 4 metres in diameter, and costs more than $\$ 40,000$. ${ }^{144}$ This technology upgrade led to a better selection of oil sand ore, ensuring higher grades entered the next stage of processing, though the trucks are still expensive, substantial consumers of energy.

2. Conditioning ${ }^{145}$

After oil sands ore is extracted, large chunks of material are removed and hot water is added to make a slurry for further processing. This conditioning is the first step in separating the trapped bitumen from the bounded sand, water, and clays. Historically, this was accomplished at the processing plant with a tumbler and hot water, after ore was transferred on a conveyer belt. Research by Syncrude in the 1980s and 90s led to both a crushing and dilution process called hydrotransport that uses colder water that can be leveraged in the field, far from the processing facility. The additional advantage was that pipeline transport performed some separation itself as former Syncrude CEO Eric Newell has noted:

As long as you pump it over a kilometre or more, you get enough mechanical energy put in through the mixing to break the bond (between bitumen and sand), so that you can go into the primary separation vessels. That enabled us to get away from conveyor belts and all that. ${ }^{146}$

These technologies enable the slurry to flow by pipeline. Removing the troublesome conveyor belts, as well as the transition to colder water, reduces energy usage and further lowers mining EROI.

3. Primary Separation ${ }^{145}$

A 'primary separation vessel' (PSV) combines the slurry from the conditioning stage and hot water and settling occurs. The slurry separates naturally within minutes into three layers: a top layer of 'froth', composed mostly of bitumen; a 'middlings' layer of bitumen, sand, clay, and water; and a bottom layer of sand, which is raked out from the bottom to improve separation. The middlings mixture is pumped into large outdoor storage area known as tailing ponds, a process common to the mining industry.

\footnotetext{
142 The Government of Alberta, Facts About Alberta's Oil Sands And Its Industry (Edmonton, 2009).

${ }^{143}$ Dan Barnes, 'Alberta's Oilsands Epic Stretches Back More Than A Century', The Edmonton Journal, 2013.

144 Joe Carroll, 'Titan'S Giant Tires Falling Flat In Alberta Oil Sands', Bloomberg, 2009,

http://www.bloomberg.com/apps/news?pid=newsarchive\&sid=awEFZg9ApljA.

45 The Government of Alberta, Facts About Alberta's Oil Sands And Its Industry (Edmonton, 2009).

${ }^{146}$ Dan Barnes, 'Alberta's Oilsands Epic Stretches Back More Than A Century', The Edmonton Journal, 2013.
} 


\section{Secondary Separation}

In the tailing ponds, further separation occurs in flotation tanks through air injection, and allows an additional 2-4 per cent of bitumen to be recovered. The mixture is then sent back to mix with the primary bitumen froth.

5. Froth Treatment 145

Bitumen froth is further heated and de-aerated to ensure air bubbles are removed. The remaining mixture is approximately 30 per cent water and 10 per cent solids (clay minerals or silts) by weight and must be further cleaned. This is either done at a froth treatment plant or through the Counter-Current Decantation Vessels used at Shell's oil sands operations.

At a Froth Treatment plant, the de-aerated bitumen is diluted with a naphtha solvent to improve viscosity. The mixture is then sent through settlers and centrifuges that act to remove the water and solids to generate a solution with less than 5 per cent water and 0.5 per cent minerals. Waste from this process is stripped of remaining naphtha and then is sent to the tailing ponds. If the product is to be upgraded on-site, the resulting diluted bitumen (called 'dilbit') is stripped of naphtha in a Diluent Recovery Unit (DRU) and the nearly pure bitumen remains are sent for upgrading.

The counter-current decantation vessels process is similar, with naphtha being used as a solvent. Advanced separation processes are then used to remove water and solids and produce dilbit.

As the oil sands mining process is complex and relatively new, opportunities exist to improve efficiency and render the endeavour more attractive to investors. This has been shown in recent decades, as estimates for EROI of mining extraction have jumped from around 1 in 1970 to roughly 5-6 in 2010. The efficiency step change, combined with growing crude prices, led to post-2000 expansions at the Suncor and Syncrude sites, as well as new mining projects led by Shell, Canadian Natural Resources (CNRL), and Imperial Oil (majority-owned by ExxonMobil).

In-Situ

With more than 80 per cent of oil sands reserves located well below the surface, inaccessible by open-pit mining techniques, many feel the long-term value of Canada's oil sands depends on how operators can separate bitumen from oil sands in the subsurface, or in-situ. Furthermore, the environmental impact at the surface of in-situ production is substantially less than mining and thus more palatable to an environmentally concerned public. Producers focused on in-situ methods are wont to mention this fact, claiming their operations to be 'a different kind of oil sands', versus the somewhat visually disturbing aerial photos of the open-face mines. ${ }^{147}$

Notwithstanding the outlandish nuclear detonation proposal, a multitude of more feasible ideas have been proposed to enable subsurface production. The technical foundation of today's oil sands in-situ commercial methods stems from the heavy oil fields of the San Joaquin Valley in California, based on decades of development into various ways of injecting steam to enhance production. ${ }^{148}$ Most techniques leverage the high temperature of steam to coerce the viscous bitumen to flow and are often simply denoted as 'thermal' methods. Because vast amounts of energy are required to generate the necessary heat (through steam or otherwise), in-situ production growth has historically lagged behind mining. This trend changed at the turn of the millennium and in-situ production is starting to now pull away from mining in annual production. This inflection point was primarily due to improved in-situ production technology that led to higher recovery rates, lower capital costs, and a substantial reduction in energy costs. Low natural gas prices in North America, and especially Western Canada since 2008, have been a boon for most in-situ producers. Thermal producers tend to live and die by their steam-to-oil ratio (SOR) - a clear measure of how effectively they can recover bitumen from the subsurface while minimizing energy and water consumption. In-situ oil sands production has been driven by the following commercial extraction processes (next generation technologies are discussed in subsection 3.3):

- Primary \& Non-Thermal Enhanced Oil Recovery (EOR)

\footnotetext{
147 Cenovus.com, 'Cenovus Advertising - A Different Oil Sands', 2015, http://www.cenovus.com/news/a-different-oilsands.html.

${ }^{148}$ Harbir Chhina, Oil Sands Oral History Project, interview by Peter McKenzie-Brown (Cenovus Energy, Calgary, 2011).
} 
Primary and non-thermal EOR methods are used to produce the lighter, less-bituminous, heavy oil found within the demarcated oil sands areas. There are some areas of geology that are favourable to economic production with these more conventional production methods, though are certainly not ubiquitous. Examples of EOR methods that are used to produce heavy oil include water flooding, gas injection, and polymer/chemical flooding. ${ }^{149}$ These methods typically have much lower capital and operating costs, though they recover only 5-10 per cent of the heavy oil in place. ${ }^{150} \mathrm{~A}$ quasi-primary, 'Made-in-Canada' method for extracting cold heavy crude at more than 10 per cent recovery is Cold Heavy Oil Production with Sand (CHOPS). Rather than filtering sand out of hydrocarbon production, CHOPS deliberately initiates sand influx during completion, produces sand with the oil, and separates it from the oil at the surface. ${ }^{151}$

- Cyclic Steam Stimulation (CSS)

Like many great discoveries, CSS (informally referred to as 'Huff-and-Puff') was discovered by accident in the heavy oil fields of Venezuela in 1959, when a steam injector well that was aimed at allowing steam flooding into a nearby producing well, began to actually produce oil itself after a blowout. ${ }^{152}$ The process injects wet steam directly into the producing well and is comprised of three stages: 1) Wet Steam Injection (Huff), lasting a few weeks; 2) Soaking, where the well is shut down for a few days; and 3) Production (Puff) where heavy oil is produced, typically for several months. The completion of all three stages represents one cycle, and producing wells go through many cycles over their lifetime. CSS operations do not function well in shallower oil sands reservoirs above a few hundred metres, and they require a shale cap to produce. Mostly through trial-and-error in the field, rather than structured laboratory research, CSS has advanced substantially since the late 1960s, when it was first used by Exxon's Imperial Oil at the Cold Lake Deposit, and the mid-1980s, when the first commercial production began. ${ }^{153}$ Recovery factors and SOR ratios have improved by increasing the number of CSS cycles over the lifetime of a well (many wells now have $>20$ cycles), shifting to horizontal wells to increase reservoir access (though these must deal differently with the steam's gravitational effects), and raising the steam's injection pressures and temperatures to match the reservoir while increasing the water content of the wet injected steam. ${ }^{152}$ In the oil sands, these improvements have helped CSS projects reach 25-30 per cent in oil recovery in recent years. CSS production growth has been steady, if less pronounced than mining and SAGD, reaching $277 \mathrm{Mbpd}$ in 2014. ${ }^{154}$

\section{- Steam Assisted Gravity Drainage (SAGD)}

Also borne out of the thermal EOR practices of the California heavy oil fields in the 1960s was the idea that during steam flooding (also called stream drives) of vertical wells, when steam is transferred from a injector well to a producing well, it is the gravity rather than the steam itself that incites oil production. ${ }^{155}$ Imperial Oil's Dr Roger Butler was well aware of this fact in the late 1960s, when he developed an in-situ extraction method using steam injection wells that generate a subsurface 'steam chamber' leading to reduced viscosity of the bitumen in such a way that it drains to a lower, horizontal well, where it can be produced. This process known as Steam Assisted Gravity Drainage (SAGD) was piloted by Imperial in 1978, patented in 1982, and has now become the most important technology in oil sands production, with the standard practice utilizing two parallel wells horizontal wells approximately $4-6 \mathrm{~m}$ apart (see Figure 35$).{ }^{156}$

Continued development through corporate and provincially funded consortium research led to several commercial endeavours starting in the late 1990s, with Cenovus Energy leading the charge with the first commercial SAGD project in 2001 at Foster Creek in the Cold Lake deposit (subsequently the first SAGD endeavour to reach project profitability in 2010). Advances in 4D seismic modelling, horizontal well drilling, and operational effectiveness played a big part in making the technology attractive, and in 2002 the Oil \&

\footnotetext{
${ }^{149}$ Christopher Holly, Martin Mader and Jesse Toor, Oil Sands Production Profile (2002-2010) (Edmonton: Alberta Department of Energy, 2012).

150 Alberta Energy Regulator, Alberta's Energy Reserves 2013 \& Outlook 2014-2023, ST98-2014 (Calgary, 2014).

151 (Dusseault 2002)

152 Johannes Alvarez and Sungyun Han, 'Current Overview Of Cyclic Steam Injection Process', Journal Of Petroleum Science Research 2, no. 3 (2013): 116-127.

${ }^{153}$ E.L. Lui, 'Imperial Oil - A Leader In Thermal In-Situ Production', 2006.

${ }^{154}$ Alberta Energy Regulator, Alberta’S Energy Reserves 2013 And Supply/Demand Outlook 2014-2023, ST98-2014 (Calgary, 2014).

${ }^{155}$ Harbir Chhina, Oil Sands Oral History Project, Peter McKenzie-Browninterview by , radio (Cenovus Energy, Calgary, 2011).

156 Imperial Oil Website, 'Aspen - A SAGD Development: Project Overview', 2014, http://www.imperialoil.ca/Canada-

English/Files/aspen_project_summary.pdf.
}

February 2016 - The Future of the Canadian Oil Sands: Growth potential of a unique resource amidst regulation, egress, cost, and price uncertainty 
Gas Journal increased Canada's petroleum reserves from 4.9 to 180 billion barrels accordingly. ${ }^{157}$ Since Foster Creek, SAGD growth has eclipsed other in-situ and even large commercial mining extraction methods.

\section{FIGURE 35: ILLUSTRATION OF THE SAGD METHOD}

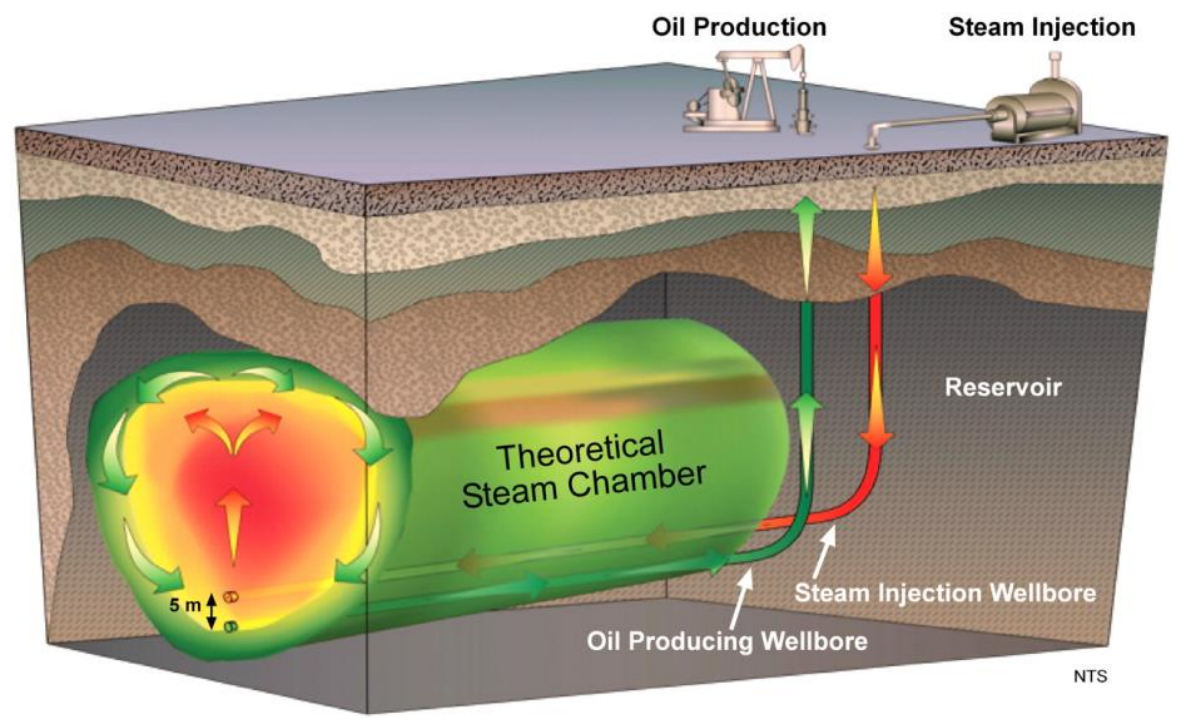

Source: The Geological Society (Petroleum Geological Conference Series).

SAGD yields considerable advantages over CSS and the more conventional heavy-oil EOR methods - the most striking is the recovery factor (up to 60 per cent with current commercialized technology) and the partially correlated measure of production per well that can be as almost 10 times higher than CSS (Figure 36). The downside is that each individual SAGD producing well has much higher energy, cost, and complexity with the need for better-quality steam and a second (non-producing) injecting well. Moreover, SAGD is only effective in higher-quality bitumen reservoirs, whereas CSS can be applied to geologies with a wider range of bitumen saturation.

Despite burgeoning production growth since 2001, all in-situ projects still suffer from the challenging energy economics that accompanies a relatively low EROI (SAGD projects are in the 3-4 range at best). Substantial operational and technological efforts, especially since the price crash of 2014, have aimed at lowering the steam required for production (SOR), lowering the cost and greenhouse gas (GHG) emissions of producing the steam, and delivering scale capital and operational cost savings through a 'lean manufacturing' approach to production (discussed further in section 3.2). 
FIGURE 36: WELL PRODUCTIVITY AND \# IN PRODUCTION, BY IN-SITU METHOD (2013)

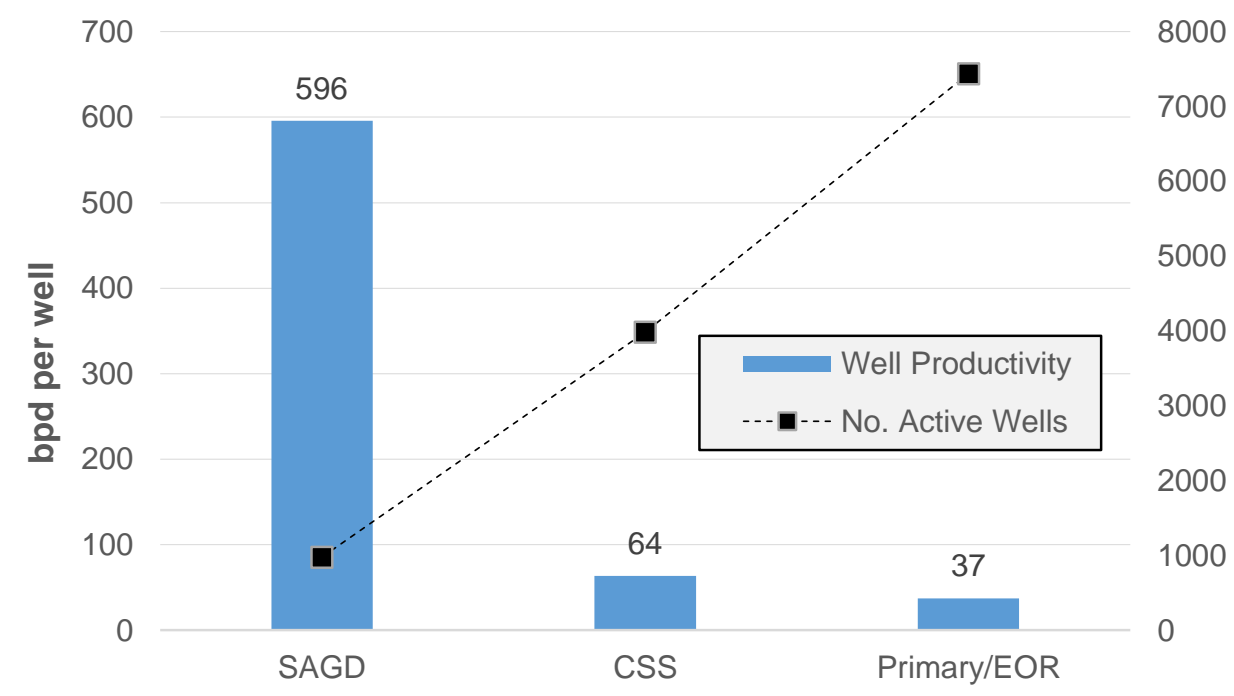

Source: Alberta Energy Regulator.

\section{Marketing bitumen}

\section{Upgrading}

Oil sands marketing has come a long way since the early Bitumount days, when separated bitumen product was barged and railed from the plant near Fort McMurray to the Edmonton markets and sold mostly as a final product for weatherproofing roofs. ${ }^{158}$ By economic imperative, GCOS's large-scale mining development in the 1960s brought with it substantial improvements in refining technology. Even with the energy intensive and costly separation process that occurs after mining, bitumen is still at least a thousand times more viscous than light crude oil. More challenging was that, until recent years, few refiners were able to process bitumen on its own, as it had to be 'upgraded' first into a lighter crude. Starting with GCOS (Suncor) in 1967 and until just recently, all mining projects have included an 'Upgrader' unit that can transform viscous bitumen (API gravity of $8-10^{\circ}$ ) into a more marketable 'Synthetic Crude Oil' (SCO) with an API greater than $32^{\circ}$. Vacuum distillation, cracking (thermal or catalytic), and desulfurization processes are used in various upgrading configurations to separate out lighter hydrocarbon streams, purify the heavier crude, and remove the asphalt. The upgrading process also removes impurities such as sulphur, nitrogen, and trace metals in the lighter streams through hydro-treating before blending the final output streams to generate SCO to be transported by pipeline.

\section{Dilbit \& Synbit: The shift away from upgrading}

Before the recent advent of large-scale light tight oil production in the US shale basins, there was a marked shift towards refiners looking at heavier crude feedstock, shifting from an average API of $32.5^{\circ}$ in 1985 to $30.3^{\circ}$ in 2008 , with a corresponding increase in average sulphur content. ${ }^{159}$ The fact that this was happening while traditionally large US imports of heavy oil volumes from Venezuela and Mexico were declining, due to under investment and mismanagement in those countries, is a testament to the growing prominence of oil sands heavy crude. Accordingly many large US refineries in the Midwest and on the Gulf of Mexico spent billions of dollars retooling their refineries with upfront coking (cracking) and other processing units to manage the heavy feedstock. Meanwhile, most oil sands producers, especially those producing in-situ, were focused on improving recovery and lowering extraction costs rather than improving upgrader economics, for which the central lever is increasing scale. Most in-situ producers, and more recently mining producers, have found that it made sense to avoid upgrading bitumen, and simply transport the diluted bitumen mixture (without removing

\footnotetext{
158 The Government of Alberta, Facts About Alberta's Oil Sands And Its Industry (Edmonton, 2009).

${ }^{159}$ American Petroleum Institute, Canadian Oil Sands Primer: Enhancing America's Energy Security (Washington, 2011).
} 

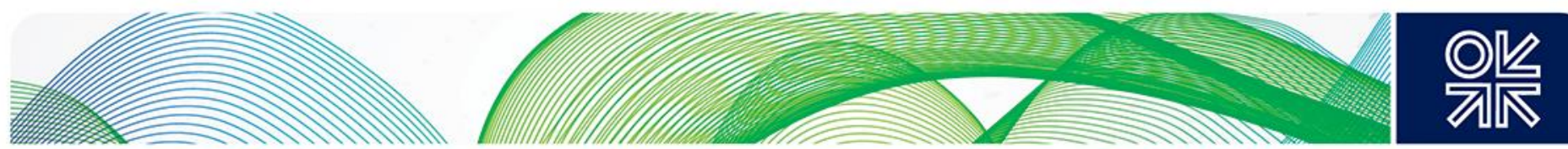

the diluent as is done before upgrading) to refineries downstream of the Edmonton and Hardisty crude hubs in Alberta. ${ }^{160}$

The diluted bitumen mixture can either be dilbit, a mixture of 25-30 per cent natural gas condensate with 70-75 per cent bitumen, or synbit, an approximately 50/50 mix of SCO from an upgrader and produced bitumen.

\section{A.3 The oil sands today}

\section{Bitumen production}

Major production capacity in the oil sands arrived in somewhat discrete chunks with only a handful of players coming on-stream on a commercial scale until the turn of the millennium (Figure 37). After the Suncor and Syncrude mining projects struggled with profitability (apart from the oil price crisis years of the late 1970s), no new mining projects would be built before Shell's Muskeg River operations came online in 2002.

\section{FIGURE 37: PRODUCTION CAPACITY BUILD-UP IN THE OIL SANDS}

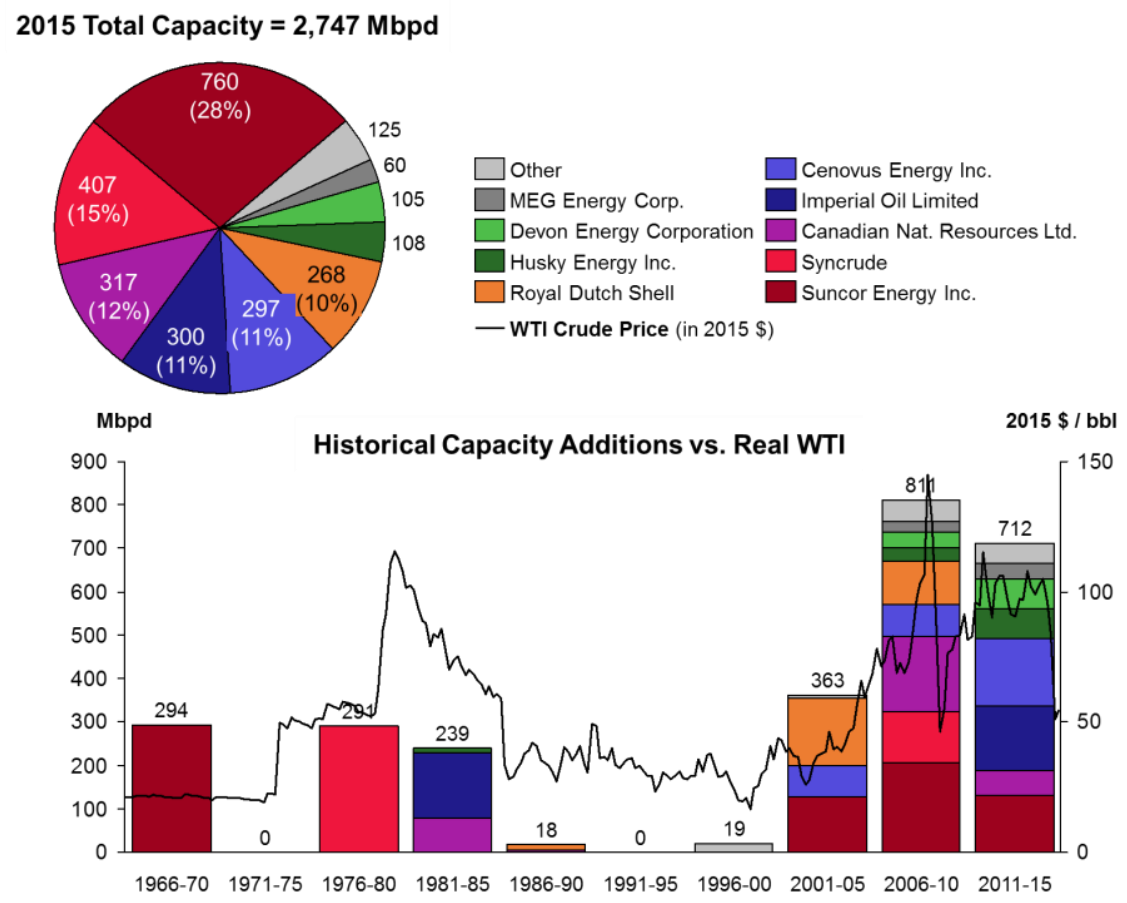

Source: Oilsands Review Datasets (2015).

The rapid upswing in global oil prices, the commercial implementation of SAGD technology, and mining process efficiency improvements spurred an investment boom starting around 1999. Shell and CNRL built large 'greenfield' mining projects while Syncrude and Suncor made sizeable 'brownfield' additions to their current mining operations. The most salient growth story is the upsurge of SAGD as the production method of choice, as demonstrated in Figure 38. Patented by Imperial Oil and accelerated into large-scale commercial production by Cenovus Energy, the technology has attracted many other players to look at oil sands investments.

The SAGD trend continues. More than 80 per cent of announced new capacity (excluding projects that have been officially suspended or cancelled) is from in-situ plays (Figure 25). While early oil sands production consisted of only two committed players willing to burden the massive costs of infrastructure (upgrading and foundational pipelines) and mining equipment, the trend towards lower

\footnotetext{
160 This trend away from upgraders has expanded from the smaller volume in-situ projects to mining production, where new proposals are looking to remove on-site upgrading from project plans. ExxonMobil's Imperial Oil is calling this the 'Next Generation of oil sands mining".
} 
upfront capital and smaller-scale for SAGD projects has attracted many more players to game, both large and small.

\section{FIGURE 38: OIL SANDS PRODUCTION HISTORY, BY PRODUCTION METHOD}

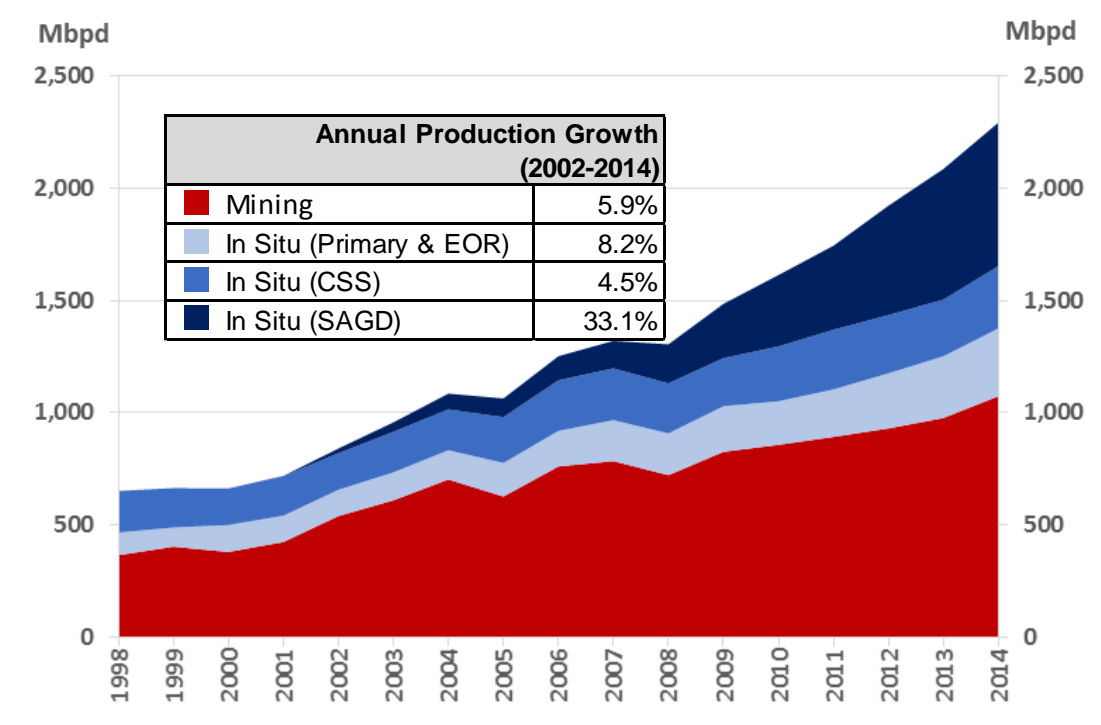

Source: Alberta Energy Regulator.

\section{Upgrading}

Historically, upgrader capacity has grown in-sync with mining projects, approaching 1.4 million bpd of on-stream capacity as of 2015 . Whereas in-situ produced bitumen typically contains less impurities and can be more easily transported by pipeline after dilution (with SCO or condensate), bitumen from the mines has required on-site upgrading facilities. This thinking began to change with the building of the Scotford Upgrader, just outside of Edmonton, by the Shell-led Alberta Oil Sands Project (AOSP) in 2002 to process bitumen from their newly on-stream Muskeg River mine north of Fort McMurray, almost $500 \mathrm{~km}$ away. ${ }^{161}$ AOSP chose to locate their upgrader beside Shell's already operating Scotford refinery and chemicals facility, and closer to a population centre rather than the higher labour cost and rather remote production location near Fort McMurray (where most other upgraders are located). This generated a strong enough business case to bring to life the first new mining project in 25 years, despite WTI prices in the $\$ 20$ range during concept and construction phases.

In the past five to ten years, as US refineries have retooled to accept more heavy crude primarily from the oil sands, price spreads between bitumen and SCO have become smaller, rendering upgrading projects less attractive. Rather than look at building their own costly upgrader, Canadian producers like Cenovus and Husky looked to US-based refiners ConocoPhillips and BP, respectively, to ensure processing capacity south of the border. Upgrader economic attractiveness has decreased so substantially that with CAD $\$ 3.5$ billion in sunk cost into its $C A D \$ 11.6$ billion Voyageur upgrader, Suncor decided to mothball the project (with partner Total in tow) and invest the unspent capital in bitumen production expansion instead. ${ }^{162}$ Imperial's new Kearl mine project, whose first phase at 110 Mbpd went online in 2013 , is the first of its kind to use no upgrader at all thanks to a proprietary bitumen froth treatment technology. With almost twice as much upgrader capacity cancelled or postponed as announced in recent years, new upgraders are unlikely in the near future. There have been calls from left-leaning politicians nonetheless, in a populist effort to generate jobs for Albertans and Canadians, for subsidization of local, if unprofitable, upgraders, refineries, and petrochemical

\footnotetext{
161 The AOSP is a joint venture with the ownership split as 60 per cent by Shell, 20 per cent by Chevron, and $20 \%$ by Marathon. 162 Brent Jang, 'Suncor Cancels Voyageur Project, Takes Hit To Profit', The Globe And Mail, 2013.
} 
facilities. The North West Upgrader, whose construction is to be completed shortly, is a prime example of this. ${ }^{163}$

\section{FIGURE 39: OIL SANDS UPGRADING CAPACITY (BITUMEN INTAKE)}

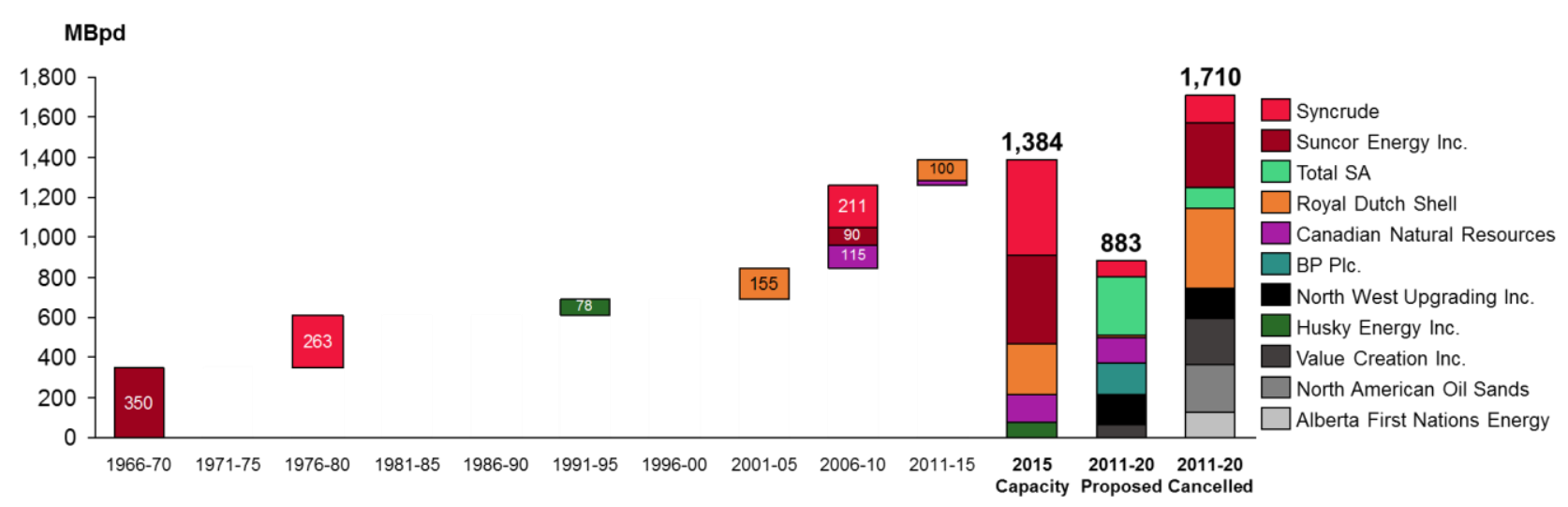

Source: Oilsands Review Database (2015).

\section{Markets}

\section{North American Refinery Capacity}

Production growth of 'difficult oil' has profoundly altered the North American oil supply landscape first with growing oil sands production since 2000, and more recently, with the explosion of light tight oil. Among the world's top five crude exporters (including Saudi Arabia, Russia, Nigeria, and the UAE), Canada is somewhat unique in that it still imports almost 600 thousand bpd of crude oil to its domestic refineries, indicative of the lag of adequate pipeline infrastructure to Eastern Canada (see Figure 40). ${ }^{164}$ These refineries have long been fed by foreign imports from the Atlantic Ocean, and have only recently consumed significant volumes of Western Canadian and US light tight oil crude, much of which is transported at a higher cost by rail.

Even before oil sands expansion, Western Canadian producers long relied on the refinery capacity of its high-consuming and trade-friendly US neighbour, mostly in the Midwest, to process their production. This trend has continued with the refineries in US PAD II processing 1.9 of Canada's 2.7 million bpd of exported crude in 2014. ${ }^{165}$ Furthermore, recent retooling of Midwestern refineries to handle the increase in bituminous feedstock (essentially upgrading on-site of the refinery) has led to PADD II processing 1.3 million bpd of heavy oil. Most of this crude is of Western Canadian origin, predominantly from the oil sands, which averaged 2.2 million bpd in bitumen production in 2014. ${ }^{164}$

The largest opportunity for oil sands export to the US lies in the massive 8.3 million bpd demand of the Gulf Coast, whose refineries have also retooled for feedstock of lower API gravity, currently processing more than 2 million bpd of imported heavy crude. With Mexican and Venezuelan heavy oil sources declining markedly in recently years, it is somewhat surprising that Gulf Coast refineries currently only handle roughly $235 \mathrm{Mbpd}$ of Canadian heavy supply. Lack of inbound transportation capacity is indeed a limiting factor. ${ }^{164}$

\footnotetext{
${ }^{163}$ Darcy Henton, 'North West Upgrader Morphed Into 'An Economic Boondoggle,' Says Former PC Finance Minister', The Calgary Herald, 2015.

164 (Natural Resources Canada 2015); (Canadian Association of Petroleum Producers (CAPP) 2015)

165 See Figure 40 on the following page for a map of US oil marketing regions
} 
FIGURE 40: NORTH AMERICAN REFINERY DEMAND (2014, MBPD)

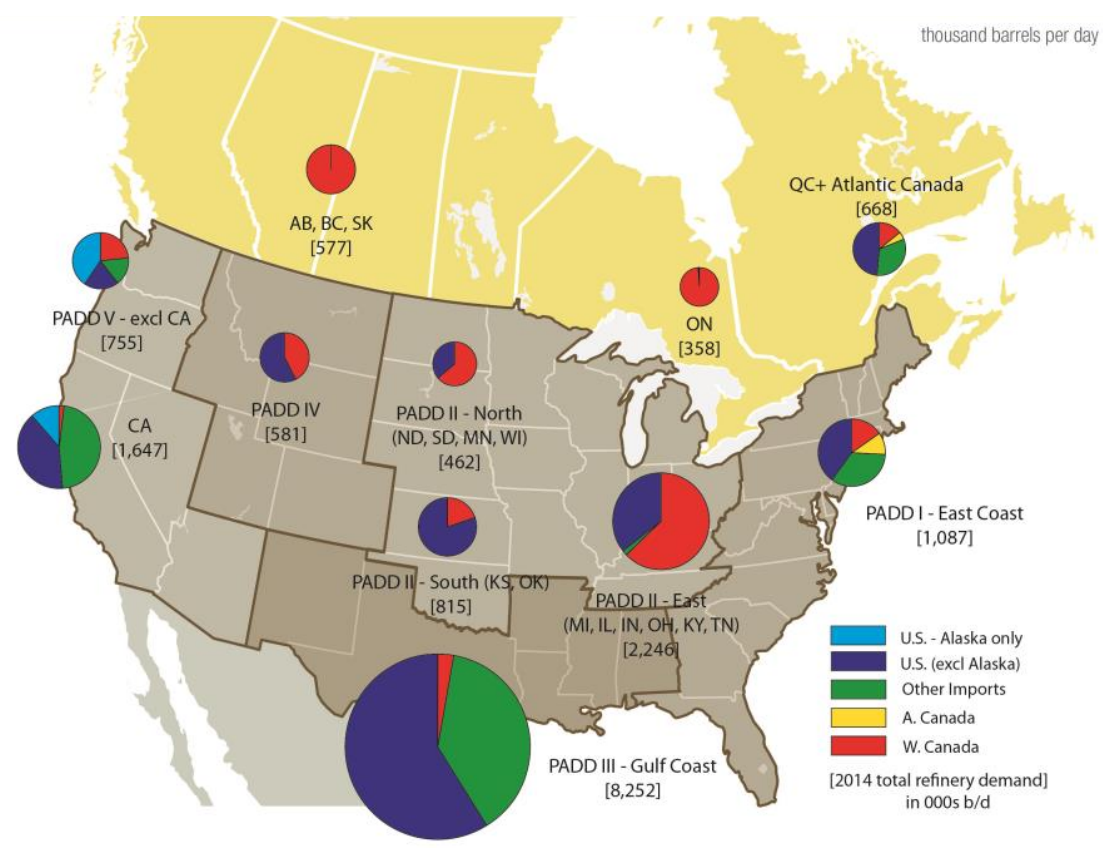

Sources: CAPP; CA Energy Commission; EIA; Statistics Canada.

\section{Transportation}

For decades, oil sands SCO production from Suncor and Syncrude upgraders was easily handled by Edmonton refineries, or sent down Enbridge's mainline along with conventional Western Canadian crude to US markets. More recently, rapid growth in oil sands production since 2001 and light tight oil production in the Bakken shale basin of the northern US since 2007 has put regional pressures on midstream infrastructure downstream of the Edmonton hub, and producers have faced substantial discounts on their crude products - both from the oil sands and the Bakken. More than 1.6 million bpd of oil sands bitumen production growth was added between 1999 and 2014, with another 0.7-1.0 million bpd predicted by 2020 with projects under construction that are unlikely to stop.

Without large-capacity pipeline access to tidewater, save for the Pacific and Gulf Coasts of the US, which currently prohibits crude exports, Western Canadian crude has been, and will continue to be, mostly landlocked. Pipeline infrastructure to the Pacific or Atlantic coasts will be needed, along with exporting terminals for trans-oceanic tankers, if oil sands production is to grow substantially over the coming decades. With Asian demand estimated to grow by 15 million bpd in the next two decades and OECD demand indicating a trend of decline, Canada's oil sands will need increased access to both the Gulf Coast and international markets to make major production growth projects attractive. ${ }^{166}$ Critical egress challenges for getting oil sands crude out of the Western Canadian Sedimentary Basin will continue to have a dampening effect on oil sands growth - this is discussed further in Section 2. 


\section{Units}

\$ US dollars

CAD\$ Canadian dollars

$\mathrm{Bbl} \quad$ Barrels of liquid

bpd Barrels per day

Mbpd Thousand barrels per day

MMbpd Million barrels per day

Ma. Million years (geology)

$\mathrm{km}^{2} \quad$ Square kilometres

$\mathrm{t} \quad$ Metric tonne $(1000 \mathrm{~kg})$

Mt Million tonnes

MWh Megawatt-hour

\section{Conversion Factors}

$\begin{array}{ll}1 \text { meter } & 3.28 \text { feet } \\ \$ 1 \mathrm{CAD} & \$ 1.34 \text { (as of } 30 \text { November } 2015-\text { unless noted, all dollar figures in USD) } \\ 1 \mathrm{MMbtu} & 1.056 \mathrm{GJ} \\ 1 \mathrm{MMbtu} \text { natural gas } & 0.972 \mathrm{Mcf} \text { natural gas }\end{array}$




\section{References}

Charles Mair, Through The Mackenzie Basin : A Narrative Of The Athabasca And Peace River Treaty Expedition Of 1899 (Toronto: W. Briggs, 1908).

Alfred R.C. Selwyn and Robert Bell, Geological And Natural History Survey And Museum Of Canada (Montreal: Dawson Brothers, Alfred R.C. Selwyn, 1885).

Paul A Chastko, Developing Alberta's Oil Sands (Calgary: University of Calgary Press, 2004).

BP plc, BP Energy Outlook 2035, 2015, http://www.bp.com/content/dam/bp/pdf/Energyeconomics/energy-outlook-2015/Energy_Outlook_2035_booklet.pdf.

IEA, 2015. World Energy Outlook 2015. Paris: The International Energy Agency.

National Energy Board of Canada, 2000. Canada's Oil Sands: A Supply and Market Outlook to 2015. Calgary.

Natural Resources Canada, Energy Markets Fact Book (2015-16), Cat. No. M136-1/2015E-PDF (Online), 2015, http://www.nrcan.gc.ca/sites/www.nrcan.gc.ca/files/energy/files/pdf/2014/140173EnergyMarketFacts_e.pdf.

Canadian Association of Petroleum Producers (CAPP), Crude Oil Production and Supply Forecast 2006 - 2020 (Calgary, 2006).

Canadian Association of Petroleum Producers (CAPP), Crude Oil: Forecast, Markets \& Transportation (Calgary, 2015).

Steve E. Hrudey et al., Environmental And Health Impacts Of Canada's Oil Sands Industry, The Royal Society Of Canada Expert Panel Report (Ottawa: The Royal Society of Canada, 2010).

Rob McWhinney, Oil Sands Environmental Impacts, Study No. 143 (Calgary: Canadian Energy Research Institute, 2014).

Vaclav Smil, Prime Movers Of Globalization (Cambridge, Mass.: MIT Press, 2010). 


\section{About the Author}

Raised in Edmonton, Alberta, Peter Findlay is currently vice-president and energy lead of the business modelling practice in Calgary, with a global financial firm. He supports and analyzes major acquisition and divestiture deals, as well as operations and investment decisions around large projects across the energy value chain. (Note, as mentioned earlier, that this research is fully independent of Peter's current employment - opinions expressed herein are those of the author, and not a reflection the employer's views or those of the Oxford Institute for Energy Studies.)

From 2008 to 2014, Peter worked with the management consulting firm A.T. Kearney, where he managed investment, analytic, and operations engagements for global IOCs, NOCs, and private equity firms. His work focused on upstream, midstream, petrochemical, and LNG assets, as well as macroeconomic energy issues in North America and the Middle East.

Peter has a bachelor's degree in mechanical engineering from the University of Alberta and completed a master's degree in fluid dynamics engineering at McGill University in Montreal. $\mathrm{He}$ earned a combined MBA degree in strategy and economics from the Warwick, ESSEC, and Mannheim business schools in Europe.

Peter lives in Calgary and enjoys skiing, mountain biking, and discussing the past and (eventual) future greatness of the Edmonton Oilers hockey team. 